\title{
Photovoltaic Module Certification/Laboratory Accreditation Criteria Development: Implementation Handbook
}

C.R. Osterwald

National Renewable Energy Laboratory

R.L. Hammond, B.D. Wood, C.E. Backus, and R.L. Sears

Arizona State University, Tempe, Arizona

G.A. Zerlaut, Consultant

SC-International, Inc., Tempe, Arizona

R.V. D'Aiello, Consultant

RD Associates, Tempe, Arizona

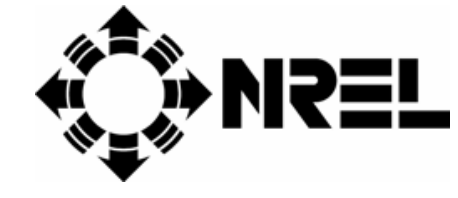

National Renewable Energy Laboratory 1617 Cole Boulevard Golden, Colorado 80401-3393 A national laboratory of the U.S. Department of Energy Managed by Midwest Research Institute for the U.S. Department of Energy under contract No. DE-AC36-83CH10093 


\section{Photovoltaic Module}

\section{Certification/Laboratory}

Accreditation Criteria Development: Implementation Handbook

C.R. Osterwald

National Renewable Energy Laboratory

R.L. Hammond, B.D. Wood, C.E. Backus, and R.L. Sears

Arizona State University, Tempe, Arizona

G.A. Zerlaut, Consultant

SC-International, Inc., Tempe, Arizona

R.V. D'Aiello, Consultant

RD Associates, Tempe, Arizona

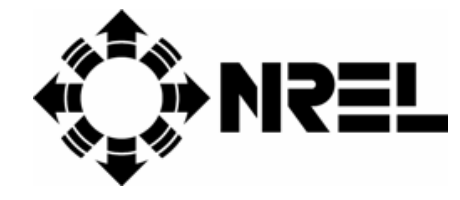

National Renewable Energy Laboratory 1617 Cole Boulevard

Golden, Colorado 80401-3393

A national laboratory of the U.S. Department of Energy Managed by Midwest Research Institute for the U.S. Department of Energy

under contract No. DE-AC36-83CH10093 


\section{NOTICE}

This report was prepared as an account of work sponsored by an agency of the United States government. Neither the United States government nor any agency thereof, nor any of their employees, makes any warranty, express or implied, or assumes any legal liability or responsibility for the accuracy, completeness, or usefulness of any information, apparatus, product, or process disclosed, or represents that its use would not infringe privately owned rights. Reference herein to any specific commercial product, process, or service by trade name, trademark, manufacturer, or otherwise does not necessarily constitute or imply its endorsement, recommendation, or favoring by the United States government or any agency thereof. The views and opinions of authors expressed herein do not necessarily state or reflect those of the United States government or any agency thereof. 


\title{
Photovoltaic Module Certification/ Laboratory Accreditation Criteria Development: Implementation Handbook
}

\author{
C.R. Osterwald \\ National Renewable Energy Laboratory \\ Golden, Colorado 80401-3393 \\ R.L. Hammond, B.D. Wood, C.E. Backus, R.L. Sears \\ Arizona State University \\ Tempe, Arizona 85287-5806 \\ G.A. Zerlaut, Consultant \\ SC-International, Inc. \\ Phoenix, Arizona 85023 \\ R.V. D'Aiello, Consultant \\ RD Associates \\ Tempe, Arizona 85284
}

\begin{abstract}
This document covers the second phase of a two-part program. Phase I provided an overview of the structure and function of typical product certification/laboratory accreditation programs.

This report (Phase II) provides most of the draft documents that will be necessary for the implementation of a photovoltaic (PV) module certification/laboratory accreditation program. These include organizational documents such as articles of incorporation, bylaws, and rules of procedure, as well as marketing and educational program documents.

In Phase I, a 30-member criteria development committee was established to guide, review and reach a majority consensus regarding criteria for a PV certification/laboratory accreditation program. Committee members represented PV manufacturers, end users, standards and codes organizations, and testing laboratories. A similar committee was established for Phase II; the criteria implementation committee consisted of 29 members. Twenty-one of the Phase I committee members also served on the Phase II committee, which helped to provide program continuity during Phase II.
\end{abstract}




\section{Acknowledgments}

The authors are grateful for the guidance provided by Richard DeBlasio, project manager for the National Renewable Energy Laboratory. In addition, the authors wish to thank the 29 criteria implementation committee members for their guidance, support, review of the numerous draft documents, and constructive comments. The names and affiliations of the committee members are listed below.

The valuable contributions of the Arizona State University staff deserve recognition. Jane Turpin assisted with the communications network and project administration. Deborah Shaver, with the Office of Sponsored Projects, provided invaluable support in administering the contract.

\section{Criteria Implementation Committee Members:}

$\begin{array}{llll}\text { Pete Eckert } & \text { Arizona Public Service Company } & \text { Jack Cannon } & \text { Sandia National Laboratories } \\ \text { Lisa Frantzis } & \text { Arthur D. Little, Inc. } & \text { Gene Zerlaut } & \text { SC-International } \\ \text { Moneer Azzam } & \text { ASE Americas } & \text { Don Aldrich } & \text { Siemens Solar Industries } \\ \text { Cheryl Keith } & \text { AstroPower } & \text { Dan Sandwisch } & \text { Solar Cells, Inc. } \\ \text { John Hoffner } & \text { City of Austin Electric Utility } & \text { David Meakin } & \text { Solar Energy Industries Association } \\ \text { Steve Chalmers } & \text { Consultant } & \text { John Wohlgemuth } & \text { Solarex Corporation } \\ \text { Gobind Atmaram } & \text { Florida Solar Energy Center } & \text { Lawrence Bond } & \text { South Florida Test Service } \\ \text { Scot Albright } & \text { Golden Photon } & \text { Steve Hogan } & \text { Spire Corporation } \\ \text { Carl Osterwald } & \text { National Renewable Energy Laboratory Jerry Anderson } & \text { Sunset Technology } \\ \text { Garyl Smith } & \text { Naval Weapons Air Station } & \text { Shawn MacGregor } & \text { TerraLab Engineers } \\ \text { Robert Spotts } & \text { Photocomm Inc. } & \text { Tom Lundtveit } & \text { Underwriters Laboratories Inc. } \\ \text { Jane Weissman } & \text { Photovoltaics for Utilities } & \text { Troy Glatfelter } & \text { United Solar Systems Corporation } \\ \text { Steve Bean } & \text { Public Service Company of Colorado } & \text { Warren Heerlein } & \text { U.S. Coast Guard } \\ \text { Bill Kaszeta } & \text { PV Resources International } & \text { Wallace Youngblood Wyle Laboratories } \\ \text { Robert D'Aiello } & \text { RD Associates } & & \end{array}$




\section{Table of Contents}

Title Page

Abstract

Acknowledgments

Criteria Implementation Committee Members

1.

Introduction

1.1 Overview

1.2 Background

1.3 Phase I

1.4 Phase II

1.5 Development

2. Terminology

2.1 Introduction

2.2 Acronyms, abbreviations, symbols

2.3 Definitions

3. The Implementation Process

3.1 Introduction $3-1$

3.1.1 Introduction and overview of the certification process $3-1$

3.2 Criteria and requirements $3-1$

3.2.1 Document PV-1 3-2

3.2.2 Document PV-2 3-3

3.2.3 Document PV-3 3-4

3.2.4 Document PV-4 3-5

3.2.5 Document PV-5 3-5

3.3 Legal structure $3-5$

3.3.1 Laboratory accreditation body $3-6$

3.4 Business plan $3-6$

3.4.1 Benefits of a certification program 3-6

3.4.2 Marketing documents: brochure and contact list $3-6$

3.4.3 Budget 3-7

4. Conclusions

4.1 Conclusions 
Annex A: PV-1. Criteria for a Model Quality System for Laboratories Engaged in Testing

Photovoltaic Modules

Foreword

A-3

1. Introduction

A-3

2. Scope

A-4

3. References

A-4

4. Definitions

A-5

5. Accommodation and environment $\quad$ A-7

6. Organization and management A-7

7. Personnel A-8

8. The quality system A-9

9. Audit and review, and verification practices A-12

10. Equipment and reference materials, instruments, or standards $\quad$ A-14

11. Test and calibration methods A-16

$\begin{array}{ll}\text { 12. Measurement traceability and calibration } & \text { A-17 }\end{array}$

13. Handling of test items A-19

14. Records $A-19$

15. Reports A-21

16. Subcontracting of testing A-22

17. Outside support services and supplies

18. Complaints A-23

PV-1.1. Calibration, Traceability, and Statistical Requirements of Accredited Laboratories Supporting the Photovoltaic Module Certification Program (Addendum to PV-1) A-24 Foreword

A-25

1. Introduction

A-25

2. Scope

A-25

3. References

A-26

4. Calibration

A-27

5. Statistical requirements

A-31

Appendix 1:

Vendor evaluation checklist 
Annex B: PV-2. Model for a Third-Party Certification and Labeling Program for

Photovoltaic Modules

Foreword

1. Introduction B-5

2. Scope B-6

3. References B-7

4. Definitions B-8

5. Certification body B-9

6. Manufacturer's or producer's quality system $\quad$ B-11

7. Initial testing and periodic retesting B-14

8. Licensing B-14

9. Surveillance B-15

10. Use of the certificate of conformity, or mark of conformity, and marking B-16

$\begin{array}{ll}\text { 11. Misuse of a certificate or mark of conformity } & \text { B-17 }\end{array}$

$\begin{array}{ll}\text { 12. Publicity by licensees } & \text { B-18 }\end{array}$

$\begin{array}{ll}\text { 13. Suspension of a license for a product } & \text { B-18 }\end{array}$

14. Withdrawal or cancellation of a license $\quad B-19$

15. Corrective action $\quad$ B-20

16. Implementation of modifications to Document PV-3 B-20

17. Liability B-21

18. Disputes $\quad$ B-21

19. Fees B-21

Appendix 1:

An approach to the review by a certification body of its own internal quality system $\quad$ B-22

(reproduction of ISO/IEC Guide 56)

Appendix 2:

Form PV250: Checklist for assessing the capabilities and quality system of manufacturers and producers

Appendix 3:

Form PV200: Specimen for initial questionnaire for factory assessment

B-31

(reproduced from ISO/IEC Guide 28)

Appendix 4:

Form PV100: Application for conformity certification by use of certificates or mark of conformity

(reproduced from ISO/IEC Guide 28)

Appendix 5:

Form PV300: Specimen of a licensing agreement for the use of a certificate or mark of conformity

(reproduced from ISO/IEC Guide 28)

Appendix 6:

Specimen of form for a license for the use of the certificates or mark of conformity

(reproduced from ISO/IEC Guide 28) 
Annex C: PV-3. Testing Requirements for a Certification and Labeling Program for

Photovoltaic Modules

Foreword

1. Introduction $\mathrm{C}-4$

2. Definitions $\quad \mathrm{C}-5$

3. References $\quad \mathrm{C}-6$

4. General test plan and sequence of testing $\quad$ C-7

5. Module qualification and performance tests $\quad$ C-8

$\begin{array}{ll}\text { 6. Reporting } & \mathrm{C}-10\end{array}$

Appendix 1:

Equipment and Apparatus Required for PV Module Testing and Certification C-11

Appendix 2:

$\begin{array}{ll}\text { Laboratory Organization and Personnel } & \text { C-14 }\end{array}$

Annex D: PV-4. Operational Procedures Manual for the Certification Body $\quad$ D-1

of the Photovoltaic Module Certification Program

Foreword

D-3

1. Introduction $\quad$ D-3

2. Scope D-4

3. Definitions D-4

4. Initial responsibilities of the executive director D-5

5. Approval of module certification test laboratories D-6

6. Establishment of the factory quality assessment team $\quad$ D-7

7. Procedual flow diagram $\quad$ D-7

8. Application for participation D-9

9. Requirements for a manufacturer's factory quality system $\quad D-11$

10. Review by PMCC of application for module certification D-12

11. The factory assessment $\quad D-13$

12. Random selection of test modules $\quad$ D-16

13. Review and determination of applicant's suitability $\quad$ D-17

14. Selection of the PV module test laboratory $\quad$ D-18

$\begin{array}{ll}\text { 15. Module testing } & \text { D-18 }\end{array}$

$\begin{array}{ll}\text { 16. Appeals } & \text { D-20 }\end{array}$

$\begin{array}{ll}\text { 17. Approval and certification processes } & \text { D-20 }\end{array}$

18. Annual, biennial, and periodic requirements $\quad$ D-21

$\begin{array}{ll}\text { 19. Challenge testing and factory audits } & \mathrm{D}-22\end{array}$

$\begin{array}{ll}\text { Bibliography } & \text { D-23 }\end{array}$ 
Annex E: PV-5. Application and Certification Procedures for the

Photovoltaic Module Certification Program

Foreword

E-3

$\begin{array}{ll}\text { 1. Introduction } & \text { E-3 }\end{array}$

2. Scope $r$ E-3

$\begin{array}{lr}\text { 3. Definitions } & \text { E-4 }\end{array}$

$\begin{array}{ll}\text { 7. Procedual flow diagram } & \text { E-4 }\end{array}$

$\begin{array}{ll}\text { 8. Application for participation } & \text { E-6 }\end{array}$

$\begin{array}{ll}\text { 9. Requirements for a manufacturer's factory quality system } & \text { E-7 }\end{array}$

$\begin{array}{ll}\text { 10. Review by PMCC of application for module certification } & \text { E-9 }\end{array}$

$\begin{array}{lr}\text { 11. The factory assessment } & \text { E-10 }\end{array}$

$\begin{array}{lr}\text { 12. Random selection of test modules } & \text { E-12 }\end{array}$

$\begin{array}{lr}\text { 13. Review and determination of applicant's suitability } & \text { E-13 }\end{array}$

$\begin{array}{lr}\text { 14. Selection of the PV module test laboratory } & \text { E-14 }\end{array}$

$\begin{array}{lr}\text { 15. Module testing } & \text { E-15 }\end{array}$

$\begin{array}{lr}\text { 16. Appeals } & \text { E-16 }\end{array}$

$\begin{array}{lr}\text { 17. Approval and certification processes } & \text { E-17 }\end{array}$

$\begin{array}{ll}\text { 18. Annual, biennial, and periodic requirements } & \text { E-18 }\end{array}$

$\begin{array}{ll}\text { 19. Challenge testing and factory audits } & \text { E-19 }\end{array}$

$\begin{array}{ll}\text { Bibliography } & \text { E-20 }\end{array}$

Appendix 1:

$\begin{array}{ll}\text { Form PV350: Licensing fee based on product sold } & \text { E-22 }\end{array}$

Annex F: Legal Structure of the PMCC F-1

$\begin{array}{lr}\text { Articles of incorporation } & \text { F-3 }\end{array}$

$\begin{array}{lr}\text { Bylaws } & \text { F-11 }\end{array}$

$\begin{array}{lr}\text { General rules of procedure for standing committees } & \text { F-27 }\end{array}$

Specific rules of procedure for standing committees:
Appeals committee

$\begin{array}{lr}\text { Appeals committee } & \text { F-39 } \\ \text { Audit and finance committee } & \end{array}$

$\begin{array}{lr}\text { Laboratory accreditation committee } & \text { F-43 }\end{array}$

$\begin{array}{lr}\text { Licensing compliance committee } & \text { F-47 }\end{array}$

$\begin{array}{lr}\text { Manufacturer's quality system compliance committee } & \text { F-51 }\end{array}$

$\begin{array}{lr}\text { Product certification committee } & \text { F-55 }\end{array}$

$\begin{array}{lr}\text { Technical committee } & \text { F-59 }\end{array}$

Annex G: Partial Business Plan for the PMCC G-1

$\begin{array}{ll}\text { Benefits of a certification program } & \text { G-3 }\end{array}$

$\begin{array}{ll}\text { Marketing brochure } & \text { G-10 }\end{array}$ 


\section{List of Figures}

Figure A-1 Hierarchy of Traceability to NIST

A-29

Figure A-2

Hierarchy of Traceability to the WMO World Radiometric Reference for PV

A-30

Terrestrial Reference Cells

Figure C-1

Laboratory Organization

C-15

Procedural Flow Diagram, Initial Certification

D-8

Figure D-1

Procedural Flow Diagram, Initial Certification

\section{List of Tables}

Table A-1 Traceability and Frequency Requirements for Instrumentation and Measurements Required for Laboratory Accreditation in Support of a Phovoltaic Module

Table C-1 Certification Program

Table G-1

Equipment and Apparatus Required for PV Module Testing and Certification

C- 12,13

Marketing contact list

G-12,13

Table G-2

Draft initial operating budget

G-14 


\section{Section 1}

\section{INTRODUCTION}

\section{$1.1 \quad$ Overview}

This handbook represents the culmination of over 2 years of effort directed toward development of a possible third-party product certification and module accreditation program for photovoltaic (PV) products. The work was originally designed as a single 1-year task to define the criteria for a PV certification/accreditation program. Toward the end of the criteria development effort, it became evident that additional work needed prior to the initiation of a certification program could be accomplished using the same development methods. These two separate but interrelated tasks were designated Phase I and Phase II. The final reports for both phases were written as stand-alone documents; thus, there is material from the first report duplicated in this handbook.

All the draft documents needed to implement a PV module certification/laboratory accreditation program have been developed and are available within this handbook. A draft 5year operating budget and a preliminary educational marketing program have also been prepared.

The next step in the implementation program is for one or more individuals to establish the legal framework by filing the Articles of Incorporation of the certification body. Following that, the incorporators should recruit participants who are willing to provide the first year of funding for the certification body and serve on the board of directors, a step that is the only remaining barrier to implementing a formal PV module certification/laboratory accreditation program.

\subsection{Background}

Third-party product certification involves a formal process of licensing a manufacturer to use a certificate of conformity. Such a certificate can take the form of a tag, label, nameplate, or document of specified form and content, affixed or otherwise directly associated with a product 
or service, attesting that the product or service is in conformity with the referenced standards or specifications. The Underwriters Laboratories label commonly found on nearly all household electrical appliances is an example of such a label. Such labels are often required through government legislation or contractual agreements.

In this report, the term third party is used to indicate an organization which issues a certification license to a manufacturer. The certification organization (or certification body) is a third party in the sense that it is neither a manufacturer nor an end user.

The accreditation of a laboratory represents an official recognition that the laboratory has the necessary personnel, physical resources, and quality assurance needed to perform a specific testing activity. The process of accreditation involves the assessment of a laboratory's capability by an authority using criteria that are generally accepted as the essential requirements for a laboratory's performance. This accreditation process helps instill confidence in suppliers, manufacturers, and users that the laboratory's test results are accurate and valid.

For PV products, there are two qualities that can benefit from a certification/ accreditation program-module electrical performance and module reliability. At the present time, no certification/ accreditation programs exist in the PV industry. Buyers and end users of PV modules must either accept what manufacturers specify for the performance and reliability of their products, find an independent laboratory capable of performing the necessary testing, or attempt to perform the testing themselves. Consensus standards that specify how PV modules should be tested for such a certification program do not exist. This situation is a natural consequence of the young age of the PV industry, in which products are continually being introduced and changed.

At present, PV module manufacturers provide product warranties and, in nearly all cases, in-house qualification testing. No formal certification program is currently in existence for PV modules. Therefore, buyers must either have their own specifications for qualifying a product prior to purchase or use the specifications of past purchasers. This situation requires buyers to have an intimate knowledge of PV module testing, which for most buyers is not practicable.

The majority of module qualification testing has been performed by the manufacturers (as 
opposed to independent testing laboratories), primarily because of: (a) economic reasons, (b) a lack of standardization, and (c) a lack of qualified laboratories to perform the tests. Also, some manufacturers have developed in-house qualification testing capabilities as part of product development and warranty offerings. Accredited, independent testing laboratories would allow these manufacturers to reduce their need for facilities to perform routine testing of proven products and manufacturing processes, thereby reducing costs. Manufacturers' liability costs would also be reduced as liability is transferred from manufacturers to the product certification body.

It is expected that a certification/accreditation program would enable manufacturers to certify products through a single process, avoiding the current situation of the multiple ad hoc standards required for different markets, different customers, or both. This would reduce the cost to the manufacturers and ultimately to the buyers of PV modules.

\subsection{Phase I}

The initial step toward the establishment of a certification/accreditation program in the PV industry was the development of criteria that specify what testing should be done in order to certify that a particular PV module product is likely to perform reliably. This step was accomplished through a National Renewable Energy Laboratory (NREL) subcontract to Arizona State University (ASU), which developed the criteria in conjunction with a committee of representatives from PV manufacturers, utilities, testing laboratories, and standards and codes organizations.

The criteria documents created during Phase I of this project were published as part of a technical report titled "Photovoltaic Module Certification/Laboratory Accreditation Criteria Development" (NREL/TP-412-7680, April 1995). This report completed the initial step by defining: (a) the applicable test standards necessary for a module design to be certified, and (b) the criteria for laboratory accreditation for both performance and reliability testing of nonconcentrating PV modules. The three criteria documents developed during Phase I, called PV-1, PV-2, and PV-3, are included in this handbook as Annexes A, B, and C. 


\subsection{Phase II}

As noted above, the original ASU subcontract was expanded in scope in October 1994 to include an implementation phase. The objectives of Phase II were to perform as much of the development and groundwork as possible that would be needed prior to the actual initiation of a certification/accreditation program, using the continuity and momentum of the first phase. Specific tasks that were to be accomplished included:

- Developing the pro forma corporation bylaws and draft articles of incorporation needed to form a certification body, using the criteria in documents PV-1, PV-2, and PV-3 (developed in Phase I)

- Developing a pro forma budget for a certification body

- Developing recommendations for obtaining seed money to implement a certification program—how much, potential sources, and potential commitments (i.e., industry)

- Recommending either the American Association for Laboratory Accreditation or the National Voluntary Laboratory Accreditation Program as the laboratory accreditation body for the program

- Identifying possible refinements to the performance testing procedures contained in PV-3

- Motivating senior-level managers of PV manufacturers to endorse and participate in the potential certification program

- Developing a measurement traceability hierarchy to either the National Institute for Standards and Technology or the World Radiometric Reference for all measurements needed for certification. 


\subsection{Development}

The approach used to develop the required documents in Phase II was similar to that used in Phase I. ASU wrote the initial drafts of the documents, which were then distributed to the criteria development committee. Comments and objections received from committee members via fax and telephone were then incorporated into the draft documents. This approach minimized the need for committee meetings; in fact, only a single meeting at the outset of Phase II was held.

Most of the documents developed under Phase II were not controversial. This was probably due to the fact that most were administrative or legal in nature. As such, only the initial drafts of the documents were sent to the committee for comments. The first draft of all documents received a majority consensus. The second and final draft of each document therefore represented a total consensus of the committee. One exception was the addendum to Document PV-1 (see Annex A), called PV-1.1, for which two drafts for comments were needed. 


\section{Section 2}

\section{TERMINOLOGY}

\subsection{Introduction}

The terms defined in this section include a consolidation of terms used and defined in documents PV-1, PV-2, PV-3, PV-4, and PV-5 (Annexes A through E, respectively) and terms that apply to accreditation, certification, and standardization programs in general.

\subsection{Acronyms, abbreviations, and symbols}

\begin{tabular}{|c|c|}
\hline A2LA & American Association for Laboratory Accreditation \\
\hline AAMVLA & American Association of Motor Vehicle Laboratory Accreditation \\
\hline AM & Air mass \\
\hline ANSI & American National Standards Institute \\
\hline ARI & Air-Conditioning and Refrigeration Institute \\
\hline ASQC & American Society of Quality Control \\
\hline ASTM & American Society for Testing and Materials \\
\hline BCS & British Calibration Service \\
\hline CASCO & Council Committee on Conformity Assessment \\
\hline CEC & Commission of the European Communities \\
\hline CERTICO & Certification Council (ISO/IEC) \\
\hline CRM & Certified Reference Material \\
\hline $\mathrm{dc}$ & Direct current \\
\hline DOE & Department of Energy \\
\hline EC & European Community or European Commission \\
\hline EOTC & European Organization for Testing and Certification \\
\hline ERDA & Energy Research and Development Administration \\
\hline ESTI & European Solar Test Installation \\
\hline GATT & General Agreements on Tariffs and Trade \\
\hline ICBO & International Congress of Building Officials \\
\hline IEC & International Electrotechnical Commission \\
\hline IEEE & Institute of Electrical and Electronics Engineers \\
\hline ILAC & International Laboratory Accreditation Conference \\
\hline $\mathbf{I}_{\mathrm{MP}}$ & Current at maximum power point \\
\hline ISCC & Interstate Coordinating Council \\
\hline$I_{S C}$ & Short-circuit current \\
\hline ISO & International Standards Organization \\
\hline $\mathrm{I}-\mathrm{V}$ & Current-voltage \\
\hline LAP & Laboratory accreditation program \\
\hline NATA & National Association of Testing Authorities (Australia) \\
\hline NBS & National Bureau of Standards \\
\hline NIST & National Institute for Standards and Technology \\
\hline NREL & National Renewable Energy Laboratory \\
\hline NVLAP & National Voluntary Laboratory Accreditation Program (NIST program) \\
\hline$P_{M P}$ & Power at maximum power point \\
\hline RAB & Registration Accreditation Board (ASQC) \\
\hline
\end{tabular}




$\begin{array}{ll}\text { RCL } & \text { Rating, Certification and Labeling (solar hot water collector program) } \\ \text { SEIA } & \text { Solar Energy Industries Association } \\ \text { SEREF } & \text { Solar Energy Research and Education Foundation (SEIA program) } \\ \text { SNL } & \text { Sandia National Laboratories } \\ \text { SRC } & \text { Standard Reporting Conditions } \\ \text { SRCC } & \text { Solar Rating and Certification Corporation } \\ \text { STC } & \text { Standard Test Conditions } \\ \text { TAG } & \text { Technical Advisory Group } \\ \text { TQM } & \text { Total Quality Management } \\ \text { UL } & \text { Underwriters Laboratories } \\ \text { V } & \text { Voltage at maximum power point } \\ \text { VOC } & \text { Open-circuit voltage } \\ \text { WRR } & \text { World Radiometric Reference }\end{array}$

\subsection{Definitions}

Air Mass: The ratio of the mass of atmosphere in the actual observer-sun path to the mass that would exist if the observer was at sea level, at standard barometric pressure, and the sun was directly overhead. Note- (sometimes called air mass ratio.) Air mass varies with the zenith angle of the sun and the local barometric pressure, which changes with altitude. For sun zenith angle, $Z$, of $62^{\circ}$ or less and local atmospheric pressure, $P$, where $P_{o}$ is standard atmospheric pressure, $A M \simeq \operatorname{secZ}\left(P / P_{0}\right)$. [ASTM E 772]

Air Mass 1.5 standard reference spectrum: The solar spectral irradiance distribution (diffuse and direct) incident at sea level on a sun-facing, $37^{\circ}$ tilted surface, as defined by ASTM E 892 . The atmospheric conditions for AM 1.5 are: precipitable water vapor, $14.2 \mathrm{~mm}$; total ozone, $3.4 \mathrm{~mm}$; turbidity (base e, $\lambda=0.5 \mathrm{~mm}$ ), 0.27 .

Baseline performance value: Initial values of $\mathrm{I}_{\mathrm{SC}}, \mathrm{V}_{\mathrm{OC}}, \mathrm{P}_{\mathrm{MP}}, \mathrm{V}_{\mathrm{MP}}, \mathrm{I}_{\mathrm{MP}}$ measured by the accredited laboratory and corrected to Standard Test Conditions, used to validate the manufacturers' performance measurements provided with the qualification modules per IEEE 1262 [PV-3].

Blocking Diode: A diode used to restrict or block reverse current from flowing backward through a module. [UL 1703]

Bypass Diode: A diode connected across one or more solar cells such that the diode will conduct if the cell(s) become reverse biased. [UL 1703]

Calibration: The set of operations which establish, under specified conditions, the relationship between values indicated by a measuring instrument or measuring system, or values represented by a material measure, and the corresponding known values of a measured quantity. The results of a calibration permit the estimation of errors of indication of the measuring instrument, measuring system, or material measure, or the assignment of values to marks on arbitrary scales. A calibration may determine other metrological properties. The result of a calibration shall, for the purposes of this model, be recorded in a document, which may be either an internal or external calibration certificate, or a calibration report. The results of calibration operations recorded as values may be referred to as "calibration factors," or, if a series of calibration values, as a "calibration curve." [PV-1]

Certificate of conformity: A tag, label, nameplate, or document of specified form and content, affixed or otherwise directly associated with a product or service on delivery to the buyer, attesting that the product or service is in conformity with the requirements of the certification program (e.g., with the referenced standards and specifications). [PV-2] 
Certification: The procedure by which written assurance is given that a product or service conforms to a specification. A third-party certification is one that is rendered by a technically and otherwise competent body other than one controlled by the producer or the buyer. [PV-2]

Certification body: An impartial body or organization possessing the necessary competence to develop promulgate, finance, and operate a certification program and to conduct certifications of conformity. Note: A certification body may operate its own testing and inspection activities or it may oversee these activities carried out on its behalf by other bodies, e.g., an independent testing labortory. [PV-2]

Certification mark: A generic term intended to include the Listing Mark, Classification Mark, Recognized Component Mark and Recognized Marking of [the Laboratory]. Authorized use of a Certification Mark by a manufacturer is the manufacturer's declaration that the product was produced according to [the Laboratory's] requirements. "Label" is synonymous with "Listing Mark," "Classification Marking," or "Certification Mark."1

Certification mark: The sign or symbol owned and controlled by the certification body that is used exclusively by the third-party certification program to identify products of services as being certified and is registered as a certification mark with the U.S. Patent Office under the Trade Mark Act of 1946. [PV-2]

Certified reference material: A reference material, one or more of whose property values are certified by a technically valid procedure, accompanied by or traceable to a certificate or other documentation that is issued by a certifying body, e.g., a standard reference cell. [PV-1]

Current at maximum power: The current at which maximum power is available from a module (for the purpose of this document, the "rated" current at maximum power will be defined as $I_{M P}$ at STC). [UL 1703]

I-V data: The relationship between current and voltage of a cell [or module] in the power-producing quadrant, as a set of ordered pairs of current and voltage readings in a table, or as a curve plotted in a suitable coordinate system such as a Cartesian one. [ASTM E 1036]

Interconnect: A conductor within a module or other means of connection which provides an electrical interconnection between the solar cells. [UL 1703]

Interlaboratory testing: Organization, performance, and evaluation of tests on the same or similar items or materials by two or more laboratories in accordance with predetermined conditions. [PV-1]

Laboratory or testing laboratory: A body or organization that performs tests and provides a formal, written report of the results. In cases in which the laboratory forms part of an organization that carries out activities in addition to testing and calibration, the term laboratory refers only to that part of the organization that actually performs the testing of photovoltaic modules. [PV-1]

\section{Mark of conformity: See Certification mark.}

Maximum Power: The point on the current-voltage (I-V) curve of a module under illumination, where the product of current and voltage is maximum. For the purpose of this doument, "rated" power is defined as $\mathbf{P}_{\mathrm{MP}}$ at STC. [UL 1703]

Metrology: The science of weights and measures or of measurement.

Producer: The manufacturer, distributor, supplier, or other party providing the product or service to be purchased and employed by a user. The producer is responsible for assuring conformity with all requirements of the certification program. [PV-2]

\footnotetext{
${ }^{1}$ From Glossary of UL Terms and Acronyms. Copyright 1990, Underwriters Laboratories Inc.
} 
Proficiency testing: Regular, periodic determination of the laboratory testing or calibration performance of unknowns, usually by means of interlaboratory comparisons. [PV-1]

PV module (flat-plate): The smallest environmentally protected, essentially planar assembly of solar cells and ancillary parts, such as interconnects, terminals, [and protective devices such as bypass diodes] intended to generate dc power under unconcentrated sunlight. The structural (load carrying) member of a module can either be the top layer (superstrate), or the back layer (substrate). [UL 1703]

Qualification test (PV): A procedure applied to a selected set of PV modules involving the application of defined electrical, mechanical, or thermal stress in a prescribed manner and amount. Test results are subject to a list of defined requirements. [PV-3]

Quality manual: A document stating the quality policy or policies and the quality system and quality practices of an organization. [PV-1]

Quality system: The organizational structure, responsibilities, procedures, processes, and resources for implementing quality management. [PV-1]

Reference material: A physical material, or substance, one or more properties of which are sufficiently well established to be used for the calibration of an apparatus, the assessment of a measurement method, or for assigning values to materials. [PV-1]

Reference standard: A physical standard, generally of the highest metrological quality available to the test laboratory, from which measurements made at that location are derived. [PV-1]

Standard reporting conditions: A fixed set of conditions to which the electrical performance data of a photovoltaic module are translated from the set of actual test conditions. [ASTM E 1036]

Standard test conditions: Conditions under which a module is tested, consisting of: (1) irradiance intensity of $1000 \mathrm{~W} / \mathrm{m}^{2}$, (2) AM1.5 solar reference spectrum [see Section 2.1.2], and (3) a cell [module] temperature of $25^{\circ} \pm 2^{\circ} \mathrm{C}$ [IEC 1215]

Test and calibration procedures manual(s): A written document, or documents, which contain the specific instructions, preferably in active voice, imperative mood, for carrying out the tests or calibrations. [PV-1]

Test method: A documented technical procedure for performing a test. The test method may be called out in either internal documentation, or, whenever possible, in a published consensus standard. [PV-1]

Test sequence: A set of one or more qualification tests applied in a specified order to a selected group of PV modules. [PV-3]

Third-party certification: A form of certification in which the producer's claim of conformity is validated, as part of a third-party certification program, by a technically and otherwise competent body other than one controlled by the producer or the buyer.

Third-party certification program: An organized system (1) under which similar products or services of any number of producers may be certified as conforming to the reference standards or specifications on a uniform and equitable basis, (2) which uses or is operated by a third-party inspection/testing body, and (3) which authorizes the use of controlled certification marks or certificates of conformity as evidence of conformity. 
Traceability: The property of a result of measurements whereby it can be related to appropriate physical standards maintained by the U.S. National Institute of Standards and Technology (NIST), or the appropriate international standards body, through an unbroken chain of comparisons. [PV-1]

Verification: Confirmation by examination and recording of physical evidence that specified requirements have been met. In connection with the management of measuring equipment, verification provides a means for checking that the deviation between values indicated by a measuring instrument and corresponding known values of a measured quantity are consistently smaller than the maximum allowable error defined in a standard, regulation, or specification peculiar to the management of the measuring equipment. The result of verification of equipment and measuring instruments leads to a decision either to maintain the item(s) in service, restore to service, or to perform adjustments, or to repair, or to downgrade, or to declare obsolete. In all cases it is required that a written trace of the verification performed be kept on the measuring instrument's individual record. [PV-1]

Voltage at maximum power: The voltage at which maximum power is available from a module. (for the purpose of this document, the "rated" voltage at maximum power will be defined as $\mathrm{V}_{\mathrm{MP}}$ at STC). [UL 1703] 


\section{Section 3 \\ THE IMPLEMENTATION PROCESS}

\subsection{Introduction}

In order to implement a certification program, three basic ingredients are needed. These are: (a) the criteria and requirements of a PV module testing, certification, and labeling program, (b) the legal structure, and (c) a business plan. The criteria and organizational structure are provided in this handbook and appropriate sections of a business plan have been developed. The supporting documentation for these three areas has been developed with the direction and support of a committee of industry experts, and is included in the annexes attached to this handbook.

The name "Photovoltaic Module Certification Corporation" (PMCC) was selected as a convenient means to refer to the certification body in some of the above-mentioned documents. The name has no legal significance and may, or may not, be used as the name of any eventual certification body.

Also, it is important to recognize that these annexes are simply draft documents that can be easily modified to meet the specific needs of the certification body at the time that it is formed. Minimal changes are anticipated, however, since the documents were developed by industry consensus.

\subsection{Criteria and requirements}

Documents PV-1, PV-2, PV-3, PV-4, and PV-5 collectively define the criteria, requirements, and procedures for a PV module testing, certification, and labeling program. These five documents are included in Annexes A through E. A brief description of each document follows. 


\subsubsection{Document PV-1}

PV-1, titled Criteria for a Model Quality System for Laboratories Engaged in Testing Photovoltaic Modules, like International Standards Organization and International Electrotechnical Commision (ISO/IEC) Guide 25 from which it was developed, serves as the basis for designing and implementing quality systems in laboratories and for recognizing the competence of laboratories by accreditation. PV-1, however, provides amplification and clarification of Guide 25 and is specific to PV module testing laboratories. Requirements of American Society for Testing and Materials (ASTM) Standard E 548 on evaluating testing laboratories and ISO/IEC Guide 38 on conformity assessment have also been incorporated.

PV-1 could be employed by:

- Laboratories engaged in testing PV devices to design, develop, and implement a quality system that meets the criteria for accreditation

- Assessment bodies, and their assessors, as the criteria against which laboratories are examined for the purpose of accreditation.

PV-1 covers:

- The criteria for organization and management of the laboratory

- The design of its quality system

- The minimum content of its quality assurance manual

- The implementation of internal auditing of its quality system

- Internal quality checking of the laboratory's data and instrumentation

- The general qualifications of its management and testing personnel

- The external and on-the-job training requirements of its test personnel

- The laboratory's general accommodation and environment criteria

- The general requirements for scientific and test instrumentation.

The document specifies the minimum requirements an accredited laboratory must have for:

- Calibration instrumentation and traceability of instrumentation and data

- Generic requirements for use of calibration and test methods 
- Handling of items for test

- Documentation and record requirements (including retention requirements)

- Minimum requirements for issuance of test reports

- Vendor qualification for subcontracting of services and purchasing of supplies

- Handling of complaints.

Document PV-1.1, titled Calibration, Traceability, and Statistical Requirements of Testing by Accredited Laboratories in Support of the Photovoltaic Module Certification Program, is an addendum to PV-1 that was developed as part of Phase II. This document sets forth the minimum requirements for calibration, calibration traceability, and statistical representation of calibration and test data with which a laboratory should comply and operate to demonstrate its competence to test PV modules.

In addition to its use as a model for the development of a laboratory's quality system, and for maintaining the quality of a laboratory's services, PV-1.1 is also intended as an aide to the assessment of a laboratory's quality program and services.

\subsubsection{Document PV-2}

Document PV-2, titled Model for a Third-Party Certification and Labeling Program for Photovoltaic Modules, was developed for use by:

- Organizations wholly independent of all PV product-esting activities that are selected, formed or otherwise approved to administer a PV module certification and labeling program

- Laboratories engaged in the dual role of testing PV modules and product certification and labeling.

This model encompasses the structure of a third-party product certification system for determining the conformity of PV modules with a series of performance and durability/reliability standards contained in PV-3. Significant portions of American National Standards Institute (ANSI) Z34.1 and ISO/IEC Guide 28 have been adopted in PV-2. 
The purpose of the PV-2 model is to define a third-party certification system for determining conformity using product standards through initial testing and assessment of a factory quality management system that is required for acceptance of a manufacturer. This is followed by surveillance that takes into account the factory quality management system and the testing of sample from the factory and the open market.

It is not the purpose of this document to address the requirements of either the operation of a laboratory that is accredited or otherwise approved to perform the testing, or to define the technical testing requirements that will result in creation of the information and data that will be used by such a product certification and labeling program.

\subsubsection{Document PV-3}

Document PV-3, titled Testing Requirements for a Certification and Labeling Program for Photovoltaic Modules, defines the testing and reporting requirements for reliability qualification and baseline electrical performance value measurements of PV modules that would be used in support of a PV module certification and labeling program. It includes minimum testing requirements for PV products, laboratory equipment (Appendix A of PV-3), and requirements for staffing and personnel qualifications (Appendix B of PV-3). It covers:

- A program of evaluation and testing

- Performance methods

- Equipment guidance

- Personnel, organization, and training.

PV-3 specifies that module designs be tested to Institute of Electrical and Electronics Engineers (IEEE) Standard 1262, titled Recommended Practice for Qualification of Photovoltaic $(P V)$ Modules. This qualification test program represents the latest methods of subjecting modules to simulated and accelerated environmental stresses that have been developed as of the time of this writing. 


\subsubsection{Document PV-4}

Document PV-4, titled Operational Procedures Manual for the Certification Body of the Photovoltaic Module Certification Program, describes the procedures and processes required for the day-to-day operation of the certification program, as well as the procedures required of module manufacturers who choose to obtain PMCC certification of their PV products.

Document PV-4 is the principal guide for managing and administering the PMCC PV module certification program, and has been constructed to conform to PV-2 (which itself conforms to ANSI Z34.1 and ISO Guide 28), and to ISO/IEC Guides 40 and 56.

\subsubsection{Document PV-5}

Document PV-5, titled Application and Certification Procedures for the Photovoltaic Module Certification Program, describes the procedures and processes required of PV module manufacturers who choose to obtain PMCC certification of one, several, or all of their models.

Documents PV-2 and PV-5 represent the major portions of the application package provided at cost to interested manufacturers who are potential applicants.

\subsection{Legal structure}

Documents to establish a legal structure for a certification body were developed and are included in Annex F. These documents are the:

- Articles of Incorporation

- Bylaws

- General Rules of Procedure

- Specific Rules of Procedure: Appeals Committee, Audit and Finance Committee, Laboratory Accreditation Committee, Manufacturer's Quality System Compliance Committee, Product Certification Committee, and Technical Committee. 


\subsubsection{Laboratory accreditation body}

In order to make the legal documents as complete as possible, a laboratory accreditation body was selected by a ballot of the implementation criteria committee. The committee, by unanimous vote, selected the American Association for Laboratory Accreditation.

\subsection{Business plan}

It was beyond the scope of this program to develop a complete business plan for a certification body. However, three key elements of a business plan were developed to aid the start-up of a certification program. These elements, contained in Annex G, are:

- Benefits of a certification program

- Marketing documents: brochure and contact list

- Budget.

\subsubsection{Benefits of a certification program}

Defining the benefits of a certification program is crucial to its implementation. Making these benefits known to potential program participants is essential if the program is to be supported and funded, and making these benefits known is part of the education program. The benefits were developed with input and consensus from the committee. Benefits and committee member comments are included in Annex G.

\subsubsection{Marketing documents: brochure and contact list}

The benefits were summarized in the brochure included in Annex G. The brochure was designed for senior-level managers (for example, chief executive officer, director of marketing, director of quality assurance, and director of research and development). One of the first tasks of the certification body may be to distribute such a brochure to these managers, who are listed in Annex G (see Table G-1). 


\subsubsection{Budget}

A draft budget for the first 5years of operation of the certification body is presented in Annex G. This budget covers an executive director half time for the first 2 years, $75 \%$ for the third year, and full-time by the fourth year. The office manager will be full time starting the first year.

Domestic travel is included so that the executive director can sell senior managers in person on the potential benefits of participating in the program. Although no budget was allocated for international travel, it may be necessary to travel to Europe and Japan at some time during the first 5 years of operation to establish mutual recognition agreements with certification bodies in those countries. If this becomes necessary, funds will have to be allocated.

It is unlikely that funds will be available from the U.S. Department of Energy to subsidize the operating budget. The most likely source of funds will come from program participants (i.e., PV manufacturers). A self-sustaining program funded by the participant will certainly be a healthier and more stable program than one subsidized by the government. 


\section{Section 4}

\section{CONCLUSIONS}

\subsection{Conclusions}

All the draft documents needed to implement a PV module certification/laboratory accreditation program have been developed and are included in this handbook. A draft 5-year operating budget and a preliminary educational marketing program have also been prepared.

The next step in the implementation program is for one or more individuals to file the Articles of Incorporation to establish the legal framework for the certification body. Following that, the incorporators should recruit participants who are willing to provide the first year of funding for the certification body and serve on the board of directors, a step that is the only remaining barrier to implementing a formal PV module certification/laboratory accreditation program. 


\begin{abstract}
Annex A
PV-1. Criteria for a Model Quality System

for Laboratories Engaged in Testing Photovoltaic Modules
\end{abstract}

and

PV-1.1. Calibration, Traceability, and Statistical Requirements of Accredited Laboratories Supporting the

Photovoltaic Module Certification Program

(Addendum to PV-1) 


\section{Document PV-1}

\section{Criteria for a Model Quality System for Laboratories Engaged in Testing Photovoltaic Modules}

$\begin{array}{lll}\text { Foreword A-3 } & \text { A-3 }\end{array}$

1. Introduction A-3

2. Scope A-4

3. References A-4

4. Definitions A-5

5. Accommodation and environment A-7

6. Organization and management A-7

7. Personnel A-8

8. The quality system A-9

9. Audit and review, and verification practices A-12

10. Equipment and reference materials, instruments, or standards A-14

11. Test and calibration methods

12. Measurement traceability and calibration $\quad$ A-17

13. Handling of test items A-19

14. Records A-19

15. Reports A-20

16. Subcontracting of testing A-22

17. Outside support services and supplies $\quad$ A-22

18. Complaints A-23

Glossary

ANSI American National Standards Institute

ASQC American Society of Quality Control

ASTM American Society for Testing and Materials

ISO International Standards Organization

IEC International Electrotechnical Commission

IEEE Institute of Electrical and Electronics Engineers

NIST National Institute of Standards and Technology

UL

Underwriters Laboratories 


\section{FOREWORD}

It is intended that the requirements of a laboratory quality system presented in this document be employed (1) by laboratories engaged in testing photovoltaic devices as a guide to designing, developing and implementing a quality system that meets the criteria for accreditation, and (2) by assessment bodies, and their assessors, as the criteria against which laboratories are examined for the purposes of accreditation. The criteria established in this document represent minimum acceptable guidance, and an expanded quality system beyond that required by this document is encouraged.

This model is one of a series of documents that together purport to address the totality of the criteria and requirements of a photovoltaic device testing, certification, and labeling program. The other documents in this series are:

PV-2 Model for a Third-Party Certification and Labeling Program for Photovoltaic Modules

PV-3 Testing Requirements for a Certification and Labeling Program for Photovoltaic Modules

PV-4 Operational Procedures Manual for the Certification Body of the Photovoltaic Module Certification Program

PV-5 Application and Certification Procedures for the Photovoltaic Module Certification Program

In crafting the requirements set forth in this model, the relevant requirements of ASTM Standard E 548 on evaluating testing laboratories, ISO/IEC Guides 25 and 38 on conformity assessment have been largely adopted.

\section{Introduction}

1.1 All laboratories accredited, or otherwise approved, for the purpose of performing testing of photovoltaic modules shall be required to comply with these criteria.

1.2 A laboratory is said to conform to these criteria if it fulfills all of the requirements defined herein. To aid the assessment of laboratories to these requirements, only those requirements that can be objectively and independently verified are contained in this document

1.3 When conformance to this model is claimed, all provisions of the criteria and requirements set forth in this document shall be met.

1.4 Laboratories meeting the requirements of these criteria comply, within the context of their testing activities, with the requirements of ASTM Standard E 548 and ISO Guide 25, and with the relevant requirements of the ISO 9000 series of quality standards. 


\section{Scope}

2.1 This document sets forth the minimum requirements with which a laboratory shall comply and operate to demonstrate its competence to test photovoltaic modules.

2.2 In addition to its use as a model for the development of a laboratory's quality system, and for maintaining the quality of a laboratory's services, these criteria are for use in aiding the assessment of a laboratory's quality program and services.

2.3 This document covers the organization and management criteria of the laboratory, the design of its quality system, the minimum content of the laboratory's Quality Assurance Manual, the implementation of internal auditing of its quality system, and internal quality checking of its data and instrumentation.

2.4 This document also covers the general qualifications of its management and testing personnel, the external and on-the-job training requirements of its test personnel, the laboratory's general accommodation and environment criteria, and general requirements for scientific and test instrumentation.

2.5 This document also sets forth the minimum requirements for calibration instrumentation and traceability of instrumentation and data, generic requirements for use of calibration and test methods, handling of items for test, documentation and record requirements (including retention requirements), minimum requirements for issuance of test reports, vendor qualification for subcontracting of services and purchasing of supplies, and handling of complaints.

\section{References}

\subsection{ASTM E 548:}

"General Criteria for Evaluating Testing Laboratories"

3.2 ASTM E 882:

"Guide for Accountability and Quality Control in the Chemical Analysis Laboratory"

3.2 ASTM E 1187:

"Terminology Relating to Laboratory Accreditation"

3.3 ASTM E 1322:

"Standard Guide for Selection, Training and Evaluation of Assessors for Laboratory

Accreditation Systems"

3.4 ASTM E 1579:

"Standard Guide for Ensuring Data Integrity in Highly Computerized Laboratory Operations"

3.5 ISO Guide 25:

"General requirements for the Accreditation of Calibration and Testing Laboratories"

3.6 ISO Guide 38:

"General requirements for the acceptance of testing laboratories" (in revision) 
3.7 ISO 9000 and ANSI/ASQC 90:

"Quality management and quality assurance standards—Guidelines for selection and use"

3.8 ISO 9001 and ANSI/ASQC 91 :

"Quality systems-Model for quality assurance in design/development, production, installation and servicing"

3.9 ISO 9002 and ANSI/ASQC 92:

"Quality systems-Model for quality assurance in production and installation"

3.10 ISO 9004 and ANSI/ASQC 94 :

"Quality management and quality system elements-Guidelines"

3.11 ISO 8402:

"Quality-Vocabulary"

3.12 ISO TAG 4:

"Guide to the Expression of Uncertainty in Measurement" (draft)

3.13 ANSU/ASME PTC 19.1-1985, Part 1

"Measurement Uncertainty-Instruments and Apparatus"

\section{Definitions}

4.1 The relevant definitions from the referenced documents, including ISO 8402 on vocabulary, are repeated for use and clarification of the requirements of this document. Additional clarifications have been added to several definitions to aid in meeting the specific requirements of this model.

4.2 Laboratory, or testing laboratory: A body, or organization, that performs tests and provides a formal, written report of the results. In cases in which the laboratory forms part of an organization that carries out activities in addition to testing and calibration, the term laboratory refers only to that part of the organization that actually performs the testing of photovoltaic modules.

4.3 Calibration: The set of operations that establish, under specified conditions, the relationship between values indicated by a measuring instrument or measuring system, or values represented by a material measure, and the corresponding known values of a measured quantity.

The results of a calibration permit the estimation of errors of indication of the measuring instrument, measuring system, or material measure, or the assignment of values to marks on arbitrary scales.

A calibration may determine other metrological properties. The result of a calibration shall, for the purposes of this model, be recorded in a document, which may be either an internal or external calibration certificate, or a calibration report.

The results of calibration operations recorded as values may be referred to as "calibration factors," or, if a series of calibration values, as a "calibration curve." 
4.4 Test method: A documented technical procedure for performing a test. The test method may be called out in either internal documentation, or, whenever possible, in a published consensus standard.

4.5 Verification: Confirmation by examination and recording of physical evidence that specified requirements have been met.

In connection with the management of measuring equipment, verification provides a means for checking that the deviation between values indicated by a measuring instrument and corresponding known values of a measured quantity are consistently smaller than the maximum allowable error defined in a standard, regulation, or specification peculiar to the management of the measuring equipment.

The result of verification of equipment and measuring instruments leads to a decision either to maintain the item(s) in service, restore to service, or to perform adjustments, or to repair, or to downgrade, or to declare obsolete.

In all cases it is required that a written trace of the verification performed be kept on the measuring instrument's individual record.

4.6 Quality system: The organizational structure, responsibilities, procedures, processes, and resources for implementing quality management.

4.7 Quality manual: A document stating the quality policy or policies and the quality system and quality practices of an organization.

4.8 Reference standard: A physical standard, generally of the highest metrological quality available to the test laboratory, from which measurements made at that location are derived.

4.9 Reference material: A physical material, or substance, one or more properties of which are sufficiently well established to be used for the calibration of an apparatus, the assessment of a measurement method, or for assigning values to materials.

4.10 Certified Reference Material (CRM): A reference material, one or more of whose property values are certified by a technically valid procedure, accompanied by or traceable to a certificate or other documentation that is issued by a certifying body, e.g., a standard reference cell.

4.11 Traceability: The property of a result of measurements whereby it can be related to appropriate physical standards maintained by the U.S. National Institute of Standards and Technology (NIST), or the appropriate international standards body, through an unbroken chain of comparisons.

4.12 Proficiency testing: Regular, periodic determination of the laboratory testing or calibration performance of unknowns, usually by means of interlaboratory comparisons.

4.13 Interlaboratory testing: Organization, performance, and evaluation of tests on the same or similar items or materials by two or more laboratories in accordance with predetermined conditions. 
4.14 Test and calibration procedures manual(s): A written document, or documents, which contain the specific instructions, preferably in active voice, imperative mood, for carrying out the tests or calibrations.

\section{Accommodation and environment ${ }^{1}$}

5.1 Laboratory accommodation shall include the provision of regular, essentially permanent, ample work space for testing photovoltaic modules and for performing any necessary calibrations. Energy sources, lighting, heating, air-conditioning and ventilation shall be such as to facilitate the correct performance of tests and the internal calibrations required.

5.2 The environment in which these activities are undertaken shall not invalidate the results or adversely affect the required uncertainty level of any measurement. Particular care shall be taken when such activities are undertaken at sites other than a permanent laboratory facility.

5.3 The laboratory shall provide equipment for the effective monitoring, control, and recording of environmental conditions as appropriate. Due attention shall be paid, for example, to dust, electromagnetic interference, humidity, mains voltage, temperature, and sound and vibration levels, as appropriate to the tests and calibrations performed.

5.4 There shall be effective separation between neighboring areas in which there are incompatible activities.

5.5 Access to and use of all areas affecting the quality of measurement or testing activities shall be defined and controlled through documented procedures.

5.6 Adequate measures shall be taken to ensure good housekeeping and safety in the laboratory.

\section{Organization and management}

6.1 The laboratory shall be legally identifiable. It shall be organized and operated in such a way that its permanent facilities, and any relevant temporary mobile facilities, meet the requirements of this model.

6.2 The laboratory shall:

6.2.1 Have managerial staff with the authority and resources needed to discharge their duties.

6.2.2 Have arrangements to ensure that its personnel are free from commercial or financial conflicts of interest and other pressures that may adversely affect the results of testing activities. The laboratory shall have a written policy relating to potential conflicts of interest, including the disclosure by staff of gifts from clients.

\footnotetext{
${ }^{1}$ It is the laboratory's responsibility to comply with the relevant environmental, health, and safety requirements. These aspects are outside the scope of this model.
} 
6.2.3 Be organized in such a way that confidence in its independence of judgment and integrity is maintained at all times.

6.2.4 Specify and document the responsibility, authority, and interrelation of all personnel who manage, perform, or verify work affecting the quality of testing or calibrations.

6.2.5 Provide supervision by persons familiar with the calibration and test methods and procedures, the objective of each such calibration or test, and the assessment of test or calibration results. The ratio of supervisory to nonsupervisory personnel shall be such as to ensure adequate supervision.

6.2.6 Have a technical manager (however named) who has overall responsibility for the technical operations of the laboratory. The technical manager must have sound knowledge of the principles of photovoltaic testing and must have the ability to make critical evaluations of test results.

6.2.7 Have a quality manager (however named) who has responsibility for the laboratory's quality system, its implementation and its maintenance. The quality manager's job may be a full-time or a part-time job, depending on the size of the staff and the technical scope of the laboratory in disciplines other than photovoltaic testing. The quality manager shall have direct access to the technical manager and to the highest level of management at which decisions are taken for the laboratory on policy or resources or both.

6.2.8 Nominate and document the staff members who shall have full authority in the absence of the technical or quality manager or both.

6.2.9 Where interlaboratory comparison or proficiency testing programs are either not available, or otherwise not appropriate, have an internal program to assess proficiency using one or more of the following: correlation charting, statistical techniques, independent measurements or periodic checks of measured conditions using calibrated instruments.

\section{Personnel}

7.1 The laboratory shall have sufficient personnel having the necessary education, training, technical knowledge, and experience for their assigned functions.

7.2 Job descriptions of all personnel involved in photovoltaic testing shall be prepared and shall include position title, minimum requirements for the position, responsibilities and reporting relationships, and any supervisory responsibilities.

7.3 The laboratory shall ensure that the training of its personnel is maintained up-to-date. Procedures shall be developed to identify training needs, for training new personnel, and for developing and maintaining the expertise of existing personnel in all test techniques. Particular attention should be given to new or only occasionally used test methods, procedures, and techniques. Procedures for cross-training shall be developed and shall be implemented as needed. 
7.4 Records on the relevant qualifications, training, skills and experience of the technical personnel shall be maintained by the laboratory. A list of all tests and calibrations that each staff member has been assessed for and found competent to perform shall be maintained. Cross-training records shall be maintained up-to-date.

\section{The quality system}

8.1 The laboratory shall establish and maintain a quality system appropriate to the type and scope of photovoltaic testing required by Document PV-3. All elements of this system as listed in 8.5 of this document shall be documented. The quality documentation, including up-to-date referenced test procedures and operating documents, shall be available for use by the laboratory personnel. The laboratory shall define and document its policies and objectives for, and its commitment to, good laboratory practice and the quality of testing services. The laboratory management shall ensure that these policies and objectives are documented in a quality manual and communicated to, understood by, and implemented by all laboratory personnel engaged in photovoltaic testing. The quality manual shall be maintained current under the authority and responsibility of the quality manager.

8.2 The laboratory's quality manual shall be specific to the laboratory physically involved in testing photovoltaic devices and shall therefore be unique to the laboratory; it shall not be a generic quality manual pertaining to a parent organization. The content, structure, and format of the manual shall reflect this uniqueness.

8.3 All copies of the manual shall be numbered, and a log shall be maintained with respect to the recipient of each control copy. The manual shall be a living document, i.e., each section shall be separately numbered, and each page shall contain the appropriate page number of that section and the following document control information: date of issue, authority, and amendment number.

8.4 The quality manual, and related quality documentation, shall state the laboratory's policies and operational procedures established to meet the requirements of this model.

8.4.1 Complete and detailed test and calibration procedures shall not be contained in the quality manual. The laboratory's specific requirements and wording of the procedures presented in Document PV-3 shall be maintained in a separate test and calibration procedures manual or in separate manuals unique to the photovoltaic test laboratory.

8.4.2 Rules shall be developed and employed for the unique identification of all quality documentation, for changes to the documents, for their distribution, and for the registration of copies issued. The control information required on all documentation in the quality system shall include a unique identification of the document, the revision number, the date of issue, and the person authorizing the issuance of the revision so that the identity of the controlling document at any time is clear. 
8.5 The minimum contents of the quality manual shall include the following:

8.5.1 A quality policy statement, including objectives and commitments, that is prepared, issued, and endorsed by top management.

8.5.2 The organization and management structure of the laboratory, its place in any parent organization, and relevant organizational charts. The organizational charts shall include all positions and names. These should be consistent with job descriptions and training records.

8.5.3 The responsibility, authority, and interrelation of all personnel who manage, perform, or verify work affecting the quality of tests and calibrations. These relationships should be identified further by use of a separate organizational chart.

8.5.4 Procedures for control and maintenance of the quality system and related operating procedures documentation. These shall include, in addition to the requirements specified in Section 8.4.2:

(a) The procedures, responsibilities, and authorities for drafting, changing, approving, and issuing documents in the quality system, and documents for performing testing and calibration (test methods, calibration procedures, job orders and travelers).

(b) Procedures for preventing obsolete or superseded documents from being used shall be documented.

(c) Complete historical files of all quality documents issued shall be maintained and the location of these files shall be documented in the quality manual.

(d) The quality manual shall contain a master list of all quality documents with current issue dates and identities of copy holders (where relevant).

8.5.5 The job descriptions of the management and key operating staff shall be listed in the appendix of the quality manual. Job descriptions of all other operating and support staff and training records shall be prepared and their location identified in the quality manual.

8.5.6 The laboratory's approved signatories for test reports and certifications shall be identified. The criteria for selecting the approved signatories shall be as specified in Document PV-2.

8.5.7 The laboratory's policy and reference to procedures, for achieving traceability of all measurements.

8.5.8 Arrangements for ensuring that the laboratory reviews all new work to ensure that it has the appropriate facilities and resources before commencing such work. The manual shall describe policies or procedures to screen incoming test requests to determine whether it is within the laboratory's capacity to accept the job. Evidence of this review shall be documented. 
8.5.9 The laboratory's scope of tests, listed in tables (whether in the body or an appendix of the manual) covering the test procedures in one, and the calibration procedures in another. The documents pertaining to test and calibration procedures, respectively, shall be identified and their distribution noted.

8.5.10 The procedures for handling test items. This policy shall describe the system of work flow through the laboratory and shall be supported by a flow chart indicating the key elements of the overall test program.

8.5.11 Reference to major test and calibration equipment used in the laboratory. This reference shall be supported by an appended listing, in tabular form, of all such instrumentation. Information provided in the listing shall include the items required in Sections 10.5.1 through 10.5.10.

8.5.12 Reference to procedures for the calibration, verification and maintenance of instrumentation and equipment.

8.5.13 Reference to current verification practices including interlaboratory comparison and proficiency test programs (if made available for photovoltaic testing), use of reference materials and reference physical standards, and internal quality control, or procedures.

8.5.14 Procedures to be followed for feedback and corrective action whenever testing discrepancies are detected, or departures from documented policies and procedures occur.

8.5.15 The laboratory management's policy and arrangements for exceptionally permitting departures from documented policies and procedures, or from standard specifications.

8.5.16 Policy and procedures for resolution of complaints received from clients or other parties about the laboratory's technical testing activities.

8.5.17 Procedures for protecting the confidentiality and proprietary rights of clients.

8.5.18 Procedures for audit and review of the quality system, as described in Section 9 of this document.

8.5.19 Procedures for training of the staff in the implementation and application of, and compliance with, the quality system and related operating procedures.

8.5.20 Copies of or reference to procedures for the management of personnel (staff) and personnel records, and their location.

8.5.21 If work is subcontracted, procedures to ensure that subcontractors are competent and comply with the requirements of this guide, as described in Section 16 of this document.

8.5.22 Copies of or reference to procedures to ensure that outside support services and supplies are of adequate quality, according to Section 17 of this document. 
8.5.23 Copies of or reference to procedures for avoiding deterioration or damage to test and calibration items during storage, handling, preparation, and test.

8.5.24 Copies of or reference to procedures for the receipt and retention or safe disposal of test and calibration items, including all provisions necessary to protect the integrity of the laboratory.

8.5.25 Copies of or reference to procedures to ensure that purchased equipment, materials, and services comply with specified requirements when no independent assurance of the quality of outside support services or supplies is available.

\section{Audit and review, and verification practices}

9.1 The laboratory shall periodically, or as required under Section 18 of this document, conduct objective internal or contracted audits of its activities to verify that its operations continue to comply with the requirements of the quality system. Such audits shall be carried out by trained and qualified staff members who are, wherever resources permit, independent of the activity to be audited.

9.1.1 Audits shall be carried out not less than annually.

9.1.2 These audits shall include both general criteria (documents, records, and policies) and technical compliance (test methods and practices).

9.1.3 Where the audit findings cast doubt on the correctness or validity of the laboratory's test results, the laboratory shall take immediate corrective action and shall immediately notify, in writing, any client whose work may have been affected, and shall provide a copy of all such information and correspondence to any product certification program body for which the testing is performed.

9.1.4 The objectives of these audits are to discover:

(a) Whether management objectives (as defined by the quality system) are being achieved

(b) Whether designated duties are being carried out satisfactorily

(c) Whether appropriate calibrations of equipment, or materials, or both, are being properly carried out and whether the results are within the acceptable error limits for the quantities and properties being measured

(d) Whether procedures described in the quality system are being followed

(e) Opportunities for quality improvement. 
9.1.5 The quality manager shall be responsible for ensuring that all components of the laboratory's activities are audited at least annually on behalf of management. The task of carrying out audits may be delegated to other staff with appropriate technical training and familiarity with the quality system. Additionally,

(a) The laboratory shall have a planned schedule for the audits that includes all activities

(b) The audit procedures shall be documented

(c) The audits shall be carried out in accordance with the planned schedule and in accordance with the documented procedures

(d) The results of the audits shall be documented

(e) Effective corrective action shall be undertaken within a reasonable time frame with respect to all nonconforming items

(f) A record of all completed corrective actions shall be maintained.

9.2 The quality system adopted to satisfy the requirements of this model shall be reviewed at least once a year by senior management to ensure its continuing suitability and effectiveness and to introduce any necessary changes or improvements. The management review shall include the following:

\subsubsection{Matters arising from the previous review}

9.2.2 Reports of any formal second- or third-party (e.g., external) assessments

9.2.3 Reports of internal audits done since the last management review, including any corrective actions required and taken

9.2.4 Results of participation in any interlaboratory comparisons or proficiency test programs (if available)

9.2.5 Results of internal quality, data and instrumentation checks or verification procedures

9.2.6 Details of any complaints from clients

9.2.7 Staff training and cross-training (for both new and existing staff)

9.2.8 Adequacy of resources (personnel, equipment)

9.2.9 Future plans, new work requirements, new staff, new equipment. 
9.3 All audit and review findings and any corrective actions that arise from them shall be documented. The Quality Manager shall ensure that these actions are discharged within the agreed timetable.

9.3.1 Corrective action shall be taken whenever evidence arises that the quality system is not functioning properly. Corrective action shall be taken under the following circumstances:

(a) When there is a need to correct an immediate failure. This may require, as appropriate, retesting and withdrawing an invalid test report, and issuing a new test report.

(b) When there is a need to investigate the underlying cause of a failure. This may involve test personnel not being properly trained in the use of a new instrument or may involve the use of defective equipment or equipment found to be out of calibration.

9.4 In addition to periodic audits, the laboratory shall ensure the quality of results provided to clients by implementing independent checks. These checks shall be reviewed and shall include, as appropriate, but not be limited, to the following:

9.4.1 Internal quality control schemes using, whenever possible, statistical techniques (such as Spearman's rank correlation to discover reversals; $x$-y correlation coefficients between two measurements of an independent variable, or between measurements of two independent variables; Statistical Process Control (SPC) charting, uncertainty analyses, etc.)

9.4.2 Participation in proficiency testing or other interlaboratory comparisons (if made available for photovoltaic testing)

9.4.3 Regular use of certified reference materials or reference instruments, or both, in-house quality control using secondary reference materials, or reference test specimens, or both, including accepted calibrated standards for measurement of optical, electrical, thermal, and physical properties of items employed in the testing as detailed in Sections 10 and 11 of this document

\subsubsection{Replicate testing}

\subsubsection{Retesting of retained test items}

9.4.6 Correlation of results for different characteristics of an item.

\section{Equipment and reference materials, instruments, or standards}

10.1 The laboratory shall be furnished with all items of measurement and test equipment required for the correct performance of calibrations and tests. In those cases in which the laboratory needs to use equipment outside its permanent control, it shall ensure that the relevant requirements as described in Section 16 of this document are met. 
10.2 All significant items of test equipment (including data processing) and reference materials (and instruments) required to perform the tests (or calibrations), or control critical test conditions, shall be permanently and uniquely identified. This identification shall include, in addition to the requirements of the equipment list specified in Section 8.5.11, the use of a numerical or alphanumeric asset number, or instrument number, engraved on or printed on a label that is affixed to the item of equipment in a conspicuous place.

10.3 All measuring instruments and test equipment used to acquire data or control critical test conditions shall be properly maintained and their maintenance status clearly stated on an appropriate label or other record affixed thereto. Maintenance procedures shall be documented, preferably in a Maintenance Manual. Any item of equipment that has either been subjected to overloading (electrical, thermal, physical, or otherwise), or mishandling, or gives suspect results, or has been shown by verification to be defective, shall be taken out of service, clearly identified, and stored at a specific place until it has been repaired and shown by calibration verification or test to perform correctly. The laboratory shall examine the effect of this defect on previous tests or calibrations and, as required in Section 9.1.2 of this document, advise any clients whose reports or certificates may have been affected.

10.4 Each item of measuring instruments and test equipment used to acquire data or control critical test conditions, including reference materials, and reference instruments (e.g., reference standards), shall be labeled, marked, or otherwise identified to indicate its calibration status.

10.5 Records shall be maintained of each item of equipment and all reference materials, and reference instruments, significant to the tests performed. The records shall include as a minimum:

10.5.1 The name of the test equipment

10.5.2 The manufacturer's name, type identification, model number, and serial number or other unique identification

10.5.3 Date received and date placed in service

10.5.4 Current location in the laboratory, if relevant

10.5.5 Condition when received (e.g., new, used, reconditioned, out-of-service)

10.5.6 Copy of the manufacturer's operating manuals and instructions, where available

10.5.7 Dates and results of calibrations or verifications, or both, and date of next calibration or verification, or both

10.5.8 Details of maintenance carried out to date and planned for the future

10.5.9 History of any damage, malfunction, modification or repair 
10.5.10 The following additional information should also be placed in the equipment records file:

(a) Service agents and their contacts, including telephone numbers (for calibration and maintenance when outside vendors are employed)

(b) Checking requirements, including the frequencies and procedures

(c) Records of in-service checks

(d) The performance capabilities of the equipment, such as measurement limits, ranges and scales, estimates of measurement errors, stability, repeatability

(e) The identity of staff responsible for monitoring the calibration and maintenance of the equipment

(f) Authorized users.

\section{Test and calibration methods}

11.1 The laboratory shall follow documented instructions on the use and operation of all relevant equipment, and on the handling and preparation of items for testing or calibration, or both, where the absence of such instructions could jeopardize the tests or calibrations. All instructions, standards, manuals, and reference data relevant to the work of the laboratory shall be maintained up-to-date and be made readily available to the staff.

11.2 The laboratory shall use appropriate documented methods and procedures for all tests and calibrations and related activities within its scope of activities, including sampling, handling, transport, storage, and preparation of items to be tested or calibrated, and estimation of uncertainty of measurement or analytical error in the calibration or test data. If possible, errors should be divided into bias (systematic) and precision (random) error-i.e., uncertainty analysis (e.g., ANSI/ASME PTC 19.1-1985, Part 1, Measurement Uncertainty Instruments and Apparatus). These procedures shall be consistent with the uncertainty level required, and with any standard specifications relevant to the calibrations or tests concerned.

11.2.1 Many, if not all, of the test methods required by the photovoltaic product certification program outlined in Document PV-2 and compiled in Document PV-3 will represent the documentation required in Section 11.2 of this document.

11.3 Where methods are not specified by the client or by the requirements of Documents PV-2 and PV-3, the laboratory shall select appropriate methods that have been published either as national or international standards (e.g., ASTM, IEEE, ANSI, IEC and ISO, or UL), or by reputable technical organizations, or in relevant scientific texts or journals. Reference to, and deviations from, the methods and procedures shall be clearly documented and made available to the laboratory test operator and client. 
11.4 Where it is necessary to employ methods that have not been established as consensus standards according to Section 11.3 of this document, these shall be subject to agreement with the client, be fully documented and validated, and be available for examination by the client and other authorized recipients of the relevant reports.

11.5 Where sampling is carried out as part of a test method, the laboratory shall use documented procedures and appropriate statistical techniques to select samples.

11.6 Calculations and data transfers shall be subject to appropriate independent checking as noted in Section 9.4 of this document.

11.7 When computers or automated equipment are used for the capture, processing, manipulation, recording, reporting, storage, or retrieval of test and calibration data, the laboratory shall ensure that:

11.7.1 Computer software is documented and validated as adequate for use

11.7.2 Procedures are established and implemented for protecting the integrity of data; such procedures shall include, but not be limited to, integrity of data entry or capture, data storage, data transmission and data processing

11.7.3 Computer and automated equipment is maintained to ensure proper functioning and provided with environmental and operating conditions necessary to maintain the integrity of test and calibration data

11.7.4 Appropriate procedures are documented and implemented to maintain security of data, including the prevention of unauthorized access to, and amendment of, computer records

11.7.5 The documented procedures to meet the foregoing requirements conform to the guidelines stated in ASTM E 1579.

\section{Measurement traceability and calibration}

12.1 All measuring and testing equipment having an effect on the accuracy or validity of calibrations or tests shall be calibrated or verified, or both, before being put into service. The laboratory shall have an established program for the calibration and verification of its measuring and test equipment, including the use of necessary reference materials and reference standards and appropriate independent, between-calibration checks.

12.2 The overall program of calibration, verification, and validation of measurement and test equipment shall be designed and operated so as to ensure that measurements made by the laboratory are, with the exception noted in Section 12.2.1, either traceable to national standards of measurement or recognized natural physical constants, or are otherwise satisfactorily validated such as by a verified self-ratioing comparison mechanism. 
12.2.1 Solar radiation measuring instrumentation employed in the program of photovoltaic testing shall be traceable to the World Radiometric Reference (WRR) through one or more of the absolute, self-calibrating cavity pyrheliometers that regularly participate in the International Pyrheliometric Comparisons held every 5 years at Physical Meteorological Observatory in Davos, Switzerland.

12.3 Calibration certificates shall indicate the traceability to national standards of measurement, or to the WRR as noted in Section 12.2.1, or to natural constants, or shall state other acceptable means of validation, and shall provide either the measurement results and associated uncertainty of measurement or a statement of compliance with an identified metrological specification. Calibration records shall clearly state the as-found values and the laboratory's tolerance limits for each instrument or device requiring calibration.

12.4 Should traceability to national or international standards of measurement or other direct means of validation not be possible or practicable, the laboratory shall provide other satisfactory evidence of verification of its measurement or test results, for example, by participation in a suitable program of interlaboratory comparisons or proficiency testing.

12.5 Reference standards of measurement held by the laboratory shall be used for calibration only and for no other purpose.

12.6 Reference standards of measurement shall be calibrated by a body that can provide certified traceability to a national or international standard of measurement.

12.7 The laboratory shall document and implement a program of calibration and verification for its reference standards.

12.8 As relevant, any reference standards, including on-site primary, transfer, or working standards, and designated measuring and testing equipment, shall be subjected to in-service checks between calibrations and verifications.

12.9 Reference materials shall be traceable to national or international standards of measurement or to national or international certified standard reference materials, unless it can be demonstrated that neither is possible.

12.10 All procedures for in-house calibration shall be documented, including an estimation of uncertainty. These should include acceptance criteria, and corrective action if equipment falls outside these criteria.

12.11 The staff member responsible for monitoring and for calibration program implementation for each item of equipment shall be identified.

12.12 There shall be a comprehensive calibration-scheduling program to alert staff of all calibration due dates.

12.13 Reagents shall be kept in properly labeled, clean containers. Their shelf life shall not have expired and they shall otherwise not be used after a reasonable period of time. 


\section{Handling of test items}

13.1 The laboratory shall follow documented procedures for the receipt, retention, or safe disposal, or return to client, of test items, including all provisions necessary to protect the integrity of the laboratory.

13.1.1 When the laboratory has total or partial responsibility for sampling, the laboratory shall follow the instructions for sampling given in Document PV-2.

13.2 To ensure that there can be no confusion regarding the identity of test items at any time, the laboratory shall have a documented system for uniquely identifying items to be tested.

13.3 On receipt, the condition of the test item, including any abnormalities or departures from standard conditions as prescribed in the relevant test method, shall be recorded. When there is any doubt as to the suitability of an item for test, or an item does not conform to the description provided, or the test required is not fully specified, the laboratory shall consult the client for further instruction before proceeding. The laboratory shall establish whether the item has received all necessary preparation, or whether the client requires preparation to be undertaken or arranged by the laboratory.

13.4 The laboratory shall follow documented procedures and use appropriate facilities to avoid deterioration or damage to the test item during storage, handling, preparation, and test. Relevant instructions provided with the item shall be followed. When items have to be stored or conditioned under specific environmental conditions, these conditions shall be maintained, monitored, and recorded where necessary. Where a test item or portion of an item is to be held secure (for example, for reasons of record, safety, propriety, or value, or to enable check tests to be performed later), the laboratory shall follow documented storage and security arrangements that protect the condition and integrity of the secured items or portions concerned.

\section{Records}

14.1 The laboratory shall maintain a record system to suit its particular circumstances and comply with any applicable regulations, including the record requirements of Document PV-2 when the testing program defined by Document PV-2 applies.

14.2 The laboratory shall retain on record all original observations, calculations and derived data, calibration records, and a copy of the calibration certificate, test certificate or test report for a period of not less than 7 years. The records for each test shall contain sufficient information to permit their repetition. The records shall include the identity of laboratory personnel involved in sampling, preparation, calibration of equipment, and testing activities.

14.2.1 The laboratory shall maintain a system that provides a traceable link between the sample as received and the test report or test certificate that is eventually issued on that test item, including all raw data. This requirement shall apply to both manually accumulated and computer-acquired data. Information contained in the record shall include, as a minimum, the following: 
(a) A description of each sample, including its condition, model number, serial number, and detailed structure and composition of test item

(b) The individual sample, or test item, identification

(c) Identification of the test method, or test program, and any deviations

(d) Identification of the specific equipment and instrumentation used in the tests, and any related calibration information

(e) Original test data and observations

(f) Typed or printed name and signature of the person performing the test

(g) A copy of the test report as issued

(h) Dates, times (where relevant), and location of tests performed.

14.2.2 Original observations shall be entered in ink at the time of the test into bound, numbered logbooks or onto properly designed work sheets that are permanently affixed to the logbooks.

14.2.3 Mistakes shall never be erased or deleted. Mistakes shall be noted by drawing a single line through the error and entering the correct value alongside, or in adjacent columns or rows. The line-out shall be initialed by the person making the change, and the reason for the change shall be noted in the margin or in a conspicuous and adjacent place.

14.2.4 The individual pages of the logbooks, or the work sheets, shall be provided with a place for dating and initialing by a higher authority.

14.2.5 Computer records shall be kept in accordance with the rules described in Section 11.7 of this document.

14.2.6 Any special instructions for completion of logbooks and work sheets provided by Document PV-2 shall be followed for tests and testing programs covered by Document PV-2.

14.3 All records (including those listed in Section 10.5 of this document, pertaining to calibration and test equipment), certificates, and reports shall be safely stored, held secure, and maintained in confidence to the client, except as provided by the disclosure requirements in Document PV-2.

\section{Reports}

15.1 The results of each test or series of tests shall be reported accurately, clearly, unambiguously, and objectively, and in accordance with instructions in the test methods. 
15.2 When applicable, the results shall be reported in a test report in accordance with the requirements of Document PV-2. In all other cases, each report shall include at least the following information:

(a) A title, e.g., "Test Report," "Report of Test," and date of issue

(b) Name and address of the test laboratory, and the location where the test was carried out if different from the address of the laboratory

(c) Unique identification of the report (such as a serial number) and the total number of pages; pages shall be numbered consecutively, and each page shall also carry the report number and total number of pages

(d) Name and address of client

(e) Description and unambiguous identification of the item or items tested

(f) Characterization and condition of the test item(s)

(g) Date of receipt of test item(s) and date(s) of performance of test(s)

(h) Identification of each standard test method used or unambiguous description of any nonstandard method used (including reference to internal test procedure documentation)

(i) Reference to any special instrumentation or equipment used

(j) Reference to any relevant sampling procedure

(k) Any additions to, or deviations or exclusions from, the test method, and any other information relevant to a specific test, such as environmental conditions

(l) Measurements, examinations and derived results, supported by tables, graphs, sketches, and photographs, as appropriate, and any known failures identified

(m) A statement of either the estimated uncertainty of the test result(s) or the reason that no such estimate is possible, including reference to a more detailed error analysis, if required

(n) a signature and title or an equivalent identification of the person(s) accepting responsibility for the content of the test certificate or report, however produced, and the date of issue

(o) As relevant, a statement to the effect that the results relate only to the items tested

(p) A statement that the test report shall not be reproduced except in full, without the written approval of the laboratory. 
15.3 Where the test report contains results of tests performed by subcontractors, these results shall be clearly identified as so performed.

15.4 Particular care and attention shall be paid to the arrangement of the test report. When the tests are performed in accordance with the program of testing specified in Document PV-2, the reporting format specified in Document PV-2 shall be followed.

15.5 Material amendments to a test report after it has been issued shall be made only in the form of a further document, or data transfer, which includes the statement "Supplement to Test Report, serial number ... [or as otherwise identified]," or an equivalent form of wording. Such amendments shall meet all the relevant requirements of Section 14 of this document.

15.6 The laboratory shall ensure that, where clients require transmission of test results by telephone, telex, facsimile, or other electronic or electromagnetic means (e.g., electronic mail), staff will follow documented procedures that ensure that the requirements of this model are met and that confidentiality is preserved.

\section{Subcontracting of testing}

16.1 When the laboratory subcontracts any part of the testing, this work shall be placed with a laboratory complying with the requirements of this document, or one that is accredited to ISO Guide 25. In an absence of accreditation, the laboratory shall perform a documented audit of the proposed subcontractor with reference to those aspects of the testing intended to be subcontracted.

16.2 The laboratory shall ensure and be able to demonstrate that its subcontractor is competent to perform the activities in question and complies with the same criteria of competence as the laboratory in respect to the work being subcontracted. The laboratory shall immediately advise the client in writing whenever it intends to subcontract any portion of the testing to another party.

16.3 The laboratory shall record and retain details of its investigation of the competence and compliance of its subcontractor laboratories and maintain a register of all subcontracted test activities.

\section{Outside support services and supplies}

17.1 When the laboratory procures outside services and supplies, other than those referred to earlier in this document in support of tests, the laboratory shall use only those outside support services and supplies that are of adequate quality to sustain confidence in the results of tests. Purchase requisitions for critical test materials shall contain sufficiently detailed descriptions of the material to assure conformance with the test specification. 
17.2 When no independent assurance of the quality of outside support services or supplies is available, the laboratory shall follow documented procedures to ensure that purchased equipment, materials and services comply with specified requirements. The laboratory shall ensure that purchased support equipment and consumable materials are not used until they have been inspected, calibrated, or otherwise verified as complying with any standard specifications or requirements documented in the methods for the tests concerned.

17.3 Documented procedures shall be developed and implemented for any test materials requiring handling, storage, or disposal.

17.4 The laboratory shall maintain records of all suppliers from whom it obtains support services, support equipment, or supplies required for tests. These records shall include the brand names of consumables and the results of any acceptance tests performed, maintenance histories of frequently purchased instruments and tools used in testing, and the status of suppliers' registration to one of the ISO 9000 standards whenever possible or relevant.

\section{Complaints}

18.1 The laboratory shall follow a documented policy and procedures for the resolution of complaints received from clients and other parties about technical testing activities. A record shall be maintained of all such complaints and of the investigations and any corrective actions taken by the laboratory.

18.2 When a complaint, or any other similar or equivalent circumstance, raises doubt concerning the laboratory's compliance with documented policies or procedures, or with the requirements of this document or otherwise concerning the quality of its tests, the laboratory shall ensure that those areas of activity and responsibility involved are promptly audited in accordance with Section 9.1 of this document or have records to indicate that the deficiency was detected and previously corrected. 


\section{Document PV-1.1}

Calibration, Traceability and Statistical Requirements of Accredited Laboratories Supporting the Photovoltaic Module Certification Program

(Addendum to Document PV-1)

Table of Contents

Page

Foreword

A-25

1. Introduction

A-25

2. Scope

A-25

3. References

A-26

4. Calibration

A-27

5. Statistical requirements

Appendix 1

Vendor evaluation checklist

Glossary

$\begin{array}{ll}\text { A2LA } & \text { American Association for Laboratory Accreditation } \\ \text { ACR } & \text { absolute cavity radiometer } \\ \text { ANSI } & \text { American National Standards Institute } \\ \text { ASQC } & \text { American Society of Quality Control } \\ \text { ASTM } & \text { American Society for Testing and Materials } \\ \text { ISO } & \text { International Standards Organization } \\ \text { IEC } & \text { International Electrotechnical Commission } \\ \text { IEEE } & \text { Institute of Electrical and Electronics Engineers } \\ \text { NIST } & \text { National Institute of Standards and Technology } \\ \text { NVLAP } & \text { National Voluntary Laboratory Accreditation Program } \\ \text { SPC } & \text { statistical process control } \\ \text { SQC } & \text { statistical quality control } \\ \text { WMO } & \text { World Meteorological Organization } \\ \text { WRR } & \text { World Radiometric Reference }\end{array}$




\section{FOREWORD}

It is intended that the requirements for calibration, traceability of calibration, and statistical representation of calibration and test data presented in this document represent additional requirements of the laboratory quality system developed to support a photovoltaic module certification and labeling program, and that they be employed by: (a) laboratories engaged in testing photovoltaic devices in support of a photovoltaic module testing, certification, and labeling program, and (b) assessment bodies and their assessors as the criteria against which laboratories are examined for the purposes of accreditation. The criteria established in this document represent minimum acceptable guidance, and an expanded quality system beyond that required by this document is encouraged.

\section{Introduction}

1.1 All laboratories accredited or otherwise approved for the purpose of performing testing of photovoltaic energy conversion devices shall be required to comply with these requirements.

1.2 A laboratory is said to conform to these requirements if it fulfills all of the requirements defined herein.

1.3 When conformance to this document is claimed, all provisions of the requirements set for in this document shall be met.

\section{Scope}

2.1 This document sets forth the minimum requirements for calibration, calibration traceability, and statistical representation of calibration and test data with which a laboratory shall comply and operate to demonstrate its competence to test photovoltaic energy conversion devices.

2.2 In addition to its use as a model for the development of a laboratory's quality system, and for maintaining the quality of a laboratory's services, these criteria are for use in aiding the assessment of a laboratory's quality program and services.

2.3 This document also sets forth the minimum requirements for calibration frequency, traceability of calibration, and for the development of information required for the statistical representation of calibration and test data.

2.4 Measurements covered by the requirements of this document include the following:
2.4.1 Current, I (A)
2.4.2 Voltage, $\mathrm{V}(\mathrm{V})$
2.4.3 Resistance, $\mathrm{R}(\Omega)$
2.4.4 Power, P (W) 
2.4.5 Irradiance, (using a secondary reference cell), $\left(\mathrm{Wm}^{-2}\right)$

2.4.6 Irradiance (using a WMO primary ACR or a primary reference cell), $\mathrm{E}\left(\mathrm{Wm}^{-2}\right)$, covered only if the laboratory seeking accreditation will calibrate reference cells

2.4.7 Spectral Irradiance, $\mathrm{E}(\lambda)\left(\mathrm{Wm}^{-2} \mathrm{~nm}^{-1}\right)$

2.4.8 Spectral Responsivity, $\mathrm{P}(\lambda)\left(\mathrm{AW}^{-1}\right)$

2.4.9 Temperature, $\mathrm{T}\left({ }^{\circ} \mathrm{C}\right)$

2.4.10 Linear dimension, $\mathrm{L}$ ( $\mathrm{mm}$ or $\mathrm{m})$

2.4.11 Wind velocity, $v(\mathrm{~m} / \mathrm{s})$

\section{References}

3.1 Principal reference documents

\subsubsection{ISO Guide 25:}

"General Requirements for the Accreditation of Calibration and Testing Laboratories"

\subsubsection{ASTM E 1036:}

"Standard Test Methods for Electrical Performance of Nonconcentrator Terrestrial Photovoltaic Modules and Arrays Using Reference Cells"

\subsubsection{IEEE 1262:}

"Recommended Practice for Qualification of Photovoltaic (PV) Modules"

3.2 Other ASTM standards

3.2.1 ASTME 927:

"Specification for Solar Simulation for Terrestrial Photovoltaic Testing"

3.2.2 ASTM E 973M:

"Test Method for Determination of the Spectral Mismatch Parameter Between a Photovoltaic Device and a Photovoltaic Reference Cell (Metric)"

3.2.3 ASTM E 1040:

"Specification of Physical Characteristics of Nonconcentrator Terrestrial Photovoltaic Reference Cells"

3.2.4 ASTM E 1021:

"Test Methods for Measuring the Spectral Response of Photovoltaic Cells" 


\subsubsection{ASTM E 1125:}

"Test Method for Calibration of Primary Non-Concentrator Terrestrial Photovoltaic Reference Cells Using a Tabular Spectrum"

\subsubsection{ASTM E 1362:}

"Test Method for Calibration of Nonconcentrator Terrestrial Photovoltaic Secondary Reference Cells"

3.3 Uncertainty and expression of values

3.3.1 Barry N. Taylor and Kuyatt, Chris E.:

"Guidelines for Evaluating and Expressing the Uncertainty of NIST Measurement Results," NIST Technical Note 1297, Physics Laboratory, National Institute of Standards and Technology, Gaithersburg, MD 20899, January 1993

3.3.2 ASTM Special Technical Publication 15D:

"ASTM Manual on Presentation of Data and Control Chart Analysis"

\subsubsection{ISO TAG 4:}

"Guide to the Expression of Uncertainty in Measurement"

\subsubsection{ANSU/ASME PTC 19.1-1985, Part 1}

"Measurement Uncertainty-Instruments and Apparatus"

\section{Calibration}

4.1 General requirement for calibration certificates

4.1.1 All equipment and instrumentation used for the measurement of the parameters or physical properties listed in 2.4 of this document, shall be calibrated on a regular periodic basis, the frequency of which depends on the specific measurement.

4.1.2 Calibration certificates shall be provided and shall include, as a minimum, the following information:
(a) Name of calibration agency or authority
(b) Date(s) of calibration
(c) Calibration value found (as found)
(d) Calibration value (new)
(e) Traceability statement (shall be either to NIST, or to WRR) 
(f) NIST Test Reference Number for traceability to NIST (or an appropriate statement of the entire hierarchy of primary reference radiometers for traceability to the WRR)

(g) A statement of the total uncertainty of the transfer of calibration from either the NIST or WRR reference instruments to the test device being calibrated

(h) Signature of calibration officer, or person taking responsibility for the results.

\subsection{Source of calibration}

4.2.1 When an outside, independent calibration laboratory is selected to perform the laboratory's regular, periodic re-calibrations, the laboratory shall: (a) ensure that the calibration facility or laboratory is accredited either by A2LA or NVLAP ${ }^{2}$ for the exact measurements required, and shall obtain evidence to that effect, (b) ensure that the laboratory is certified to ANSI/NSCL Z540.1, and obtain evidence to that effect, and (c) investigate the competency of the vendor calibration laboratory in accordance with the requirements of 17.1 of Document PV-1.

4.2.2 When the original equipment or instrument manufacturer is selected for either the initial or re-calibration requirements, the laboratory shall ensure that all applicable traceability requirements are met, including the requirement of 4.3.x that the original equipment vendor shall have direct traceability to NIST for those measurements for which NIST traceability is applicable, or to the WRR for those measurements for which traceability to the World Meteorological Organization is required. The laboratory shall investigate the quality and competency of the manufacturer to provide accurate calibration values in accordance with the requirements of 17.1, 17.2, and 17.4 of Document PV-1.

4.2.3 The laboratory shall use the checklist contained in Appendix 1 of this document to evaluate the competency of any independent calibration facilities employed, as well as the quality and competency of original equipment and instrument manufacturers with respect to the initial calibrations provided, or to any re-calibrations obtained.

4.2.4 For the calibration of those instruments and test devices that the laboratory decides to perform without recourse to either outside independent calibration or the original manufacturer, it will be necessary to include the calibration in the laboratory's requested scope of accreditation.

4.3.1 Traceability of instruments and measurements required for laboratory accreditation in support of the PV module certification program is presented in Table A-1. Column 2 lists the test instrument that will most likely be employed by the PV test laboratory, and column 3 lists the reference instrument that will most likely be employed by either the test laboratory, the selected independent calibration laboratory, or the manufacturer's test

${ }^{2}$ For the purposes of this document, national laboratories such as NREL or Sandia National Laboratories will not be required to become accredited by A2LA or NVLAP. 


\begin{tabular}{|l|l|l|l|l|l|}
\hline Measurement & \multicolumn{1}{|c|}{$\begin{array}{c}\text { Most Likely } \\
\text { Instrument }\end{array}$} & $\begin{array}{c}\text { Typical Reference } \\
\text { Instrument }\end{array}$ & $\begin{array}{c}\text { Trace- } \\
\text { ability }\end{array}$ & $\begin{array}{c}\text { Frequency } \\
\text { of Re-cal }\end{array}$ & $\begin{array}{c}\text { Frequency } \\
\text { of Checks }\end{array}$ \\
\hline Current & Digital multimeter & Calibrated shunt & NIST & 2 years & 90 days \\
\hline Voltage & Digital voltmeter & Digital voltmeter & NIST & 2 years & 90 days \\
\hline Total irradiance & $\begin{array}{l}\text { Secondary reference } \\
\text { cell }\end{array}$ & Primary reference cell & WRR & 1 year & 60 days \\
\hline $\begin{array}{l}\text { Direct } \\
\text { irradiance }\end{array}$ & Pyrheliometer, ACR & One or more ACRs & WRR & 1 year & 90 days \\
\hline $\begin{array}{l}\text { Spectral } \\
\text { irradiance }\end{array}$ & Spectroradiometer & Standard lamp & NIST & annual & use \\
\hline $\begin{array}{l}\text { Spectral } \\
\text { responsivity }\end{array}$ & $\begin{array}{l}\text { Monochrometer, } \\
\text { lock-in amplifier }\end{array}$ & $\begin{array}{l}\text { Calibrated diode } \\
\text { detector }\end{array}$ & NIST & weekly & use \\
\hline Temperature & Digital thermometer & $\begin{array}{l}\text { Long-stem } \\
\text { thermometer }\end{array}$ & NIST & annual & 30 days \\
\hline Wind velocity & Anemometer & Anemometer & NIST & annual & 90 days \\
\hline Linear distance & Caliper, ruler & Caliper & NIST & 2 years & none \\
\hline
\end{tabular}

Table A-1. Traceability and Frequency Requirements for Instrumentation and Measurements Required for Laboratory Accreditation in Support of a Photovoltaic Module Certification Program

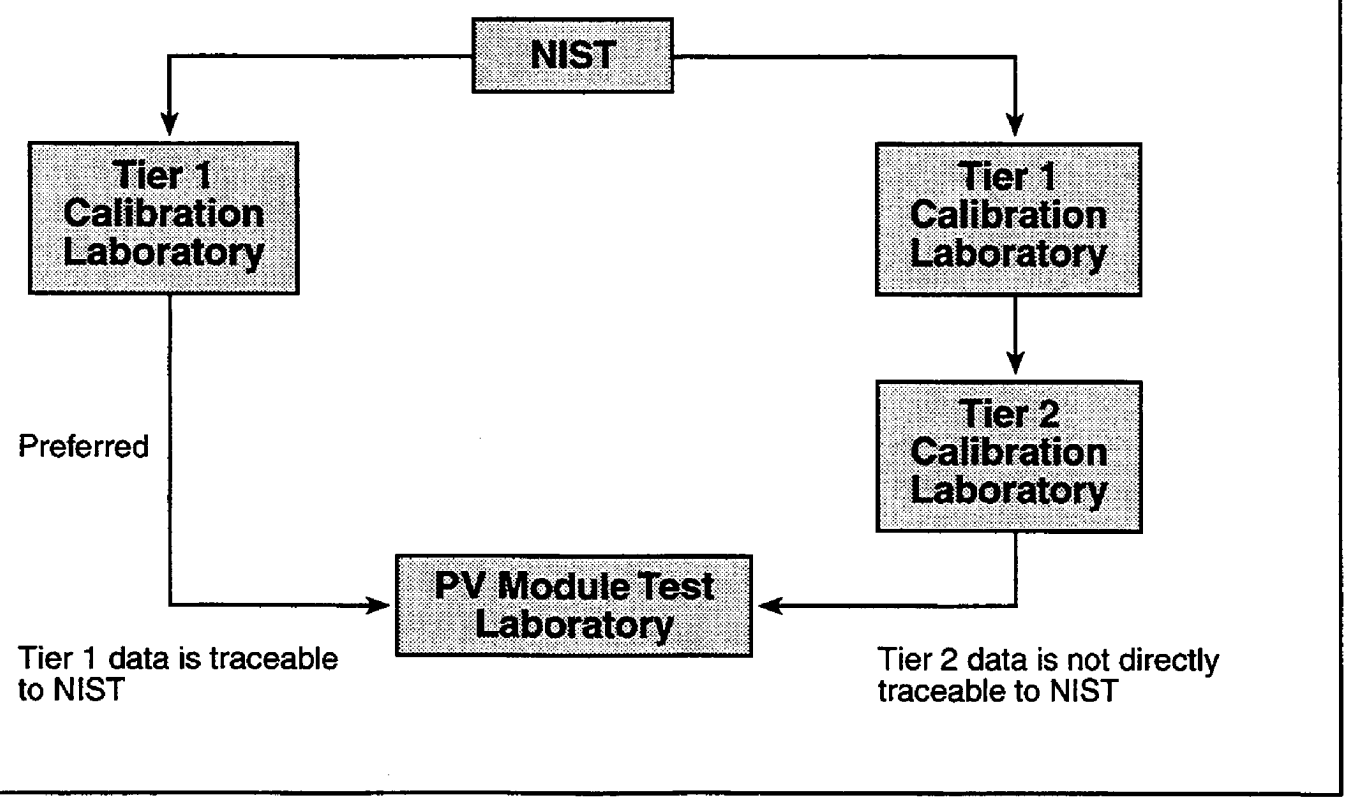

Figure A-1. Hierarchy of Traceability to NIST 


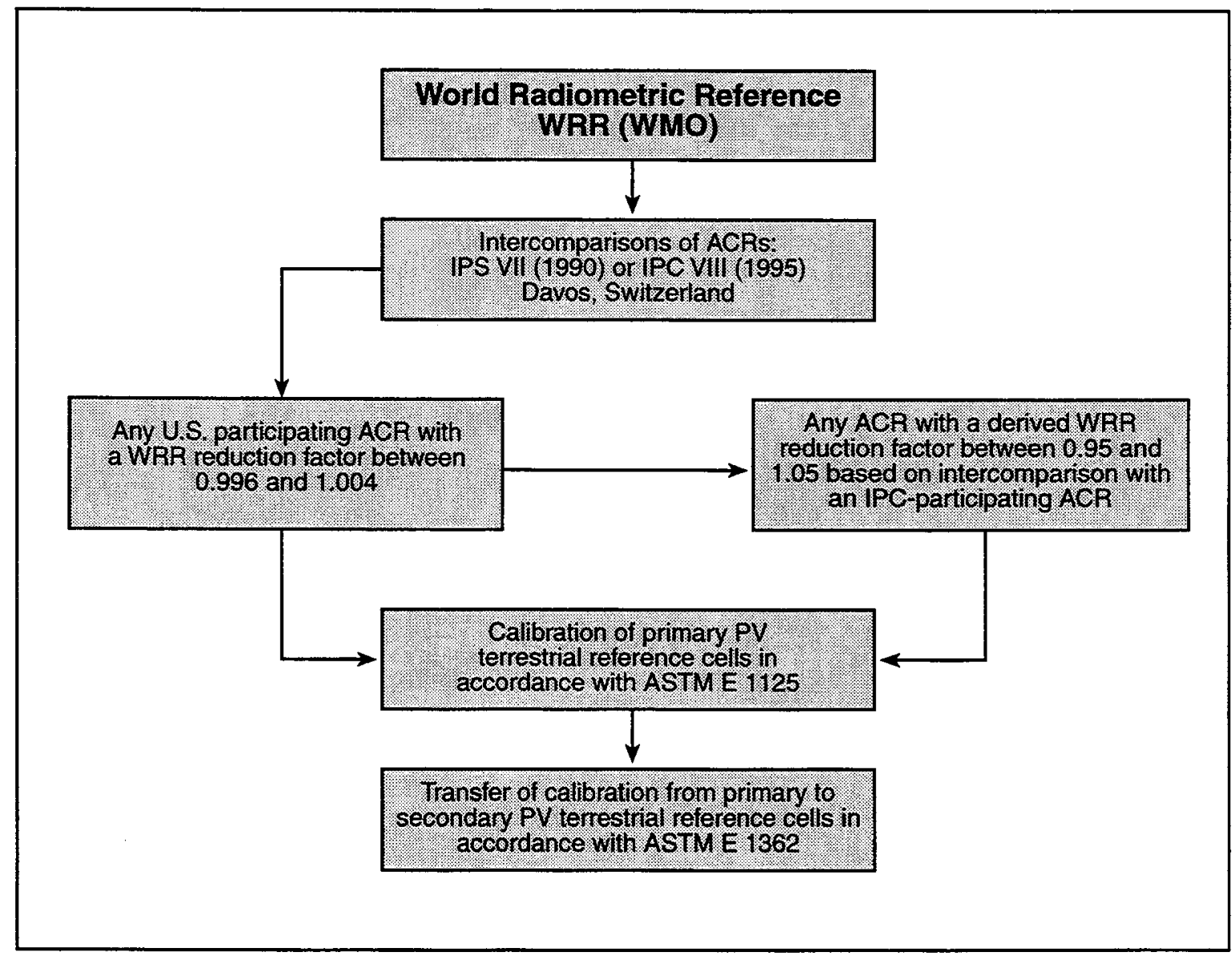

Figure A-2. Hierarchy of Traceability to the WMO World Radiometric Reference for PV Terrestrial Reference Cells

laboratory to calibrate and re-calibrate the laboratory's test instrumentation. Columns 5 and 6 of Table A-1 show the suggested and mandatory re-calibration and betweencalibration check or verification frequencies, respectively.

4.3.2 The hierarchy of NIST traceability for instruments listed in Table A-1 is presented in Figure A-1. As shown, the preferred calibration traceability scenario for the PV test laboratory would be for the laboratory to employ only Tier 1 traceability (i.e., traceable to NIST). If the test laboratory chooses to use a Tier 2 (traceable to NIST through Tier 1) calibration laboratory, it shall be responsible for assuring the competency of both the Tier 1 and Tier 2 calibration laboratories as noted in the vendor evaluation checklist, Appendix 1.

4.3.4 It shall be the PV module test laboratory's responsibility to ensure that the requirements of 4.3.3 and Figure A-2 are met regardless of whether: (a) the test laboratory performs the calibration of PV terrestrial reference cells, (b) obtains the PV reference cells from 
either the module manufacturer or a third party, or (c) performs selected portions of the calibration chain presented in Figure A-2.

\subsection{Other tests}

4.4.1 In the event that the PV module test laboratory either chooses to, or is required to, manufacture PV terrestrial reference cells used to determine the irradiance for currentvoltage (I-V) testing of modules, the cells shall be constructed in accordance with the requirements of ASTM E 1040. Dimensional requirements shall be traceable to NIST as shown in Table A-1.

4.4.2 If the test laboratory is required to determine spectral response and spectral mismatch coefficients for PV module performance, these measurements shall be performed in accordance with ASTM E 1021 and ASTM E 973, respectively. Spectral irradiance measurements shall be performed using a spectroradiometer with a calibration traceable to NIST.

4.4.3 Should the module test laboratory utilize a solar simulator for PV module performance measurements, its characteristics shall meet the requirements of ASTM E 927. The technical requirements for uniformity and spectral irradiance will necessitate the use of a spectroradiometer.

\section{Statistical requirements}

5.1 The PV module test laboratory shall ensure that calibrations obtained from outside, independent calibration laboratories or from original instrument manufacturers are provided with an expression of uncertainty by the vendor laboratory. To help the laboratory comply with this requirement, it is recommended that the vendor laboratory be requested to consider NIST Technical Note 1297, ISO TAG 4, and ASTM STP 15D.

5.2 For all internal calibrations, measurements, and the expression of test results, the laboratory shall utilize: (a) between-calibration checking of reference standards, (b) verification testing of whatever environmental conditions (temperature and relative humidity), (c) correlation analyses, and, (d) statistical process control (SPC) charting of module measurements to the extent possible.

5.3 Between-calibration checks of reference standards for voltage, current, temperature, and irradiance measurements shall be performed. This shall include but not necessarily be limited to regression analysis of the correlation between different temperature probes, different current and voltage measuring devices, and several pyranometers and PV reference cells. For example, internal reference standards should be maintained for temperature, voltage, current and irradiance measuring equipment such that the internal reference standards are only used for verification and checking purposes.

NOTE-Typically, $x-y$ correlation plots are maintained with the values from the routine measuring equipment plotted on the ordinate and those obtained from the internal reference plotted on the abscissa. Running correlation coefficients, $\mathrm{r}^{2}$, can then be maintained and confidence limits established. 
5.4 To the extent required, environmental chambers shall be spatially mapped not less frequently than annually with respect to the temperature and relative humidity they are able to maintain in the enclosure, and their control and monitoring functions shall be subjected to the betweencalibration checking and verification described in 5.3.

5.5 In the absence of an industry-developed proficiency test module, the laboratory shall be required to maintain not less than two internal reference photovoltaic modules whose short-circuit currents, open-circuit voltages, and fill factors will be determined on a regular, periodic basis for the purpose of control charting using statistical quality control (SQC) and SPC charting as appropriate. 


\section{PV-1.1 Appendix 1}

\section{Vendor Evaluation Checklist}

$\square$ Original Equipment Manufacturer

Vendor Name:

Street Address:

City:

Tel.:

State: Country:

Mail Code: Fax:

Equipment purchased, or being calibrated:

Name: Model No.:

Name: Model No.:

1. Vendor qualification, general (obtain from vendor)

Does the vendor have (mark as applicable):

$\square$ A2LA accreditation as a calibration laboratory (for applicable tests and equipment)?

$\square$ NVLAP accreditation as a calibration laboratory (for applicable tests and equipment)?

Registration to ISO 9001 or ISO 9002 (or ANSI/ASQC 91 or 92, or EN 29001 or 29002) as a manufacturer?

Accreditation to ANSI/NSCL Z540.1 or equivalent? From whom?

D.A quality assurance program?

$\square \quad$ A laboratory quality assurance manual?

A quality assurance manager? Who? 
2. Test laboratory's evaluation (telephone interview and/or site visit)

Has the undersigned (check all that apply):

Interviewed the vendor's technical manager or lab director?

Who?

Interviewed the vendor's quality manager?

Who?

$\square$ Reviewed the vendor's quality manual?

If so, does it meet the relevant requirements of ISO Guide 25 ? $\square$ Yes $\square$ No

Reviewed vendor's scope of accreditation (if accredited)?

If accredited, does the scope include the tests required?

$\square$ Yes $\square$ No

- Performed a site visit (if a vendor calibration laboratory)?

If yes, when?

lab contact?

time spent, hr?

If vendor is an accredited calibration laboratory, go to Section 3. If vendor is a manufacturer or an unaccredited calibration laboratory, complete the following:

- Does vendor have a documented quality policy? $\square$ Yes $\square$ No If yes, attach copy

- Does vendor have a documented in-house measurements verification program?

$\square$ Yes $\square$ No If yes, attach copies of any policies, procedures, etc.

- Does vendor have an established and documented equipment and reference instrument maintenance program?

$\square$ Yes $\square$ No

- Does vendor have established written "test" procedures for calibration of client instruments?

- Does vendor participate in any of the following:

D Proficiency test programs?

- Collaborative reference programs?

Interlaboratory comparisons?

- Does vendor have established any of the following:

- SPC charting of measurement checks of its reference standards?

- $x$-y correlation measurements and charting of reference standards against each other?

- Any other statistical or physical verification procedures?

What? 
- Does vendor have a documented corrective action program in place?

$\square$ Yes $\square$ No

- Does vendor have a documented complaint policy and procedures in place?

$\square$ Yes $\square$ No

- Does vendor have a documented policy and procedures for regular, periodic internal laboratory audits in place?

$\square$ Yes $\square$ No

- Qualifications of the calibrating laboratory's technical manager (however named):

Years of experience in the calibration field:

Formal education background:

Special qualifications (special courses in quality, calibration, etc.):

3. Measurement traceability (obtain copies of relevant documentation)

To what internationally recognized standards body, or bodies, are the laboratory's traceability maintained?

$\begin{array}{ll}\square & \text { NIST } \\ \square & \text { WMO } \\ \square & \text { Other: }\end{array}$

The vendor's reference standards represent: $\square$ first tier?, or, $\square$ second tier or greater traceability? If second tier, the calibration laboratory must furnish the information required by this vendor evaluation checklist for the calibration laboratory they use. NOTE: Third tier traceability will not be acceptable.

List reference standards and NIST traceability reference test numbers for applicable instrumentation:

Instrument:

Test Number(s):

The interviewer recommends conditional acceptance of the above-named vendor calibration or independent calibration laboratory.

Signed: Date: 
A-36 
Annex B

PV-2. Model for a Third-Party Certification and Labeling Program for Photovoltaic Modules 


\section{Document PV-2}

\section{Model for a Third-Party Certification and Labeling Program for Photovoltaic Modules}

Table of Contents

Page

Foreword

B-5

1. Introduction B-5

2. Scope B-6

3. References $\quad$ B-7

4. Definitions $\quad$ B-8

5. Certification body B-9

6. Manufacturer's or producer's quality system $\quad$ B-11

7. Initial testing and periodic retesting B-14

8. Licensing B-14

9. Surveillance B-15

10. Use of the certification of conformity, or mark of conformity, and marking B-16

$\begin{array}{ll}\text { 11. Misuse of a certificate or mark of conformity } & \text { B-17 }\end{array}$

$\begin{array}{ll}\text { 12. Publicity by licensees } & \text { B-18 }\end{array}$

13. Suspension of a license for a product $\quad$ B-18

14. Withdrawal or cancellation of a license B-19

$\begin{array}{ll}\text { 15. Corrective action } & \text { B-20 }\end{array}$

16. Implementation of modifications to Document PV-3 B-20

$\begin{array}{ll}\text { 17. Liability } & \text { B-21 }\end{array}$

18. Disputes B-21

19. Fees B-21 
Appendix 1

An approach to the review by a certification body of its own internal quality system (reproduction of ISO/IEC Guide 56)

Appendix 2

Form PV250: Checklist for assessing the capabilities and quality system of manufacturers and producers

Appendix 3

Form PV200: Specimen for initial questionnaire for factory assessment

(reproduced from Appendix 1 of Annex B from ISO/IEC Guide 28)

Appendix 4

Form PV100: Application for conformity certification by use of certificates or mark of conformity

(reproduced from Annex B from ISO/IEC Guide 28)

Appendix 5

Form PV300: Specimen of a licensing agreement for the use of a certificate or

mark of conformity

(reproduced from Annex C from ISO/IEC Guide 28)

Appendix 6

Specimen of form for a license for the use of the certificates or mark of conformity

(reproduced from Appendix 1 of Annex C from ISO/IEC Guide 28)

\section{Glossary}

ANSI

ASQC

ASTM

ISO

IEC

IEEE

NIST

UL
American National Standards Institute

American Society of Quality Control

American Society for Testing and Materials

International Standards Organization

International Electrotechnical Commission

Institute of Electrical and Electronics Engineers

National Institute of Standards and Technology

Underwriters Laboratories 
B-4 


\section{FOREWORD}

It is intended that the requirements for a model for a third-party certification and labeling program presented in this document be employed as a model by (1) organizations selected, formed, or otherwise approved to engage in the role of a photovoltaic module certification and labeling entity that is wholly independent of all photovoltaic product testing activities or (2) laboratories engaged in the dual role of testing photovoltaic modules on the one hand, and carrying out a product certification and labeling program, on the other.

It is not the purpose of this document to set forth the requirements for either the operation of a laboratory that is accredited or otherwise approved to perform the testing, or the technical testing requirements that will result in creation of the information and data that will be used by such a product certification and labeling program (or by an organization engaged in product certification). However, this model is one of a series of documents that together purport to address the totality of the criteria and requirements of a photovoltaic testing, certification, and labeling program. The other documents in this series are:

PV-1 Criteria for a Model Quality System for Laboratories Engaged in Testing Photovoltaic Modules

PV-1.1 Calibration, Traceability, and Statistical Requirements of Accredited Laboratories Supporting the Photovoltaic Module Certification Program (Addendum to PV-1)

PV-3 Testing Requirements for a Certification and Labeling Program for Photovoltaic Modules

PV-4 Operational Procedures Manual for the Certification Body of the Photovoltaic Module Certification Program

PV-5 Application and Certification Procedures for the Photovoltaic Module Certification Program

In crafting the criteria set forth in this model, the requirements of ANSI Z34.1, an American National Standard for "Certification-Third Party Certification Program," and ISO/IEC Guide 28, "General Rules for a Model Third-Party Certification System for Products," have been taken into consideration, and significant portions of both have been adopted.

\section{Introduction}

1.1 This document describes a model and the general rules for the model's use in developing and implementing a third-party product certification program for photovoltaic modules.

1.2 The application and use of this document shall not contravene any federal, state, or local statutory requirements.

1.3 These general rules represent the generic criteria under which a producer is authorized to use the certification program's certificate of conformity or the program's mark (certification mark) as a label to indicate that the associated manufacturing process and the photovoltaic modules produced therefrom are in compliance with applicable test standards and specifications. 


\section{Scope}

2.1 The model described by the criteria and requirements of this document encompasses the structure of a third-party product certification system for determining the conformity of photovoltaic modules with a series of performance and durability-reliability standards contained in Document PV-3.

2.2 This model is applicable to certification of conformity of photovoltaic modules to other test standards and specifications having a broad level of recognized acceptance, selected from time to time by the certification body's, or program's, technical committee, however named. These standards and specifications include revisions of the methods contained in Document PV-3, as well as new methods that become important to the operation of the certification program. Recognized acceptance of such standards and specifications shall be any of, or any combination of, the following:

(a) An American National Standard

(b) A standard promulgated by ASTM, IEEE or any other domestic national standards organization

(c) An international standard promulgated by either the International Electrotechnical Commission (IEC) or the International Standards Organization (ISO)

(d) A standard or specification published by the federal, state, or local governments.

2.3 Conformity to the requirements of Document PV-3 shall be determined through initial testing and assessment of a factory quality management system and its acceptance followed by surveillance that takes into account the factory quality management system and the testing of samples from the factory and the open market.

2.4 A certification body operating a product certification or certification and labeling program for photovoltaic modules shall itself have in place a Quality Assurance System that meets the relevant requirements of Document PV-1. 1

2.5 The certification body shall be responsible for selecting, or otherwise approving or accrediting, the laboratory or laboratories used for testing photovoltaic modules to the requirements of Document PV-3. Approval or accreditation of the laboratory or laboratories shall be based on the successful completion of an outside assessment of the laboratory's competence when audited against the criteria set forth in Document PV-1.

2.6 When conformance to this model is claimed, it shall pertain to the provisions of all criteria and requirements set forth in this document.

\footnotetext{
${ }^{1}$ Alternatively, conformity to the relevant requirements of ISO 9002 is acceptable.
} 


\section{References}

3.1 ANSI Z34.1:

"Third-Party Certification Program"

3.2 ISO/IEC Guide 28:

"General rules for a model third-party certification system for products"

3.2 ASTM E 548:

"General criteria for Evaluating Testing Laboratories"

3.3 ASTM E 1322:

"Guide for Selection, Training and Evaluation of Assessors for Laboratory Accreditation Systems"

3.4 ISO/IEC Guide 25:

"General requirements for the accreditation of calibration and testing laboratories"

3.5 ISO/IEC Guide 23:

"Methods of indicating conformity with standards for third-party certification systems"

3.6 ISO/IEC Guide 27:

"Guidelines for corrective action to be taken by a certification body in the event of misuse of its mark of conformity"

3.7 ISO/IEC Guide 38:

"General requirements for the acceptance of testing laboratories" (in revision)

3.8 ISO/IEC Guide 55:

"Testing laboratory accreditation systems-General recommendations for operation"

3.9 ISO/IEC Guide 56:

"An approach to the review by a certification body of its own internal quality system"

3.10 ISO 9001 and ANSI/ASQC 91:

"Quality Systems-Model for quality assurance in design/development, production, installation and servicing"

3.11 ISO 9002 and ANSI/ASQC 92:

"Quality systems-Model for quality assurance in production and installation" 


\section{Definitions}

4.1 The relevant definitions pertaining to testing, calibration, and verification contained in Document PV-1 are incorporated by reference and are not repeated.

4.2 Certification activities:

4.2.1 Certification: The procedure by which written assurance is given that a product or service conforms to a specification. A third-party certification is one that is rendered by a technically and otherwise competent body other than one controlled by the producer or the buyer.

4.2.2 Certification program: The system that relates to specific products, processes, or services to which the same particular standards and rules, and the same procedure, apply. Such a program uses or is operated by a third-party inspection/testing body or organization, and the program authorizes the use of controlled certification marks or certificates of conformity as evidence of conformity.

4.2.3 Certification body: An impartial body or organization possessing the necessary competence to develop, promulgate, finance, and operate a certification program and to conduct certifications of conformity.

NOTE: A certification body may operate its own testing and inspection activities or it may oversee these activities carried out on its behalf by other bodies, e.g., an independent testing laboratory.

4.2.4 Producer: The manufacturer, distributor, supplier, or other party providing the product or service to be purchased and employed by a user. The producer is responsible for assuring conformity with all requirements of the certification program.

4.2.5 Certification mark: The sign or symbol owned and controlled by the certification body that is used exclusively by the third-party certification program to identify products or services as being certified and is registered as a certification mark with the U.S. Patent Office under the Trade Mark Act of 1946.

4.2.6 Certificate of conformity: A tag, label, nameplate, or document of specified form and content, affixed or otherwise directly associated with a product or service on delivery to the buyer, attesting that the product or service is in conformity with the requirements of the certification program (e.g., with the referenced standards and specifications).

4.2.7 License (for certification): Document, issued under the rules of a certification program, by which a certification body grants to a person, manufacturer, or producer, the right to use the certificates or marks of conformity for its products, processes, or services in accordance with the rules of the relevant certification program.

4.2.8 Licensee (for certification): Person, manufacturer, or producer to which a certification body has granted a license. 
4.3 Testing and inspection activities:

4.3.1 Tests: Technical operations that consist of the determination of one or more characteristics of a given product, process, or service according to a specified procedure.

4.3.2 Testing: Actions or the process of carrying out one or more tests.

4.3.3. Testing/Inspection body (third-party): An organization (if a testing body, a laboratory) that possesses the necessary technical competence and that is other than one operated or controlled by a manufacturer, supplier, or buyer (user) of a certified product or service in that it has no organizational, financial, or commercial involvements with the producer or buyer that might pose a potential conflict of interest.

NOTE: An inspection body is an organization, often organized separately from the testing laboratory, and often a functional arm of the certification body (whether an organizational or a subcontracted entity) that performs initial inspections of a manufacturer's or producer's operations, including any subsequent surveillance procedures that may be required.

4.4 Conformity and standards:

4.4.1 Conformity: Fulfillment by a product, process, or service, of specified requirements.

4.4.2 Conformity evaluation: Systematic examination of the extent to which a product, process, or service fulfills specified requirements.

4.4.3 Inspection: Evaluation for conformity by measuring, observing, testing, or gauging the relevant characteristics as required by a specification or standard.

4.4.4 Conformity surveillance: Evaluation for conformity to determine the continuing conformity with specified requirements.

4.4.5 Standard: A prescribed set of conditions and requirements, established by authority or agreement, for continuous application. It takes the form of a document containing a set of conditions to be fulfilled, or an object of comparison. For the purposes of this document, the provisions as defined and used in this document shall be such as to be suitable to and capable of certification.

\section{Certification body}

5.1 The photovoltaic certification body whose name is identified with the certification and labeling program for photovoltaic modules shall be one of the following:

(a) A trade association

(b) An existing product certification body 
(c) A professional or technical society.

(d) An organization of photovoltaic manufacturers or of laboratories engaged in testing photovoltaic modules

(e) An organization oriented to the public, consumers, or users of photovoltaic modules

(f) A third-party testing/inspection organization.

5.2 The photovoltaic certification body shall:

5.2.1 Comply with the general requirements for third-party certification as outlined in Sections 6 through 19 of this model

5.2.2 Have a structure that permits choosing its governance members, if it operates under either a governing board or board of directors, from among those interests involved in the process of certification without any single interest predominating

5.2.3 Have as a minimum an internal quality system and audit procedure in accordance with the requirements presented in Appendix 1 of ISO/IEC Guide 56, which is reproduced in full in Appendix 1 of this document

5.2.4 Be responsible for and assure that certification is based on:

5.2.4.1 The results of actual tests of the characteristics of the photovoltaic modules performed by a laboratory in accordance with the requirements of Documents PV-1 and PV-3

5.2.4.2 Formal reports of the results of the testing and inspection of the photovoltaic modules

5.2.4.3 The furnishing of photovoltaic modules by the producers and/or distributors of such modules that are manufactured under a system of quality assurance in accordance with Section 6.2 of this model, such as ISO 9000 Series of quality assurance standards

\subsubsection{Be responsible for:}

5.2.5.1 Assessment of, or causing to be assessed, those testing laboratories that make application and furnish their qualifications for accreditation by the photovoltaic certification body as a laboratory approved to perform the testing required in accordance with Document PV-3. The testing laboratory accreditation system shall be operated in compliance with the requirements of ISO/IEC Guide 55, and the assessment of candidate laboratories shall be carried out by qualified laboratory assessors in accordance with the requirements of Document PV-1 
5.2.5.2 Levying, or otherwise approving, of the laboratory assessment fees in accordance with rules established by the photovoltaic certification program

5.2.5.3 Regular periodic reassessment and reaccreditation of laboratories initially qualified to perform photovoltaic testing with a frequency in accordance with rules established by the photovoltaic certification program

5.2.5.4 Initial inspection of the manufacturer's or producer's factory and assessment of its quality management system in accordance with the checklist presented in Appendix 2 of this document

5.2.5.5 Regular periodic reassessment and reapproval of the manufacturer's or producer's quality system with a frequency in accordance with rules established by the photovoltaic certification program.

\section{Manufacturer's or producer's quality system}

6.1 Initial inspection and assessment

6.1.1 To facilitate the inspection and assessment, a manufacturing and quality management system data form shall be developed that contains pertinent information needed to be acquired from the applicant. An example of the required data form is presented in Appendix 3 of this document, and an example of an acceptable application for participation in the photovoltaic certification program is presented in Appendix 4 of this document.

6.1.2 On receipt of the manufacturer's program data form and application requesting participation in the photovoltaic module certification program, the certification body shall seek any clarifications necessary to the determination that the manufacturer is likely to be approved as a certification program participant.

6.1.3 After confirmation of the acceptance of the program data form and application, the certification body shall make the necessary arrangements with the applicant for initial inspection and assessment in accordance with the established rules of the certification program. The certification body's assessor or the assessment team shall be persons who are knowledgeable in:

(a) The applicable photovoltaic testing standards and specifications (e.g., Document PV-3)

(b) Appropriate laboratory test procedures

(c) Quality assessment techniques and procedures

(d) The quality system elements required for photovoltaic certification. 
6.1.4 The matters to be investigated by the assessment team at the manufacturer's factory shall include, as a minimum, the following:
6.1.4.1 Determination that all the information provided by the manufacturer in the certification program data form is correct

6.1.4.2 Determination that the manufacturer has the necessary equipment, staff, and facilities required for the production of a quality product and therefore for participation in the certification program

6.1.4.3 Determination that the applicant demonstrates the quality control test procedures required of a manufacturer's quality assurance program
6.1.4.4 Assurance that those quality system elements required for participation in the certification program, as detailed in Appendix 2, are being performed, or practiced as a routine part of the manufacturing process.

6.1.5 The certification body shall inform the applicant in writing of the results of the initial inspection of facilities and assessment of applicant's quality system.

6.1.6 If, on the basis of the inspection and assessment, the requirements for licensing are not met, the certification body shall inform the applicant in writing of those criteria in which the application has failed.

6.1.7 If the applicant can provide objective evidence that the required remedial action has been taken to remove the deficiencies found within the time period specified by the photovoltaic certification program, the applicant will be judged to have complied with the certification program's requirements for licensing.

6.1.8 If the applicant cannot provide objective evidence that the required remedial action has been taken, or evidence has not been provided in the time period required, the certification body will repeat that portion of the inspection and assessment for which remedial action was originally required. Failing either, the application shall be denied and communicated to the manufacturer in writing.

6.1.9 The fees and costs associated with the initial inspection shall be in accordance with the rules established by the certification body.

\subsection{Manufacturer's quality management system}

6.2.1 Assessment of the manufacturer's quality management system shall form a significant portion of the initial inspection.

6.2.2 The manufacturer shall implement a quality management system that meets, as a minimum, the requirements listed in Section 6.2.5. 
6.2.3 All of the manufacturer's records produced for implementation of the quality management system related to photovoltaic certification shall be readily available for inspection by the inspectors or assessors, or both, assigned by the certification body.

6.2.4 The manufacturer shall appoint designated persons to be responsible for the quality management system and the company's contact person to the certification body for matters relating to certification. Ideally, they should be the same person. The quality manager, however named, shall be independent from production management.

6.2.5 The manufacturer's quality system shall have, as a minimum, the following elements (which are a synopsis of ISO 9001):

6.2.5.1 A quality assurance manual containing the policies and procedures that relate, as a minimum, to the quality system elements presented in Sections 6.2.5.2 through 6.2.5.10

6.2.5.2 Procedures to control and verify the design of the product, with emphasis on design changes

6.2.5.3 Procedures that ensure that purchased product conforms to specified requirements

6.2.5.4 Procedures that govern the control of manufacturing processes, document manufacturing work instructions, and document the operation of manufacturing and process equipment

6.2.5.5 Procedures and documentation covering inspection and testing of product, including reporting of results, retention of test and inspection records

6.2.5.6 Procedures for maintenance, operation, and calibration of inspection and testing equipment and instruments, including retention of records of calibration, outof-calibration occurrences

6.2.5.7 Procedures for control of nonconforming product and for nonconformity review and disposition

6.2.5.8 Procedures for corrective actions relating to nonconforming product, customer complaints, discrepancies in manufacturing processes and deficiencies found in internal audits

6.2.5.9 Procedures for handling, storage, packaging, and delivery of product

6.2.5.10 Procedures for maintenance of quality records

6.2.5.11 Procedures for performing internal quality audits. 


\section{Initial testing and periodic retesting}

7.1 Sample selection

7.1.1 Photovoltaic test specimens shall be selected at random by an employee or an agent of the certification body from a lot of manufactured product either in the factory or in the field in accordance with rules and procedures established for the certification program.

7.1.2 The lot from which specimens are chosen shall be of sufficient size to eliminate the possibility of selecting compliant specimens that otherwise might not be representative of sold product.

7.1.3 The employee or agent of the certification body shall establish that the product chosen for initial test has been manufactured from production tools and assembled using methods established for production runs.

7.1.4 Where testing is based on prototype product, confirmation tests or examinations, or both, shall be made on production samples as soon as possible. When production samples are found not to meet the requirements for certification, labeling, and licensing, revocation of certification shall be in accordance with procedures established by the certification body.

7.2 Initial testing

7.2.1 Initial testing shall be carried out by a laboratory accredited in accordance with the requirements of this model and Document PV-1, and the test procedures shall be those specified in Document PV-3.

7.2.2 Where the certification body chooses to use test data produced by laboratories other than one accredited by the certification body, such as in an international program of reciprocity of product certification, the certification body shall ensure that the test laboratory conducting the testing complies with all of the criteria of ISO/IEC Guide 25 and with those specific requirements of Document PV-1 established by the certification body for the purposes of reciprocity of test data.

7.3 Periodic retesting

7.3.1 Periodic retesting shall be carried out in accordance with the frequency and rules established for the photovoltaic certification program.

\section{Licensing}

8.1 When complete fulfillment of the requirements of the photovoltaic certification program has been established, the certification body will inform the manufacturer and will submit a licensing agreement for the applicant's signature. An example of a licensing agreement is presented in Appendix 5 of this document. 
8.2 On completion of the licensing agreement, the certification body issues a license to the manufacturer for use of the certification body's certificate of compliance, or mark. An example of a license is given in Appendix 6 of this document.

8.3 A licensee wishing to extend a license to additional types or models of photovoltaic modules produced in the same factory should apply using the same application form that was used initially (an example form is given in Appendix 4 of this document). The conditions under which the certification body shall require full testing shall be defined in the rules for the certification program. For example, the certification body may institute procedures for type testing that eliminate the need for retesting modules whose only design change from a certified product is cosmetic (providing that objective evidence is submitted for consideration by the certification body).

8.4 If the licensee wishes to apply for certification of a photovoltaic module manufactured in another factory, an additional application must be made, the factory must be inspected, and the quality system must be assessed, completely independent of existing certifications and licenses.

\section{Surveillance}

9.1 The certification body may, in accordance with procedures established for the photovoltaic certification program, exercise surveillance procedures in lieu of frequent retesting of a licensed product. However, surveillance shall in no way contravene the requirement for periodic retesting of licensed product.

9.2 The certification body may use its own employee(s) or appoint an agent to carry out the surveillance under the authority of the certification body. In case the certification body exercises its prerogative to use surveillance techniques, permission to use surveillance shall be a provision of the licensing agreement.

9.3 The licensee shall be informed about the results of the surveillance.

9.4 The licensee shall inform the certification body of intended modifications to the licensed product, the manufacturing processes, or the quality management system that may have an effect on the product's compliance. On such notification, the certification body shall make a determination of whether to initiate a full inspection and test sequence or to schedule a surveillance visit.

9.5 Where the licensee has made modifications to the licensed product, the manufacturing processes, or its quality management system, regardless of whether the certification body has been so notified, the licensee shall not release certified products resulting from such changes until the certification body has given the licensee written permission to do so.

9.6 The licensee shall maintain a record of all complaints relative to the photovoltaic modules covered by the license, and shall make these available to the certification body on request 
10. Use of the certificate of conformity, or mark of conformity, and marking

10.1 General

10.1.1 Certificates and marks of conformity shall be limited for use in the photovoltaic certification program to indicate that compliance with the standard is under the jurisdiction of the certification program.

10.1.2 The use of certificates and marks of conformity shall be described and controlled by the certification body in documentation separate from this model and from Documents PV-1 and PV-3.

10.1.3 The precise rules and procedures for use of representations of conformity shall be developed in accordance with the provisions of ISO/IEC Guide 23. The rules developed by the certification body shall specify whether certificates and marks are issued jointly, or whether they are issued separately for different purposes, or whether they are issued on the basis of preference expressed by the manufacturer.

10.1.4 The rules shall specify the exact conditions under which physical representations of conformity are permitted or used, specific limitations on their use, types and forms of certificates or marks, or both, and procedures for dealing with misuse, or misrepresentation, of certificates and marks of conformity.

10.2 Certificate of conformity

10.2.1 The purpose of issuing certificates of conformity is to provide the end user information as to the standards covered by the certificate.

10.2.2 Certificates of conformity may relate to all of the requirements of a standard or to selected provisions only.

10.2.3 When issued, certificates of conformity shall contain as a minimum the following information:

(a) Name and address of the certification body

(b) Name and address of the manufacturer

(c) Identification of the photovoltaic module certified and model or type number, and the lot and serial-number series, if relevant, to which the certificate applies

(d) Reference to Document PV-3, or to appropriate provisions and sections of Document PV-3

(e) Coded reference to the test results such that there is a capability of relating the certificate to the test results on which it was based

(f) Date of issue of certificate 
(g) Signature and title of authorizing officer of the certification body.

The rules of the photovoltaic certification program may specify additional information to be included.

10.3 Marks of conformity

10.3.1 The mark of conformity, or certification mark, shall be designed such as to minimize the possibility of counterfeiting. It shall be in the form of a nontransferable label, or mark, in the sense that it cannot be removed from one photovoltaic device and placed on another.

10.3.2 If a formal certificate of conformity, issued in the context of Section 10.2, is not issued simultaneously with issuance of the mark, a separate certification shall be issued that lists the information required by Section 10.2.3.

10.3.3 When only certain components of a photovoltaic system bear a certification mark, care shall be taken to ensure that the user or consumer is not mislead into assuming that the entire system is certified.

10.3.4 A mark of conformity shall be issued and used only where it relates to all the requirements of a standard and not to selected sections or characteristics.

10.3.5 When issued, a license for the use of the mark of conformity shall be issued to the manufacturer by the certification body only. No other source of the mark shall be authorized, or permitted.

$10.4 \quad$ Marking

10.4.1 The requirements, procedures, and instructions for use of the physical process of marking and the placement of the mark shall be included in the rules established by the certification body and shall be a part of the provisions of the documentation required by Sections 10.1.2 and 10.1.3 of this document.

11. Misuse of a certificate or mark of conformity

11.1 The certification body shall operate a surveillance program as part of its program on licensing of the conformity certificate or mark.

11.2 Incorrect references to the certification system or misleading use of the mark found in advertisements, catalogues, or product literature, shall be handled in accordance with procedures established by the certification body, and the subject of suitable action, including corrective actions, shall be covered in the licensing agreement.

11.3 In cases of misuse of certificates or the mark of conformity by licensees, corrective action shall be taken. 


\section{Publicity by licensees}

12.1 Licensees of the photovoltaic certification program's mark of conformity, or certificate of conformity, shall have the right to publish that the licensed manufacturer has been authorized to issue a certificate of conformity or apply a mark of conformity for products to which the license applies.

12.2 Provision shall be made in the licensing agreement that requires the licensee to take sufficient and due care of his publications and advertising so that no confusion arises between certified and noncertified products.

12.3 If permitted by the rules established by the certification body, the manufacturer may publish parts of a test report that relate to the certification of his products except that the licensee may do so only with the written permission of the certification body.

12.4 The certification body is encouraged to establish rules requiring that licensees submit their proposed promotional, catalog, and advertising materials to the certification body for approval prior to publication.

\section{Suspension of a license for a product}

13.1 The applicable tenets of this section shall be included in the licensing agreement.

13.2 The license applicable to a specific product may be suspended for a limited period under the following circumstances:

(a) If the surveillance, or required retesting, shows noncompliance with the requirements of such a nature that immediate withdrawal is not necessary

(b) If a case of improper use of the certificate or the mark, e.g., misleading prints or advertisements is not solved by suitable retractions and appropriate remedial measures by the licensee

(c) If there has been any other contravention to the rules and procedures of the certification program, or requirements of the certification body.

13.3 The licensee may not identify as certified any product that has been produced under a suspended license applicable to that product.

13.4 A license may also be suspended after mutual agreement between the manufacturer and the certification body for reasons of existence of a finite period of nonproduction or inactivity, or for other reasons.

13.5 An official suspension of a licensee shall be confirmed by the certification body in a registered letter to the manufacturer (or by other equivalent means). 
13.6 The certification body shall indicate under what conditions the suspension will be removed, such as, for example, corrective action taken in accordance with Section 15 of this document.

13.7 At the end of the suspension period, the certification body will ascertain if the conditions for reinstating the license have been fulfilled and shall notify the manufacture either that the license has been reinstated or that the license has been withdrawn (see Section 14).

\section{Withdrawal or cancellation of a license}

14.1 The applicable tenets of this Section shall be included in the licensing agreement.

14.2 Apart from the temporary suspension of a license, a license may be withdrawn or canceled in the following circumstances:

(a) If the surveillance shows that the noncompliance is of a serious nature

(b) If the licensee fails to comply with the due settlement of his financial obligations

(c) If there is any other contravention of the licensing agreement

(d) If inadequate measures are taken by the licensee in the case of suspension.

14.3 In the circumstances described in Section 14.2, the certification body shall have the right to withdraw or cancel the license by informing the licensee by registered letter (or by equivalent means). The specification of time limit shall be contained in the licensing agreement (see Article 10 of the specimen licensing agreement in Appendix 5 of this document).

14.4 The licensee may give notice of appeal. The certification body shall consider all appeals, but shall reserve the right to reject, after due consideration, the appeal by licensee, thereby letting the withdrawal or cancellation stand.

14.5 The certification body shall ensure that documented appeals procedures are adopted for use in the photovoltaic certification program.

14.6 The procedures adopted by the certification body for withdrawal or cancellation of a license shall include procedures for considering and acting appropriately on the consequences in relation to products certified under the license, whether the mark of conformity shall be removed from all products in stock, and if practical, whether the mark shall be removed from products already sold, or whether a clearance of the stock of marked products should be allowed within a short period of time, and if other actions are required.

14.6.1 In any case, the manufacturer shall be required to notify the purchasers of decertified product that the license has been canceled. 
14.7 The license may be cancelled for any of the following reasons:

(a) If the licensee does not wish to continue the license

(b) If the rules are changed and the licensee either will not or cannot ensure compliance with the new requirements (see Section 16)

(c) If the product is no longer manufactured or the licensee ceases to operate

(d) Noncompliance with other provisions of the licensing agreement.

14.8 The certification body shall have the right to publish all revocations of licenses to use the certification program's certificates and marks of conformity. However, regardless of whether the certification body established such a policy, the publication of revocations of license shall apply to all withdrawals and cancellations.

\section{Corrective action}

15.1 In cases of misuse of a certificate or a mark of conformity, corrective action shall be taken to safeguard their use.

15.2 Procedures for corrective action shall be established and documented by the certification body. Such procedures shall conform, as a minimum, to the requirements of ISO/IEC Guide 27.

\section{Implementation of modifications to Document PV-3}

16.1 There are a number of circumstances that can force changes in the testing procedures and other product requirements that impact the manufacturers. These include

(a) Improvements in test methods of such significance as to require revisions of Document PV-3

(b) The necessity for adding test methods to Document PV-3

(c) Changes required by federal, state, or local mandates, laws, or regulations.

16.2 The certification body shall establish procedures for revising Document PV-3.

16.3 The effective date of modification to a standard must be published by the certification body, and all licensees listed under the photovoltaic certification program shall be notified to provide adequate time for resubmittal of their applications.

16.4 Factors that shall be considered when choosing an effective date include, but are not necessarily limited to, the following:

(a) The urgency of complying with revised health, safety, or environmental requirements 
(b) The length of time and financial costs for retooling and manufacturing a product to meet revised requirements

(c) The extent of stock on hand and whether it can be reworked to meet the revised requirements

(d) Avoidance of unintentional commercial advantage given to a particular manufacturer or design

(e) Operational problems of the certification body.

\section{Liability}

17.1 Where questions of product liability are at issue, they must be dealt with on the basis of the relevant law.

17.2 The certification body shall take all possible steps to secure affordable officers' and directors' insurance.

18. Disputes

18.1 Disputes between the certification body and licensees or potential licensees shall be handled in the same manner as appeals.

18.2 The certification body's appeals procedures shall include procedures for the resolution of disputes arising from matters other than license revocation actions.

19. Fees

19.1 The certification body shall establish a fee structure for the licensing process that provides adequate revenue for the operation of the photovoltaic module certification program.

19.2 The certification body shall establish assessment fees that include reimbursement of expenses associated with:

(a) The inspection, assessment, and accreditation of the certification program's test laboratories

(b) The inspection, assessment, and approval of the manufacturer's production facilities, organizational capabilities, and quality system as a condition of acceptance as a participant in the certification program (notwithstanding the additional requirements for testing and the consequences derived therefrom). 


\section{PV-2 Appendix 1}

An approach to the review by a certification body of its own internal quality system (reproduction of ISO/IEC Guide 56) 


\section{An approach to the review by a certification body of its own internal quality system}

\section{Introduction}

0.1 One of the most essential elements for the operation of an international certification system or for mutual recognition of national certification systems is confidence in the competence of the certification bodies participating in the system or engaged in mutual recognition.

0.2 Confidence can be built through a progressively expanding set of acceptance arrangements, bilateral or multilateral, in the process of a step-by-step approach to an international certification system, as described in ISO/IEC Guide 42.

0.3 The aim of the procedure recommended in this Guide is to facilitate and accelerate the initiation of such a process, by providing certification bodies with a means of maintaining and improving their competence. "1

0.4 It is recognized that confidence in the conformity certification system operated by a certification body will be based both

- on the organizational structure and documented procedures of the certification body, and

- on the manner in which the procedures are applied and how the organizational structure serves to enhance the effectiveness of the certification body's operation.

0.5 Confidence should be based on identical fundamental elements and criteria to be met by certification bodies, which necessitates the appropriate organization and administrative structure, surveillance facilities and testing facilities (if includedl, and legal and fees structure - the performance of all functions being specified by the certification system.

0.6 The following factors contribute to increased confidence among certification bodies participating in an international certification system, or involved in mutual certification arrangements:

1) use of equivalent standards;
2) use of procedures which provide for appropriate organizational and administrative structure, comparable testing equipment and methods, comparable surveillance procedures, comparable legal protection and other features which assure that none of the participants is at undue risk in accepting other participants' work.

0.7 Agreements between parties operating certification systems in different countries will generally include provisions covering a number of items not dealt with in this Guide, including such items as exchanges of personnel, comparison of surveillance, testing and inspection techniques, the legal system to be utilized in case of dispute, etc.

\section{Scope}

This Guide provides a framework for use by a certification body in assessing itself, its procedures, and its operations. The framework incorporates requirements and recommendations to be found in all relevant ISO/IEC reference documents. Using this framework, a certification body should be able to compile a documentary record of its internal quality system review procedure. It will also be possible to use this documentary record for subsequent distribution to all parties concerned.

Certification bodies may include other specific elements and criteria depending on specific needs.

\section{References}

ISO/ITC booklet, Certification - Principles and practice

ISO/IEC Guide 2, Genera/ terms and their definitions concerning standardization ond related activities

ISO/IEC Guide 7, Requirements for standards suitable for product certification

\footnotetext{
1) Most of the points addressed in this Guide are covered in more detail in other ISO/IEC guides (see clause 2). The purpose of this Guide is only to facilitate the approach to the first steps recommended, for example, in ISO/IEC Guide 42. In no way is it implied, however, that a certification body that has used this Guide to review its internal quality procedures will automatically be recognized by other certification bodies. Agreements between certifying bodies (reciprocity) require some form of assessment of each other's arrangements regarding procedures, experience, organizational structure, legal framework, rules, auditing, testing, etc. A system of assessment involving examination teams may be required for a valid implementation of mutual recognition, as is the case, for example, in the IEC Quality assessment system for electronic components (IECO).
} 
ISO/IEC Guide 16, Code of principles on third-party certification systems and related standards

ISO/IEC Guide 23, Methods of indicating conformity with standards for third-party certification systems

ISO/IEC Guide 25, General requirements for the technical competence of testing laboratories

ISO Guide 27, Guidelines for corrective action to be taken by a certification body in the event of misuse of its mark of conformity

ISO/IEC Guide 28, General rules for a mode/ third-party certification system for products

ISO/IEC Guide 38, General requirements for the acceptance of testing laboratories

ISO/IEC Guide 39, General requirements for the acceptance of inspection bodies

ISO/IEC Guide 40, General requirements for the acceptance of certification bodies

ISO/IEC Guide 42, Guidelines for a step-by-step approach to an international certification system

ISO/IEC Guide 44, General rules for ISO or IEC international third-party certification schemes for products

ISO/IEC Guide 54, Testing laboratory accreditation systems General recommendations for the acceptance of accreditation bodies

\section{Definitions}

The relevant definitions in ISO/IEC Guide 2:1986, or any later edition, are applicable.

\section{Credibility}

Of prime importance to any certification scheme, whether intended for internal, bilateral or multilateral use, will be its credibility and therefore acceptability. This aspect must be kept foremost during any self-assessment programme, and becomes critical to any international scheme.

\section{Elements to be addressed}

The elements to be addressed in a comprehensive internal quality system review procedure are the following:

- documentation (clause 6);

- testing laboratories (clause 7):

- inspection services (clause 8);

- certification staff (clause 9)

- checklist for assessment (clause 10).

\section{Documentation}

6.1 Before self-assessment can commence, the system under operation should be fully documented.

6.2 The elements to be documented are covered in the ISO/ITC booklet, Certification - Princip/es and practice, in which eight typical systems are identified (systems 1 to 8 ).

6.3 The main types of documentation are outlined in Chapter 5 of the ISO/ITC booklet, Certification - Principles and practice.

6.4 In addition to the operational documentation the certifjcation body should have a manual to cover

a) legal identification of the certification body

b) the administrative structure of the certification body;

c) terms of reference of the governing board;

d) organizational chart which depicts responsibilities and reporting structure;

e) list of names, qualifications and experience of each member of the staff engaged in the actual certification process, including details regarding availability of staff in places other than headquarters:

f) information on any certification training received by the staff, including training in the principles and practice of quality assurance;

g) staff instructions;

h) documentation and change control:

i) records, including system used for their maintenance, and blank copies of report forms used;

j) procedures covering the control of marks of conformity and actions to be taken in cases of misuse;

k) procedure for investigating complaints received and taking any necessary corrective action;

1) procedures and staff instructions to ensure confidentiality:

m) publications:

n) appeals (see ISO/ITC booklet, Certification - Principles and practice, Chapter 5.11).

The general requirements pertaining to these elements are given in ISO/IEC Guide 40.

\section{Testing laboratories}

7.1 The testing laboratory may be an integral part of the certification body or it may be a separate entity. 
7.2 It is not intended that this Guide cover the work of testing laboratories.

7.3 - It is of critical importance that the testing work performed for certification purposes be done by a competent testing laboratory.

7.4 Testing work performed for certification purposes is to be done by a testing laboratory that meets the criteria specified in ISO/IEC Guides 25 and 38 and additional specific criteria appropriate for the type of product involved.

7.5 The certification body should have a system of laboratory selection based on these points.

7.6 A laboratory suitably accredited for the purpose should be capable of satisfying the above requirements.

\section{Inspection services}

8.1 The inspection body may be an integral part of the certification body or it may be a separate entity.

8.2 Inspection work performed for certification purposes is to be done by an inspection body that meets the criteria of ISO/IEC Guide 39 and additional specific criteria appropriate for the type of product involved.

\section{Certification staff}

9.1 Staff should be competent for the functions they undertake and should have the necessary education, training, technical knowledge and experience.

9.2 Information on the academic or other qualifications and experience of each member of the staff should be maintained by the certification body. Records of training and experience should be kept up-to-date.

9.3 Staff should have available to them clear documented instructions pertaining to their duties and responsibilities. These instructions should be maintained up-to-date.

9.4 When work is sub-contracted to an outside body, the certification body is responsible for the sub-contracted work and should ensure that the party performing the work meets the requirements for a testing laboratory referred to in 7.4, and the requirements for an inspection body referred to in $\mathbf{8 . 2}$.

9.5 In small organizations, one person may fulfil more than one function.

\section{Checklist for assessment}

NOTE - The following checklist for assessing a certification body's operation of third-party certification systems is based on ISO/IEC Guides 7, 23, 25, 27, 28, 38, 39 and 40.

\subsection{Standards}

Standards upon which the system is based, covering products, processes and services, shall be suitable for use as a basis for certification.

\subsection{Procedures}

Procedures by which the system is operated include provision for

a) competent and responsible management and appropriately trained staff:

b) participation on a non-discriminatory basis;

c) both initial and continuing validation activities;

d) selection and retention of qualified testing and inspec. tion services;

e) dispute resolution through an impartial appeals mechanism;

f) notification to licensees of changes in standards and procedures:

g) confidentiality of proprietary information;

h) maintenance of records;

i) safeguarding use of mark, including legal support;

j) revocation of authorization to use mark;

k) monitoring procedures regarding periodic inspections, etc;

1) training programme on certification for the benefit of industries and staff engaged in certification work.

\subsection{Requirements for licensing}

Requirements for licensing include (see clause 6 of ISO/IEC Guide 28)

a) supplier's quality management system and documentation lonly for Systems 5 and 6 described in the ISO/ITC booklet, Certification - Principles and practicel;

b) technically appropriate resources for testing and inspection;

c) complaint records system;

d) provisions against non-conforming products to which the mark is applied;

e) provision for notification of product changes;

f) practices relating to the use of the certification body name or mark of conformity.

\subsection{Indication of conformity}

Conformity is indicated by a certificate or mark which

a) reflects the registered mark of the certification body:

b) includes information on product, standards, supplier and other parties, where applicable (see ISO/IEC Guide 23): 
c) presents clearly the extent of the certification, where applicable.

\subsection{Documentation}

Documentation required by the system includes

a) availability of a published programme directory listing products, processes and services which may be certified, standards, licensees, and other parties;

b) file of legally binding agreements with licensees;

c) availability of statement covering operating procedures;

d) availability of annual review or report.

\subsection{Fee structure and financial aspects}

The certification body should have well laid out guidelines from the financial point of view for granting licences and for operating the certification system (see clause 19 of ISO/IEC Guide 28).

NOTE - When complete, the checklist will be accompanied by a document which will key each item to relevant sections of the ISO/IEC reference documents.

\section{Appeal}

The certification body should provide for an independent line of appeal available to its licensees. 


\section{PV-2 Appendix 2}

\section{Form PV250}

Checklist for assessing the capabilities and quality system of manufacturers and producers 


\title{
Appendix 2
}

\section{Checklist for inspection and assessing the capabilities and quality system of manufacturers and producers ${ }^{2}$}

\author{
1. Management responsibility \\ 1.1 Is a quality policy defined, documented, understood, implemented, and maintained? \\ 1.2 Are the responsibilities and authorities for all personnel specifying, achieving, and monitoring \\ quality defined? \\ 1.3 Are in-house verification resources defined, trained, and funded? \\ 1.4 Has a staff person been designated to implement and maintain the quality system?

\section{Quality system} \\ 2.1 Has a quality manual been prepared? Is it used by all pertinent employees? \\ 2.2 Have quality procedures been prepared and implemented? \\ 2.3 Do the management and staff understand the requirements for certification?
}

\section{Contract review}

3.1 Are incoming contracts and purchase orders reviewed to determine if the requirements are adequately defined, whether they agree with the bid, and whether they can be implemented?

3.2 Are adequate records of such contract reviews maintained?

\section{Design control}

4.1 Do design projects receive adequate planning?

4.2 Are design input parameters adequately defined?

4.3 Are design output parameters, including crucial product characteristics, adequately defined and documented?

4.4 Is the design output verified to determine if the input requirements are met?

4.5 Are design changes appropriately reviewed, controlled, and documented?

\section{Document control}

5.1 Is the generation of all quality and production-related documents controlled?

5.2 Is the distribution of such documents controlled?

5.3 Are changes to documents controlled?

5.4 Are obsolete documents promptly removed from all points of issue and use?

\section{Purchasing}

6.1 Are potential subcontractors and subsuppliers evaluated for their ability to provide the stated requirements?

6.2 Are the requirements clearly defined in contract documents and data?

6.3 Is the effectiveness of the subcontractor's quality assurance system assessed?

\footnotetext{
${ }^{2}$ Adapted from a summary of ANSI/ASQC Q91 requirements authored by Dennis Arter, Columbia Quality Inc., Pasco, WA
} 
7. Product identification and traceability

7.1 Is the product identified by item and batch, or lot, during all stages of production, delivery, and installation?

7.2 Is the product uniquely identified in relation to any required traceability to specifications or standards?

\section{Process control}

8.1 Are production processes defined, planned, and documented?

8.2 Is production performed under controlled conditions that include (a) documented work instructions, (b) in-process controls, (c) approval of processes and equipment, and, (d) establishment of criteria for workmanship?

8.3 Are processes that cannot be verified after production monitored and controlled throughout the processes?

8.4 Are production records adequately prepared and maintained?

\section{Inspection and testing}

9.1 Is incoming material inspected, tested, or otherwise verified before use?

9.2 Is in-process inspection and verification (where required) performed and documented?

9.3 Is final inspection and testing performed prior to release of the finished product?

9.4 Are the results of inspection and testing adequately documented and maintained?

10. Inspection, measuring, and test equipment

10.1 Are all items of equipment and instruments controlled, calibrated, and maintained?

10.2 Are the required measurements identified and documented?

10.3 Are the required instruments and test equipment adequately identified?

10.4 Is their calibration and maintenance status affixed to the items and contained in an adequate calibration and maintenance file?

10.5 Are periodic independent in-test parameters performed?

10.6 Are between-calibration verification checks performed?

10.7 Is the validity of measurements assessed when out-of-calibration conditions are found?

10.8 Are the environmental conditions properly maintained and monitored in metrology laboratories?

10.9 Are the measurement uncertainties of test equipment and instruments known and documented?

10.10 Whenever software is used as a part of the in-process or final testing procedures, is it periodically and adequately checked?

11. Inspection and test status

11.1 Is the status of inspections and tests maintained for production items as they progress through various processing stages?

11.2 Are records maintained to indicate the person who released conforming product at all pertinent stages?

12. Control of nonconforming product

12.1 Are the measures to control nonconforming product adequate to prevent inadvertent use or installation?

12.2 Is nonconforming product adequately segregated?

12.2 Are there documented policies and procedures for the review and disposition of nonconforming product? 


\section{Corrective action}

13.1 Are there documented procedures for identifying the causes of nonconforming product?

13.2 Are there documented procedures for assuring that corrective actions are taken for nonconforming product?

13.3 Are records of nonconforming product, of the causes, and of the corrective actions taken, adequately maintained?

14. Handling, storage, packaging, and delivery

14.1 Are procedures for handling, storage, packaging, and delivery developed, documented and maintained?

14.2 Are handling controls adequate to prevent damage and deterioration?

14.3 Is product in stock periodically checked? Is the storage secure?

14.4 Are delivery controls used to maintain the integrity of the product between the factory and the delivery point?

15. Quality records

15.1 Are the quality records adequately identified, collected, indexed, filed, stored, maintained and eventually disposed of?

\section{Internal quality audits}

16.1 Are procedures of performing internal quality audits documented?

16.2 Are audits planned and performed?

16.3 Are the results of internal audits communicated to top management?

16.4 Are procedures for corrective action documented? Are deficiencies found corrected?

16.5 Are records of deficiencies and corrective actions maintained?

\section{Training}

17.1 Are training needs identified and documented? Is training provided?

17.2 Is cross-training provided?

17.3 Are records of training maintained?

\section{Servicing}

18.1 Are written procedures available for servicing activities? Are they used?

18.2 Does the service provided meet the relevant specifications and requirements? 


\section{PV-2 Appendix 3}

\section{Form PV200}

Specimen for initial questionnaire for factory assessment

(reproduced from Appendix 1 of Annex B from ISO/IEC Guide 28) 
ISO/IEC GUIDE 28-1982 (E)

\section{Appendix 1 to annex $B$}

\section{Specimen" for initial questionnaire for factory assessment}

This questionnaire should be filled in and returned together with the application form. It is intended to provide preliminary information relative to the applicant and his capability to control the quality and continuing conformance of his products to the requirements of relevant specifications.

This document will be used by the certification body's inspection staff during preliminary visits to the factory or factories involved as a part of the initial inspection.

Supplements may be included where it is necessary to expand any statements.

A separate document should be completed for each factory involved, or variations between factories clearly indicated.

The statements should relate to the facilities available as the date of completion of this form.

The information given in this document will be treated in the strictest confidence.

Information on the following subjects will furthermore facilitate the treatment of the application.

Date sample is available for evaluation :

Will this be production or prototype sample?

If protoype, when is production scheduled?

Has product been tested to the standard? (if so please attach report) :

Urgency of application.

INDEX

Section 1 - Factory organization

Section 2 - Materials, components and services

Section 3 - Manufacture

Section 4 - Quality control and testing

Section 5 - Records and documentation

Section 6 - Application of indications of conformity

\section{Section 1 - Factory organization}

\subsection{Procedures/paperwork}

Please give following information on basic system

1.1.1 Do you produce against orders or for stock?

1.1.2 Do you issue a Works Order or equivalent?

1) This specimen was selected from a current national practice; no attempt was made to harmonize the wording with the main part of this Guide. The specimen can be adapted in accordance with the actual situation for a given scheme. 
1.1.3 If so does this identify a batch as a separate entity?

1.1.4 Do products and/or containers carry Works Order identification in manufacture?

1.1.5 If not how does system allow for products to be isolated in case of doubtful quality?

1.1.6 Please give any other relevant information on basic system

\subsection{Quality control/inspection staff}

Please give following information on factory $Q C$ staff organization :

1.2.1 Head of Quality Assurance

1.2.2 Reporting to?

1.2.3 Is there a separate QC/Inspection Dept?

1.2.4 If so indicate

1.2.4.1 Chief Inspector if different from 1.2.1

1.2.4.2 If staff are aware of the tests in the relevant standard(s)

1.2.5 Are storeman/production operators responsible for inspection and test on

\subsubsection{Materials?}

1.2.5.2 In process operations?

1.2.5.3 Final product?

1.2.6 If so are they monitored by OC staff?

1.2.7 Are Quality Audit checks carried out and by whom?

1.2.8 Please give any other information on QC staff organization

\section{Section 2 - Materials, components and services}

\subsection{Purchase specifications/materials quality assurance}

Please detail main materials purchased, specification used and major suppliers involved.

Please also give quality assurance methods adopted on receipt of materials, components, or services, indicating action taken on rejects.

\section{Section 3 - Manufacture}

\subsection{System}

Please detail various steps in manufacture - a production schedule and/or supplement in chart form showing stages may be advantageous.

\subsection{Maintenance system plant and equipme}

What maintenance system is in operation? 


\section{Section 4 - Quality control and testing}

\subsection{System}

Please detail Quality Control system, including sampling system followed, with particular reference to the tests in the relevant standard. A OC schedule or supplement cross-referenced to chart required in 3.1 is advantageous.

Please attach any QC manual or instructions on Quality Control issued to staff.

\subsection{Test equipment/instruments, gauges and tools}

Please detail test equipment used, makers' names and references, and indicate system and frequency of checking and if certificates are available.

\section{Section 5 - Records and documentation}

\subsection{General}

5.1.1 Please indicate form of master specification, i.e. drawings, product/parts schedule, reference sample, etc. Also indicate other general records available.

5.1.2 Please indicate system used to amend design/specification.

\subsection{Compliance - Specification}

5.2.1 Please indicate level of defectives found in past six months. If tests in accordance with the relevant standard(s) have already been carried out, attach copies of summary of test results if available.

5.2.2 Please indicate the level of claims/complaints made under warranty and/or otherwise and give also as a percentage of total output.

5.2.3 Have independent tests been made on products against the standard? By whom? Please attach copies if available.

\section{Section 6 - Application of indications of conformity}

\subsection{Mark of conformity}

Please attach an illustration if available and indicate method, e.g. special label, embossing, etc., which will be used to show mark of conformity. Please indicate at which stage of manufacture the mark of conformity will be applied.

\subsection{Certificate of conformity}

Please attach an illustration of the proposed format and indicate at which stage of manufacture or shipment the certificate is issued. A specimen certificate is reproduced in appendix 2 by way of an example. 
PV-2 Appendix 4

\section{Form PV100}

Application for conformity certification by use of certificates or mark of conformity (reproduced from Annex B of ISO/IEC Guide 28) 


\section{Annex B}

Specimen of form for

APPLICATION for CONFORMITY CERTIFICATION

BY USE OF CERTIFICATES OR MARK OF CONFORMITY

To be sent to

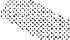

(Certification body)

Address :

Information regarding the applicant :

The applicant's name and address of registered office

Phone and telex numbers :

Manufacturing place of the product :

Name and title of person responsible for

the quality management system :

Business address :

Phone and telex numbers :

Designation of product for which conformity certification is requested :

\begin{tabular}{|l|l|l|}
\hline $\begin{array}{l}\text { Description of products : (see first two columns } \\
\text { of specimen licence - appendix 1 to annex } \mathrm{Cl} \text { Relevant Specific Rules }\end{array}$ & Number : \\
& Title : \\
Date of issue :
\end{tabular}

Statement : *

We herewith declare that we will settle the costs related to this application.

Statement : *

We herewith declare to be willing, on a positive result of the initial testing and inspection, to conclude within a specified time an agreement related to the certification of the products mentioned above.

Date of application

Name and title of person authorized to sign on behalf of the applicant :

(In block letters)

Signature

- (Examples) 
PV-2 Appendix 5

\section{Form PV300}

Specimen of a licensing agreement for the use of a certificate or mark of conformity (reproduced from Annex C of ISO/IEC Guide 28) 


\section{Annex C}

\section{Specimen of a licensing agreement for the use of a certificate or mark of conformity}

The ...... Certification Body, having its registered offices at ......, hereinafter referred to as the certification body and represented in this matter by ...... (name), ...... (title) ......, hereby grants to ......., having its registered offices at ......, hereinafter referred to as the licensee, licence to certify the products covered by the appended licence, as approved by the certification body for such products specified in the first column of the valid licence which are controlled by the licensee in accordance with the standards referred to in the second column and the Specific Rules referred to in the third column of the valid licence and on the conditions of the following general agreement.

\section{Article 1 : Regulations for certification and inspection}

The stipulations of the General Rules for the certification system (in question) apply to this agreement as well as the standard(s) and the Specific Rules, specified in the attached licence.

\section{Article 2 : Rights and obligations}

2.1 The licensee agrees that the certified products manufactured and supplied by him as specified in the licence based on and attached to this agreement will comply with the requirements stated in the standards and General and Specific Rules specified in the licence. Accordingly, the certification body authorizes the licensee to certify the products covered by the licence, as stated in the Specific Rules of the scheme.

2.2 The licensee agrees that the persons representing the certification body will have unobstructed access without prior notification to the premises of the factory covered by the license during the normal working hours of the factory involved.

2.3 The licensee agrees that the products for which the licence is granted will be produced to the same specifications as the sample that the certification body found by the initial testing to be in compliance with the standard.

\section{Article 3 : Surveillance}

3.1 The certification body carries out a continuing surveillance on the licensee's compliance with his obligations, in accordance with the conditions stated in the General Rules for the certification system and the Specific Rules for the scheme as specified in the licence.

3.2 This surveillance is carried out by the certification body employees or by employees of agencies on behalf of the certification body.

\section{Article 4 : Information on modifications in production}

The licensee shall inform the certification body of any intended modification in the product, the manufacturing process or the quality management system.

\section{Article 5 : Complaints}

The licensee shall upon request of the certification body keep records and report to the certification body any complaints regarding those aspects of the products covered by the licence.

\section{Article 6 : Publicity}

6.1 The licensee has the right to publish that he has been authorized to certify the products to which the license applies.

6.2 Among other methods the certification body gives publicity to the authorization of certifying compliance with a standard in the public journal ...... and to cancellation of this agreement with the licensee, as appropriate. 


\section{Article 7 : Confidentiality}

The certification body is responsible for seeing that confidentiality is maintained by its employees concerning all confidential information with which they become acquainted as a result of their contacts with the licensee.

\section{Article 8 : Payment}

8.1 The licensee shall pay to the certification body all expenses in relation to the surveillance, including test, inspection and administration costs.

\section{Article 9 : Agreement period}

This agreement comes into force on ..., and remains in force until ... unless withdrawn for justified reasons or cancelled by either party upon due notice given to the other party.

\section{Article 10 : Withdrawal/cancellation of licence}

If withdrawal/cancellation of the licence comes into question, the necessary time of notice prior to the withdrawal/cancellation will differ due to the situation that causes it.

Depending on the reason for the withdrawal/cancellation the following schedule of notice will be followed :

\section{Situation requiring the dispatch of notice} that can lead to withdrawal/cancellation

Manufacturer's wish to cancel :

The certification body determines that the product is hazar-

dous :

Violation of an existing standard, for other reasons than safety :

Non-payment of charges to certification body

Failure to meet other provisions of the licensing agreement :

Mandatory compliance with new requirements in relation to revision of a standard:

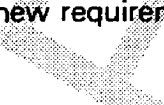

\section{Days of notice prior to withdrawal/cancellation}

to be specified by the certification body

none

$\max .60$ days

max. 30 days

$\max .60$ days

Advice of cancellation shall be sent by registered letter (or equivalent means) to the other party, stating the reasons and the date of termination of the agreement.

\section{Article 11 : Modification of product requirements}

11.1 If the requirements applying to the products covered by this agreement are modified, the certification body shall immediately inform the licensee by registered letter (or equivalent means), stating at what date the modified requirements will become effective, and advising him of any need for a supplementary examination of the products which are subject to this agreement.

11.2 Within a specified period of time after receipt of the advice described in paragrapit 11.1, the licensee shall inform the certification body by registered letter (or equivalent means) whether he is prepared to accept the modifications. If the licensee gives confirmation within the specified period of his acceptance of the modification and provided the result of any supplementary examination is favourable, a supplementary licence will be issued or other modifications of the certification body's records.

11.3 If the licensee advises the certification body that he is not prepared to accept the modification within the time specified in accordance with $\mathbf{1 1 . 2}$ or if he allows the terms for acceptance to lapse, or if the result of any supplementary examination is not favourable, the licence covering the particular product shall cease to be valid on the date on which the modified specifications become effective to the certification body, unless otherwise decided by the certification body. 


\section{Article 12 : Liability}

[To be specified in connection with the relevant legal systems.]

\section{Article 13 : Appeal/dispute}

All disputes that may arise in connection with this agreement are to be settled in accordance with the appeal procedures of the certification body.

Issued in duplicate and signed by authorized representatives of the certification body and the applicant.

For the certification body :

For the applicant:

Date

Date

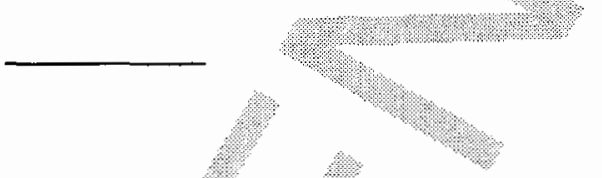

.

$\ldots \ldots \ldots \ldots \ldots \ldots \ldots \ldots \ldots$

(Signature) (title) 
PV-2 Appendix 6

Specimen of form for a license for the use of the certificates or mark of conformity (reproduced from Appendix 1 of Annex C from ISO/IEC Guide 28) 


\section{Appendix 1 to annex $\mathrm{C}$}

\section{Specimen of form for a licence for the use of the certificates or mark of conformity}

[An illustration of the certificate or mark of conformity is to be attached to this form or may be inserted here]

Licence No.

to Agreement No.

Issued by

(certification body)

To

(licensee)

\begin{tabular}{|l|l|l|l|}
\hline Products for which the licence is granted & $\begin{array}{l}\text { Cat. no., type or } \\
\text { other descriptive } \\
\text { identifiers. }\end{array}$ & Specific rules \\
\hline & & & \\
\hline
\end{tabular}

Date of issue

Signed for Certification Body

(signature) (title) 


\section{Annex C}

PV-3. Testing Requirements for a Certification and Labeling Program for Photovoltaic Modules 


\section{DOCUMENT PV-3}

\section{Testing Requirements for a Certification and Labeling Program for Photovoltaic Modules}

Foreword

C-3

1. Introduction

C-4

2. Definitions

C-5

3. References

C-6

4. General test plan and sequence of testing

C-7

5. Module qualification and performance tests

$\mathrm{C}-8$

6. Reporting

C-10

Appendix 1

Equipment and Apparatus Required for PV Module Testing and Certification

C-11

Appendix 2

Laboratory Organization and Personnel

C-14 


\section{FOREWORD}

This document sets forth the testing and reporting requirements for qualification testing and baseline performance value measurements of photovoltaic (PV) modules that may be used in support of a PV module certification and labeling program. The test methods and procedures chosen for this purpose have all been promulgated through consensus standards development procedures in relevant committees of the Institute of Electrical and Electronics Engineers (IEEE), the American Society for Testing and Materials (ASTM), or the International Electrotechnical Commission (IEC).

The requirements presented are taken largely from IEEE 1262 and ASTM E 1036 (see Sections 3.14 and 3.5). To the extent that other specific ASTM test methods are referenced in certain IEEE 1262 test procedures adopted in these requirements, the so-referenced ASTM standards are hereby incorporated as mandatory test requirements for the purposes of this document.

The test methods and procedures presented represent the minimum testing requirements for any product certification and labeling programs that may be developed for photovoltaic modules. Additionally, these test procedures and the concomitant equipment and facilities requirements represent the minimum test capabilities against which laboratories should be evaluated for testing in support of any module certification and labeling programs.

This document is one of a series of documents that together are intended to address the totality of the criteria and requirements for a PV module testing, certification, and labeling program. The other documents in this series are:

PV-1 Criteria for a Model Quality System for Laboratories Engaged in Testing Photovoltaic Modules

PV-1.1 Calibration, Traceability, and Statistical Requirements of Accredited Laboratories Supporting the Photovoltaic Module Certification Program (Addendum to PV-1)

PV-2 Model for a Third-Party Certification and Labeling Program for Photovoltaic Modules

PV-3 Testing Requirements for a Certification and Labeling Program for Photovoltaic Modules

PV-5 Application and Certification Procedures for the Photovoltaic Module Certification Program 


\section{Introduction}

1.1 Purpose

1.1.1 The purpose of this document is to delineate the testing requirements for a photovoltaic module certification and labeling program.

1.1.2 These testing requirements represent the minimum requirements against which photovoltaic modules shall be evaluated in terms of (a) their quantitative response to electrical performance-based tests and (b) their qualitative response to environmental and mechanical tests.

1.1.3 These test procedures represent the minimum capabilities against which laboratories shall be assessed and accredited in accordance with Document PV-1 for testing in support of a photovoltaic module certification and labeling program.

1.2 Scope

1.2.1 The testing requirements set forth in this document shall be used for the evaluation of terrestrial flat-plate photovoltaic modules intended for power-generating applications. These requirements are not intended for use in the testing and evaluation of photovoltaic solar-concentrator modules.

1.2.2 This document sets forth the minimum requirements with which photovoltaic modules shall comply to demonstrate their ability to meet the overall performance requirements of the certification program.

1.2.3 These requirements also represent the minimum standards with which laboratories selected by manufacturers shall comply and operate to demonstrate their competence to test photovoltaic modules ${ }^{1}$.

1.2.4 Guidelines for equipment and apparatus required are included in Appendix 1 of this document. Guidelines for the management of the testing laboratory are discussed in Appendix 2.

1.2.5 The actual electrical performance and lifetime expectancy of modules tested, certified, and labeled under the provisions of this document will depend on their design, the environment in which they are deployed, and other conditions under which they are operated. Lifetime expectancy is not within the scope of this document.

\footnotetext{
${ }^{1}$ Laboratories accredited in accordance with Document PV-1 are required to demonstrate their compliance to the general criteria of Document PV-1 in terms of their quality system and to the specific criteria required by Document PV-1 and set forth in this Document (PV-3).
} 


\section{Definitions}

2.1 Terms defined in this section are relevant to photovoltaic module testing. Terms defined in Documents PV-1 and PV-2 are incorporated by reference.

2.1.1 Air mass (AM): The ratio of the mass of atmosphere in the actual observer-sun path to the mass that would exist if the observer was at sea level, at standard barometric pressure, and the sun was directly overhead. Note-(sometimes called air mass ratio.) Air mass varies with the zenith angle of the sun and the local barometric pressure, which changes with altitude. For sun zenith angle, $\mathrm{Z}$, of $62^{\circ}$ or less and local atmospheric pressure, $P$, where $P_{0}$ is standard atmospheric pressure, $A M \simeq \sec Z\left(P / P_{0}\right)$.

[ASTM E 772]

2.1.2 AM 1.5 standard reference spectrum: The solar spectral irradiance distribution (diffuse and direct) incident at sea level on a sun-facing $37^{\circ}$ tilted surface. The atmospheric conditions for AM 1.5 are: precipitable water vapor, $14.2 \mathrm{~mm}$; total ozone, $3.4 \mathrm{~mm}$; turbidity (base e, $\lambda=0.5 \mathrm{~mm}$ ), 0.27 . [ASTM E 892, Table 2]

2.1.3 Baseline Performance Value: Initial values of $\mathrm{I}_{\mathrm{SC}}, \mathrm{V}_{\mathrm{OC}}, \mathrm{P}_{\mathrm{MP}}, \mathrm{V}_{\mathrm{MP}}, \mathrm{I}_{\mathrm{MP}}$ measured by the accredited laboratory and corrected to Standard Test Conditions, used to validate the manufacturer's performance measurements provided with the qualification modules per IEEE 1262.

2.1.4 Blocking diode: A diode used to restrict or block reverse current from flowing backward through a module. [UL 1703]

2.1.5 Bypass diode: A diode connected across one or more solar cells in a photovoltaic module such that the diode will conduct if the cell(s) become reverse biased. [UL 1703]

2.1.6 Current at maximum power $\left(\mathrm{I}_{\mathrm{MP}}\right)$ : The current at which maximum power is available from a module (for the purpose of this document, the "rated" current at maximum power will be defined as $\mathrm{I}_{\mathrm{MP}}$ at STC). [UL 1703]

2.1.7 Interconnect: A conductor within a module or other means of connection which provides an electrical interconnection between the solar cells. [UL 1703]

2.1.8 I-V data: The relationship between current and voltage of a photovoltaic device in the power-producing quadrant, as a set of ordered pairs of current and voltage readings in a table, or as a curve plotted in a suitable coordinate system (i.e., Cartesian).

(ASTM E 1036)

2.1.9 Maximum power $\left(\mathrm{P}_{\mathrm{MP}}\right)$ : The point on the current-voltage (I-V) curve of a module under illumination, where the product of current and voltage is maximum. For the purpose of this document, "rated" power is defined as $P_{M P}$ at STC. [UL 1703]

2.1.10 PV module (flat-plate): The smallest environmentally protected, essentially planar assembly of solar cells and ancillary parts, such as interconnections, terminals, [and 
protective devices such as bypass diodes] intended to generate dc power under unconcentrated sunlight. The structural (load carrying) member of a module can either be the top layer (superstrate), or the back layer (substrate). [UL 1703]

2.1.11 Qualification test (PV): A procedure applied to a selected set of PV modules involving the application of defined electrical, mechanical, or thermal stress in a prescribed manner and amount. Test results are subject to a list of defined requirements.

2.1.12 Standard Reporting Conditions (SRC): A fixed set of conditions (including meteorological) to which the electrical performance data of a photovoltaic module are translated from the set of actual test conditions. [ASTM E 1036]

2.1.13 Standard Test Conditions (STC): Conditions under which a module is typically tested in a laboratory: (1) Irradiance intensity of $1000 \mathrm{~W} / \mathrm{m}^{2}$, (2) AM1.5 solar reference spectrum [see Section 2.1.2], and (3) a cell (module) temperature of $25 \pm 2{ }^{\circ} \mathrm{C}$. [IEC 1215]

2.1.14 Test sequence: A set of one or more qualification tests applied in a specified order to a selected group of PV modules.

2.1.15 Voltage at maximum power $\left(\mathrm{V}_{\mathrm{MP}}\right)$ : The voltage at which maximum power is available from a module. (For the purpose of this document, the "rated" voltage at maximum power will be defined as $\mathrm{V}_{\mathrm{MP}}$ at STC). [UL 1703]

\section{References}

3.1 ANSI/IEEE 928-1986:

"Recommended Criteria for Terrestrial Photovoltaic Power Systems."

3.2 ASTM E 772:

"Standard Terminology Relating to Solar Energy Conversion."

3.3 ASTM E 892:

"Standard Tables for Terrestrial Solar Spectral Irradiance at Air Mass 1.5 for a $37^{\circ}$ Tilted

Surface", Table 2.

3.4 ASTM E 927:

"Standard Specification for Solar Simulation for Terrestrial PV Testing."

3.5 ASTM E 1036:

"Standard Test Methods for Electrical Performance of Nonconcentrator Terrestrial Photovoltaic Modules and Arrays Using Reference Cells."

3.6 ASTM E 973:

"Standard Test Method for Determination of the Spectral Mismatch Parameter Between a Photovoltaic Device and a Photovoltaic Reference Cell." 
3.7 ASTM E 1038:

"Standard Test Method for Determining Resistance of Photovoltaic Modules to Hail by Impact with Propelled Ice Balls."

3.8 ASTM E 1171:

"Standard Test Method for Photovoltaic Modules in Cyclic Temperature and Humidity

Environments."

3.9 ASTM E 1362:

"Standard Test Method for Calibration of Nonconcentrator Photovoltaic Secondary Reference Cells."

3.10 ASTM E 1462:

"Standard Test Methods for Insulation Integrity and Ground Path Continuity of Photovoltaic Modules."

3.11 IEC TC 82 (Secretariat) 120:

"Thin-Film Silicon Terrestrial Photovoltaic (PV) Modules-Design Qualification and Type Approval" (draft international standard).

3.12 IEC 68-1:

"Basic Environmental Test Procedures", 1988.

3.13 IEC 1215:

"Crystalline Silicon Terrestrial Photovoltaic (PV) Modules-Design Qualification and Type Approval."

3.14 IEEE 1262:

"IEEE Recommended Practice for Qualification of Photovoltaic (PV) Modules."

3.15 JPL 5101:

Jet Propulsion Laboratory, JPL 5101-161, Pasadena, CA, 1981, "Block V Solar Cell Module Design and Test Specification for Intermediate Load Applications."

3.16 NREL IQT:

National Renewable Energy Laboratory (NREL), Golden, CO, TR-213-3624, 1993, "Interim

Qualification Tests and Procedures for Terrestrial Photovoltaic Thin-Film Flat-Plate Modules."

3.17 UL 1703:

Underwriters Laboratories Inc., UL Standard 1703, Second Edition, May 7, 1993, "Standard for Safety, Flat-Plate PV Modules and Panels."

4. General test plan and sequence of testing

4.1 Conduct module qualification tests in accordance with IEEE 1262, Figure 4-1-Qualification Test Program 


\section{Module qualification and performance tests}

5.1 General test and inspection procedures

5.1.1 The sequence of testing and inspection procedures listed are in the same order as described in the sequence of tests presented in Figure 1 of IEEE 1262. No significance should be attached to the order in which the test methods are presented in the following sections with respect to the importance of their suitability to photovoltaic modules for their intended applications.

5.1.2 When modifications to the IEEE 1262 test and inspection procedures are not required for the purposes of this document, these unmodified portions of the standard shall be complied with in full as if they were repeated herein in their entireties.

5.1.3 When modifications to the referenced test and inspection procedures adopted from IEEE 1262 are required for the purposes of this document (as defined in Section 6.2), all unmodified subparagraphs of the referenced sections of such standards shall be complied with in full as if they were repeated herein in their entireties.

5.2 Modifications to specific tests defined by IEEE 1262

5.2.1 IEEE 1262: Where referred to as Baseline measurements, replace paragraph 5.2, Electrical-Performance Test, with PV-3 Section 5.2.1.1, Baseline Performance Value Test, and replace all other references to paragraph 5.2 with PV-3 Section 5.2.1.2, Electrical-Performance Test:

\subsubsection{Baseline performance value test}

PURPOSE: The purpose of this test is to verify that the manufacturer's measured I-V curve data (i.e., $\mathrm{I}_{\mathrm{SC}}, \mathrm{V}_{\mathrm{OC}}, \mathrm{P}_{\mathrm{MP}}, \mathrm{V}_{\mathrm{MP}}, \mathrm{I}_{\mathrm{MP}}$ ) are within $\pm 5 \%$ of the testing laboratory's measurements for each of the nine modules required by IEEE 1262.

PROCEDURE: Clean the module's optical surface prior to the electrical performance measurements. Measure the I-V curve for each module in accordance with ASTME 1036. Translate the performance data to the following standard reporting conditions: $25^{\circ} \mathrm{C}$ module temperature, $1000 \mathrm{~W} / \mathrm{m}^{2}$ total irradiance, and ASTM E 892 (Table 2) global spectral irradiance (i.e., Standard Test Conditions, STC). From the corrected data, determine and record $\mathrm{I}_{S C}, \mathrm{~V}_{\mathrm{OC}}$, $\mathrm{P}_{\mathrm{MP}}, \mathrm{V}_{\mathrm{MP}}$, and $\mathrm{I}_{\mathrm{MP}}$. The light source may be natural sunlight or a solar simulator. The light source must meet the requirements of a Class A solar simulator as specified by ASTM E 927. Spectral mismatch error corrections shall be made to the measured data per ASTM E 973). Because the results of these qualifications tests depend on the electrical performance measurements to determine the magnitude of any degradation of module output power, use the same measurement system (including the light source and reference cell) for I-V curve measurements throughout the test sequences. 
Reference cells used for these tests shall have the same optical and electrical properties as the modules under test. Such reference cells shall have been calibrated by a minimum of two qualified laboratories ${ }^{2}$ per ASTM E 1362 using the ASTM E 892 (Table 2) global reference spectrum. The calibration constants shall agree within $\pm 2.0 \%$ of the average value. If these reference cells are used at cell temperatures outside the temperature range of $23^{\circ}$ to $27^{\circ} \mathrm{C}$, the temperature coefficient of the calibration constant shall have also been measured by the two qualified laboratories, and the values shall agree within $\pm 5 \%$ of the average value. The average value of the calibration constant and temperature coefficient measured by the qualified laboratories shall be considered the true value.

REQUIREMENT: Values of factory measured power must be within $\pm 5 \%$ of the testing laboratory's values of measured power for all nine modules tested.

\subsubsection{Electrical-performance test}

PURPOSE: The purpose of this test is to characterize the electrical performance of test modules and to determine each module's peak output power.

PROCEDURE: Clean the module's optical surface prior to the electrical performance measurements. Determine the module's maximum power point in accordance with ASTM E 1036. Correct the performance data to the following standard reporting conditions: $25^{\circ} \mathrm{C}$ module temperature, $1000 \mathrm{~W} / \mathrm{m}^{2}$ total irradiance, and ASTM E 892 (Table 2) global spectral irradiance (i.e., Standard Test Conditions, STC). The light source may be natural sunlight or solar simulator. The light source must meet the requirements of a Class A solar simulator as specified by ASTM E 927. Spectral mismatch error corrections shall be made to the measured data per ASTM E 973). Because these qualification tests depend on the electrical performance measurements to determine the magnitude of any degradation of module output power, use the same measurement system (including the light source and reference cell) for I-V curve measurements throughout the test sequences.

REQUIREMENT: Initial test data recorded in 5.2.1.1 shall be used as the established baseline electrical output power that will serve as the comparison value for determination of the effects of qualification testing on electrical performance.

For intermediate and final performance tests, the maximum power measured for each module tested shall not be less than $90 \%$ of the initial baseline power measured by the testing laboratory. Exception: Amorphous silicon modules must meet the manufacturer's minimum rated power output, following the UV and Outdoor Exposure tests.

\footnotetext{
2 The requirements of a "qualified" laboratory shall be determined by the certification body.
} 


\section{Reporting}

6.1 Test results shall cover all of the test requirements and shall be made available only to the certification body and the manufacturer.

6.2 The testing laboratory's values for the following parameters shall be reported for the purpose of establishing a baseline performance value for: $\mathrm{I}_{\mathrm{SC}}, \mathrm{V}_{\mathrm{OC}}, \mathrm{P}_{\mathrm{MP}}, \mathrm{V}_{\mathrm{MP}}$, and $\mathrm{I}_{\mathrm{MP}}$ for each module tested. These values shall be compared with the corresponding factory module data. Factory data for all nine modules shall be within five percent $( \pm 5 \%)$ of the testing laboratory's values. ${ }^{3}$

6.3 When a module cannot be subjected to some aspect of a test required by Document PV-3, the circumstances shall be documented and reported. As an example, consider the case in which the module is too rigid to perform the twist test. The Test Report then must clearly state this omission and explain the reason and any subsequent implications and ramifications. It will be up the certification body to resolve such issues with the manufacturer, which may require the manufacturer to state the ramifications in the installation manual.

${ }^{3}$ Paragraph 6.2 of Document PV-3 was added after the final draft of Document PV-3 was reviewed by the criteria development committee. 
PV-3 Appendix 1

Equipment and Apparatus Required for PV Module Testing and Certification 
Table C-1. Equipment and Apparatus Required for PV Module Testing and Certification

\begin{tabular}{|c|c|c|c|c|}
\hline $\begin{array}{l}\text { Item } \\
\text { No. }\end{array}$ & $\begin{array}{c}\text { Requirement for Apparatus } \\
\text { Per IEEE 1262: }\end{array}$ & $\begin{array}{l}\text { Equipment } \\
\text { Required }\end{array}$ & $\begin{array}{l}\text { Requirements } \\
\text { Defined By: }\end{array}$ & Notes \\
\hline A.1 & 5.1 Visual Inspection & Camera & IEEE 1262: \& 5.1 & Documentation of visual defects \\
\hline A.2 & $\begin{array}{l}\text { 5.2.1 and 5.2.2 Electrical } \\
\text { Performance Tests }\end{array}$ & $\begin{array}{l}\text { Source of irradiance } \\
\text { I-V curve tracer } \\
\text { Reference cell, DMMs, } \\
\text { Temperature sensors }\end{array}$ & $\begin{array}{l}\text { IEEE } 1262: \S 5.2 \\
\text { ASTM E } 1036 \\
\text { ASTM E 892, ASTM E } 927 \\
\text { PV-3: } 91 \text { 5.2.1.1 and 5.2.1.2 }\end{array}$ & $\begin{array}{l}\text { Multijunction subcells require a } \\
\text { Class A solar simulator per } \\
\text { ASTM E } 927\end{array}$ \\
\hline A.3 & $\begin{array}{l}\text { 5.3 Ground Continuity Tests } \\
\text { 5.4 Electrical Isolation (Dry } \\
\text { Hi-Pot) Tests } \\
\text { 5.6 Wet Hi-Pot Tests }\end{array}$ & $\begin{array}{l}\text { Variable dc power supply } \\
\text { Ground path continuity tester } \\
\text { Ohmmeter } \\
\text { Metallic contacts } \\
\text { Test stand } \\
\text { Immersion tray (wet hi-pot) }\end{array}$ & $\begin{array}{l}\text { IEEE 1262: § 5.3, 5.4, 5.6 } \\
\text { ASTM E 1462: § } 6\end{array}$ & \\
\hline A.4 & $\begin{array}{l}5.5 \text { Wet Insulation Resistance } \\
\text { Tests }\end{array}$ & Megger or equivalent & IEEE $1262: \S 5.5$ & \\
\hline A.5 & $\begin{array}{ll}5.7 & \text { Thermal Cycle Tests } \\
5.8 & \text { Humidity Freeze Cycle } \\
\text { Test }\end{array}$ & $\begin{array}{l}\text { Chamber(s) } \\
\text { Temperature measuring and } \\
\text { recording device } \\
\text { Test base }\end{array}$ & $\begin{array}{l}\text { IEEE } 1262: \S 5.7 \text { and } 5.8 \\
\text { ASTM E } 1171\end{array}$ & \\
\hline A. 6 & $\begin{array}{l}5.9 \text { Robustness of } \\
\text { Terminations }\end{array}$ & $\begin{array}{l}\text { Torque wrench } \\
\text { Tensile strength gauge }\end{array}$ & $\begin{array}{l}\text { IEEE 1262: } \$ 5.9 \\
\text { UL 1703: Sec. } 28\end{array}$ & \\
\hline A.7 & 5.10 Twist Test & $\begin{array}{l}\text { Test fixture } \\
\text { Continuity tester }\end{array}$ & IEEE 1262: § 5.10 & \\
\hline A.8 & $\begin{array}{l}\text { 5.11.1 Static Mechanical Load } \\
\text { Test }\end{array}$ & $\begin{array}{l}\text { Rigid test structure } \\
\text { Continuity tester } \\
2400 \mathrm{~Pa} \text { uniform static load }\end{array}$ & IEEE 1262: § 5.11.1 & \\
\hline A.9 & $\begin{array}{l}\text { 5.11.2 Dynamic Mechanical } \\
\text { Load Test }\end{array}$ & $\begin{array}{l}\text { Rigid test structure } \\
\text { Continuity tester } \\
1440 \mathrm{~Pa} \text { uniform dynamic load }\end{array}$ & $\begin{array}{l}\text { IEEE 1262: } \$ 5.11 .2 \\
\text { UL 1703: } \$ 39\end{array}$ & \\
\hline A.10 & $\begin{array}{ll}5.12 & \text { Surface-Cut } \\
& \text { Susceptibility Test } \\
\end{array}$ & $\begin{array}{l}\text { Cut test tool (e.g. UL 1703, } \\
\text { Fig. 23.1) }\end{array}$ & $\begin{array}{l}\text { IEEE 1262, II } 5.5 \\
\text { UL 1703: \& } 24\end{array}$ & \\
\hline A.11 & 5.13 Damp Heat Test & Chamber(s) & IEEE $1262: \& 5.13$ & \\
\hline
\end{tabular}


Table C-1. Equipment and Apparatus Required for PV Module Testing and Certification (continued)

\begin{tabular}{|c|c|c|c|c|}
\hline $\begin{array}{l}\text { Item } \\
\text { No. }\end{array}$ & $\begin{array}{c}\text { Requirement for Apparatus } \\
\text { Per } \\
\text { IEEE 1262: } \\
\end{array}$ & $\begin{array}{l}\text { Equipment } \\
\text { Required }\end{array}$ & $\begin{array}{l}\text { Requirements } \\
\text { Defined By: }\end{array}$ & Notes \\
\hline A.12 & 5.14 Hail-Impact Test & $\begin{array}{l}\text { Ice-ball launcher and velocity } \\
\text { measuring instrument }\end{array}$ & $\begin{array}{l}\text { IEEE 1262: § } 5.5 \\
\text { ASTM E } 1038\end{array}$ & \\
\hline A.13 & $\begin{array}{l}\text { 5.15 Bypass-Diode Thermal } \\
\text { Test } \\
\text { 5.15.1 Nonintrusive } \\
5.15 .2 \text { Intrusive }\end{array}$ & $\begin{array}{l}\text { Oven } \\
\text { Temperature measuring } \\
\quad \text { instrument } \\
\text { Constant current power supply } \\
\text { Sample and hold voltmeter } \\
\text { IR heat lamps }\end{array}$ & IEEE 1262: §5.15 & \\
\hline A.14 & $\begin{array}{l}\text { 5.16.1 Non-intrusive Hot Spot } \\
\text { Endurance Test }\end{array}$ & $\begin{array}{l}\text { Source of irradiance } \\
\text { I-V curve tracer } \\
\text { Temperature detector } \\
\text { ammeter } \\
\text { irradiance monitor }\end{array}$ & IEEE 1262: §5.16 & \\
\hline A.15 & $\begin{array}{l}\text { 5.16.2 Intrusive Hot Spot } \\
\text { Endurance Test } \\
\text { (Requires special test module) }\end{array}$ & $\begin{array}{l}\text { Constant current/voltage power } \\
\text { supply } \\
\text { Source of irradiance (w/o IR) } \\
\text { I-V curve tracer } \\
\text { Temperature detector } \\
\text { Voltmeter, ammeter } \\
\text { Irradiance monitor } \\
\text { IR heat lamps }\end{array}$ & IEEE 1262: §5.16 & \\
\hline A.16 & $\begin{array}{l}5.17 \text { Ultraviolet Conditioning } \\
\text { Test }\end{array}$ & $\begin{array}{l}\text { Source of UV or sunlight } \\
\text { UV radiometer } \\
\text { Oven or module heater }\end{array}$ & IEEE 1262: § 5.17 & \\
\hline A.17 & 5.18 Outdoor Exposure Test & Solar irradiance monitor & IEEE $1262: \$ 5.18$ & \\
\hline A.18 & 5.19 Annealing Procedure & Oven or module heater & IEEE $1262: \& 5.19$ & \\
\hline
\end{tabular}




\section{PV-3 Appendix 2}

\section{Laboratory Organization and Personnel}

\section{Introduction}

This section will provide guidelines to the organization, structure, and functional requirements for personnel needed to effectively manage and operate a PV qualification laboratory.

Economics will dictate the staff needs to be kept small, yet large enough to perform all tasks required by Documents PV-1 and PV-3. Because of the technical nature of the testing, combined with stringent requirements for documentation and conformance to standards, the staff will need to be multidisciplinary with extensive cross-training.

\section{Organization}

A simplified organization chart for operation of a certification laboratory is shown in Figure C1. The number of people needed to fill each functional box will depend on the level of PV testing and other related businesses operated by the laboratory. During the formative stages, a total of two or three carefully selected staff members should be adequate to perform all tasks. During this period, certain functions, such as periodic equipment maintenance and certain of the facility requirements, will likely be contracted. The initial staff, being limited to a few individuals, will have to be highly trained, multidisciplined, and quite versatile.

\section{Functional Requirements}

The functions needed to operate the laboratory depicted in Figure C-1 are:

Director:

- Provides technical expertise, marketing, and leadership for the laboratory

- Provides customer interface

- Provides interface to the certification body

- Maintains contacts and information flow with government, industry, and organizations relevant to the laboratories' business

- Is responsible for the overall laboratory operation; sets and maintains laboratory policy

- Reviews all records and reports

- Sets and keeps budgets

- Plans the laboratory needs for personnel and equipment

- Reviews performance of the laboratory and its personnel.

Quality Assurance:

- Conducts and records all calibration functions

- Writes, maintains, and controls the quality manual

- Reviews all reports, and periodically checks data

- Conducts training

- Acquires, keeps, and maintains all physical standards and certificates

- Helps select and qualify laboratories for outside testing if such testing is required

- Establishes and maintains relationships with vendors 
Figure C-1. Laboratory Organization

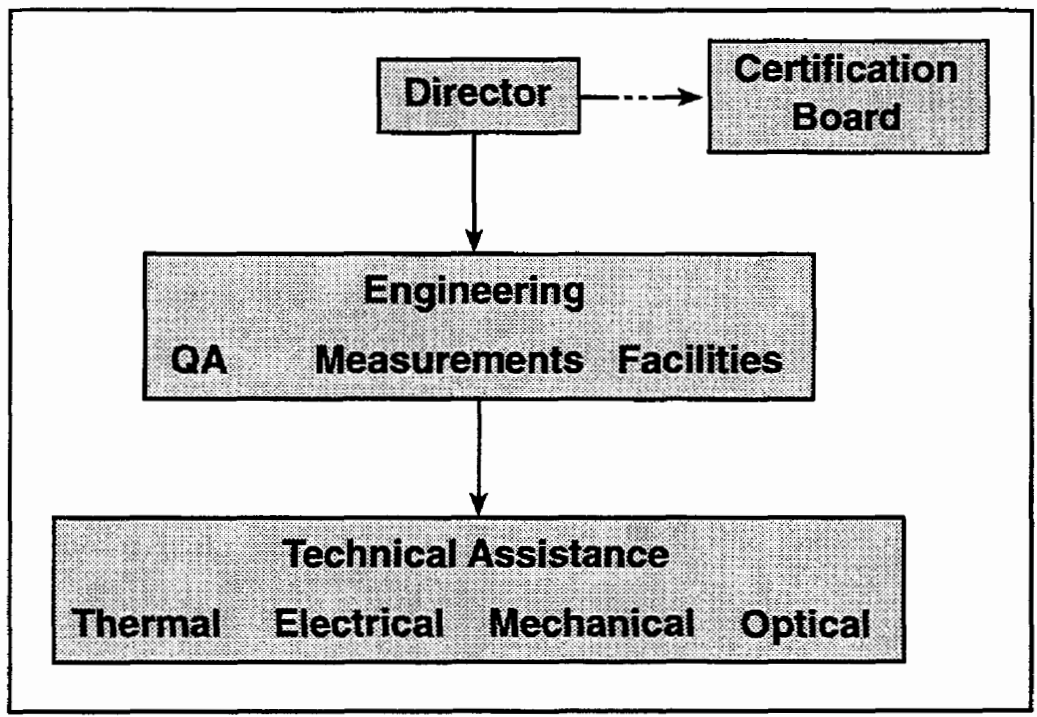

- Provides interface and communications with engineering

- Conducts annual audit

- Is responsible for Plant Safety Program.

Measurements Engineering:

- Is responsible for all product testing

- Plans flow, logistics, and personnel requirements

- Prepares all technical reports

- Arranges and conducts special tests, i.e., round-robin

- Supervises outside testing and checks results

- Plans for and is responsible for equipment calibration

- Interfaces with quality assurance

- Provides technical training

- Establishes standards and reviews performance of laboratory personnel

- Provides interface and reacts to communications from quality assurance.

Equipment/Facilities Engineering:

- Maintains all equipment

- Provides for equipment installation or movement

- Provides periodic preventative and required maintenance

- Provides repair and service

- Keeps traceable records

- Maintains building/facility, including HVAC, support equipment/supplies, and cleaning function. 
Laboratory Technician (Electrical, Thermal, Mechanical, Optical):

- Conducts assigned tests

- Monitors equipment and testing function

- Records and maintains data log

- Calibrates assigned equipment.

\section{Operational Guidelines}

The total number of people on staff will depend on the level of testing and on other business the laboratory may conduct. Considering the cost-sensitive nature of the PV industry, and in the formative stages when the laboratory is gaining an experience base and credibility, it would be prudent to keep testing costs low. Operation of the laboratory during this stage should be characterized by a minimum staff of two or three people, with emphasis on automated, computerized equipment base. For economy and efficiency, a selected number of tests may be sent to qualified outside laboratories.

To obtain and maintain accreditation, the following guidelines are offered regarding organization, personnel and laboratory function:

- Maintain lines of responsibility and authority, especially in reporting to and interacting with the certification body.

- Maintain and provide good record keeping, especially on calibration, data log books, and certification and training of personnel.

- Follow and assure all safety regulations.

- Provide evidence of training and cross-training of technicians and equipment operators. Require that at least two people be trained for each major test or procedure.

- When subcontracting testing, ensure the qualification and competence of the subcontracting laboratory. Document these.

- Set a goal to initially subcontract no more than $50 \%$ of the tests in Table C-1, and after 3 years of operation, no more than $20 \%$.

- Keep good records of customer communications, especially complaints and complaint resolution.

- Keep the quality assurance manual current and ensure that the stated quality system is in force. 


\section{Annex D}

PV-4. Operational Procedures Manual for the Certification Body of the

Photovoltaic Module Certification Program 


\section{Document PV-4 \\ Operational Procedures Manual for the Certification Body of the Photovoltaic Module Certification Program}

Table of Contents

Page

$\begin{array}{ll}\text { Foreword } & \text { D-3 }\end{array}$

1. Introduction D-3

2. Scope D-4

3. Definitions D-4

4. Initial responsibilities of the executive director D-5

5. Approval of module certification test laboratories $\quad$ D-6

6. Establishment of the factory quality assessment team $\quad$ D-7

7. Procedural flow diagram D-7

8. Application for participation D-9

9. Requirements for a manufacturer's factory quality system $\quad$ D-11

10. Review by PMCC of application for module certification D-12

11. The factory assessment D-13

12. Random selection of test modules D-16

13. Review and determination of applicant's suitability $\quad$ D-17

14. Selection of the PV module test laboratory D-18

15. Module testing D-18

16 Appeals D-20

17. Approval and certification processes D-20

18. Annual, biennial, and periodic requirements D-21

19. Challenge testing and factory audits D-22

$\begin{array}{ll}\text { Bibliography } & \text { D-23 }\end{array}$

Glossary

$\begin{array}{ll}\text { A2LA } & \text { American Association for Laboratory Accreditation } \\ \text { ANSI } & \text { American National Standards Institute } \\ \text { ASQC } & \text { American Society of Quality Control } \\ \text { CAR } & \text { Corrective Action Report } \\ \text { FQAT } & \text { Factory Quality Assessment Team } \\ \text { ISO } & \text { International Standards Organization } \\ \text { IEC } & \text { International Electrotechnical Commission } \\ \text { MQSC } & \text { Manufacturer's Quality System Compliance (committee) } \\ \text { PMCC } & \text { Photovoltaic Module Certification Corporation } \\ \text { RAB } & \text { Registration Accreditation Board } \\ \text { TQM } & \text { Total Quality Management }\end{array}$




\section{FOREWORD}

This document is one of a series that together purport to address the totality of the criteria and requirements of the Photovoltaic Module Certification Corporation (PMCC) photovoltaic module testing, certification, and labeling program. The other documents in this series which have been issued are:

PV-1 Criteria for a Model Quality System for Laboratories Engaged in Testing Photovoltaic Modules

PV-1.1 Calibration, Traceability, and Statistical Requirements of Accredited Laboratories Supporting the Photovoltaic Module Certification Program (Addendum to PV-1)

PV-2 Model for a Third-Party Certification and Labeling Program for Photovoltaic Modules

PV-3 Testing Requirements for a Certification and Labeling Program for Photovoltaic Modules

PV-5 Application and Certification Procedures for the Photovoltaic Module Certification Program

It is intended that this document be employed by the PMCC staff and standing committees in the operation and management of the PMCC photovoltaic module testing, certification, and labeling program, hereinafter called the PMCC module certification program.

\section{Introduction}

1.1 This document describes the procedures and processes required for the day-to-day operation of the PMCC PV module certification program, as well as the procedures required of module manufacturers who choose to obtain PMCC certification of their PV modules. This document must be revised once the program start-up procedures have been completed.

1.2 This document is the principal guide for managing and administering the PMCC PV module certification program, and has been constructed to conform to Document PV-2 (which itself conforms to ANSI Z34.1 and ISO Guide 28), and to ISO/IEC Guides 40 and 56.

1.3 Access to the module certification processes shall not be conditional upon membership in any association or group, nor shall there be undue financial conditions to restrict participation. These procedures will be operated and administered in a nondiscriminatory manner. 


\section{Scope}

2.1 The module certification program shall be administered by PMCC in such a manner as to ensure conformity to the requirements of this document with respect to:

(a) Maintaining an administrative structure consisting of a governing board and a permanent staff, however small or large

(b) Creating standing and other committees consistent with the rules of procedure for such committees as specified in the General Rules of Procedure and the Specific Rules of Procedure in Annex F of this handbook.

(c) Preparation and maintenance of a PMCC quality system and quality manual consistent with the requirements of ISO/IEC Guide 56, which is reproduced in its entirety in Appendix 1 of Document PV-2.

2.2 PMCC staff shall establish and maintain, or cause to be established and maintained, a laboratory accreditation program in accordance with Documents PV-1 and PV-2 and shall render to program applicants and participants whatever assistance may be required to establish contact with the appropriate approved test laboratory, or laboratories.

2.3 PMCC staff shall establish and maintain, or cause to be established and maintained, a manufacturer's quality system assessment and surveillance program in accordance with Document PV-2, and shall render to program applicants and participants whatever assistance may be required to establish contact with the appropriate quality audit person, persons, group, or organization selected for determining the suitability of manufacturer's quality system.

2.4 Conformity by participating manufacturers to the requirements of this document shall be determined through initial testing to the requirements of Document PV-3 and to the satisfactory results of the assessment of the manufacturer's factory quality management system as noted in 2.3 above.

2.5 Continuing conformity to the requirements of this document, and to the general requirements of the PMCC PV module certification program, shall depend upon:

(a) Evidentiary results of any supplemental, periodic, or other testing and surveillance audits of the manufacturer's quality system as may be generally instituted or specifically required by the board of directors of the PMCC and/or its agents

(b) The timely rendering to PMCC of the certification fees required to maintain the module certification program.

\section{Definitions}

3.1 The relevant definitions pertaining to testing, calibration, and verification contained in Document PV-1, those pertaining to certification activities contained in Document PV-2, and those pertaining to the technical basis for testing contained in Document PV-3, are incorporated by reference and are not repeated. 
3.2 Application procedures:

3.2.1 Applicant: A manufacturer or distributor of PV modules who by their desire to produce and/or distribute said modules as PMCC-certified products have made application for participation in the PMCC PV module certification program

3.2.2 Participant: A manufacturer or distributor of PV modules who by their desire to produce and/or distribute said modules as PMCC-certified products have made application for participation in the PMCC PV module certification program, have submitted their module(s) for testing to an A2LA-accredited testing laboratory approved by the PMCC for testing to the requirements of Document PV-3, and, having met all other requirements, are accepted for participation in the certification program and possess the right to represent their certified modules as such.

\section{Initial responsibilities of the executive director}

\subsection{Housekeeping activities}

4.1.1 The executive director, working closely with the chairman of the PMCC board of directors, shall immediately:

(a) Establish the necessary bank account(s)

(b) Seek, arrange for, and obtain initial start-up funding from whatever sources may be available including, but not limited to, advances on participation fees from program participants and state, federal, or public grants

(c) Arrange for affordable accounting and legal representation. ${ }^{1}$

4.1.2 The executive director shall locate and arrange for the following that are appropriate to the start-up condition of the module certification program:

(a) Office space

(b) Telephone and facsimile services

(c) Office furniture

(d) Word processing capabilities.

4.1.3 Working closely with the board of directors, the executive director shall design or have designed the appropriate letterhead stationery and those documents and forms that will be required to initially promote and manage the module certification program.

\footnotetext{
${ }^{1}$ Legal representation will be required for the purpose of ensuring the legality and providing risk reduction with respect to the articles of incorporation, corporate bylaws, and rules of procedure.
} 
4.2.1 The executive director, working with the program participants and the PMCC board of directors, shall arrange for the formation and staffing of the standing committees for which rules of procedures are available (see the General Rules of Procedure and the Specific Rules of Procedure in Annex F of this handbook).

4.2.2 The most likely candidates for chairmanship of the standing committees shall be consulted with respect to candidates for membership on their respective committees.

4.2.3 Once the minimum number of members have agreed to serve on the various standing committees, and immediately following the seating of the board of directors, the executive director shall arrange for the convening of the initial meetings of the standing committees.

\section{Approval of module certification test laboratories}

5.1 Working with the program's laboratory accreditation committee, the executive director shall provide notice to the American Association for Laboratory Accreditation (A2LA) of PMCC's intent to establish a laboratory approval program based on laboratory accreditation by A2LA.

5.2 The laboratory accreditation committee shall provide A2LA with:

(a) The specific testing criteria contained in Document PV-3, as well as individual test standards and any additional information requested by A2LA

(a) A list of technically qualified potential assessors who may be readily or already trained as laboratory assessors.

5.3 By whatever means are most appropriate, the executive director shall advertise the existence of the module certification program and the need for one or more qualified laboratories that will be required to perform module testing in accordance with Document PV-3.

5.4 Based on the decision of the board of directors with respect to criteria that will be applied to the approval of laboratories for testing in support of the module certification program and in compliance with Document PV-3, a precondition of which shall be laboratory accreditation by the A2LA, program participants and potential participants will be notified of the approved laboratory, or approved laboratories. Further, the executive director shall arrange to include the names and contact information of all approved laboratories in program literature. 
6. Establishment of the factory quality assessment team

6.1 The committee on manufacturer's quality system compliance (MQSC) shall draw up the criteria for service on the factory quality assessment team (FQAT), said criteria to be approved by the board of directors of PMCC.

6.2 Working with the MQSC committee, the executive director shall provide notice to the photovoltaic manufacturing community that it is seeking trained quality system auditors who are certified as quality assessors either by the ANSI/ASQC Registration Accreditation Board (RAB), or by ASQC, to serve on the FQAT. Members of the MQSC committee shall be eligible to serve on the FQAT unless they have conflicts of interest as delineated in the rules of procedure for this committee.

6.3 The MQSC committee shall arrange to hold a one- to two-day training and review session for the RAB-certified auditors that have applied and been accepted for service on the FQAT. The scope of the training session shall consist, as a minimum, of the elements of quality system operation, documentation, and records as proscribed in Section 11 of this document and on Form PV350, contained in Appendix 1 of Document PV-5.

6.4 The chairman of the MQSC committee shall, in concert with the executive director and the board of directors, determine the compensation scale, and the factory quality assessment fee schedule, for the factory quality assessments that will be required of module manufacturers as a condition of participation in the module certification program.

6.5 The chairman of the MQSC committee shall, with the advice and consent of the executive director of PMCC, select the most qualified of the attendees for service on the FQAT.

\section{Procedural flow diagram}

7.1 The hierarchy and order of all programmatic activities affecting both participants and PMCC staff are presented in the flow diagram of Figure D-1.

7.2 These diagrams represent the procedural flow for applications, payment of application fees, submission of signed licensing agreements, manufacturer's quality audits, submission of modules for testing, module testing, rendering of test fees to the test laboratory, rendering of required sales information and royalty payments under the terms of the license, and acceptance of the findings of the test laboratory and PMCC.

7.3 It is recognized that due to the exigencies of the certification program, it may be necessary from time to time to alter the exact order in which the various tasks and steps are either permitted or caused to take place. In no case shall it be construed that the participant has the right to make changes without the express written consent of the executive director of the PMCC. 


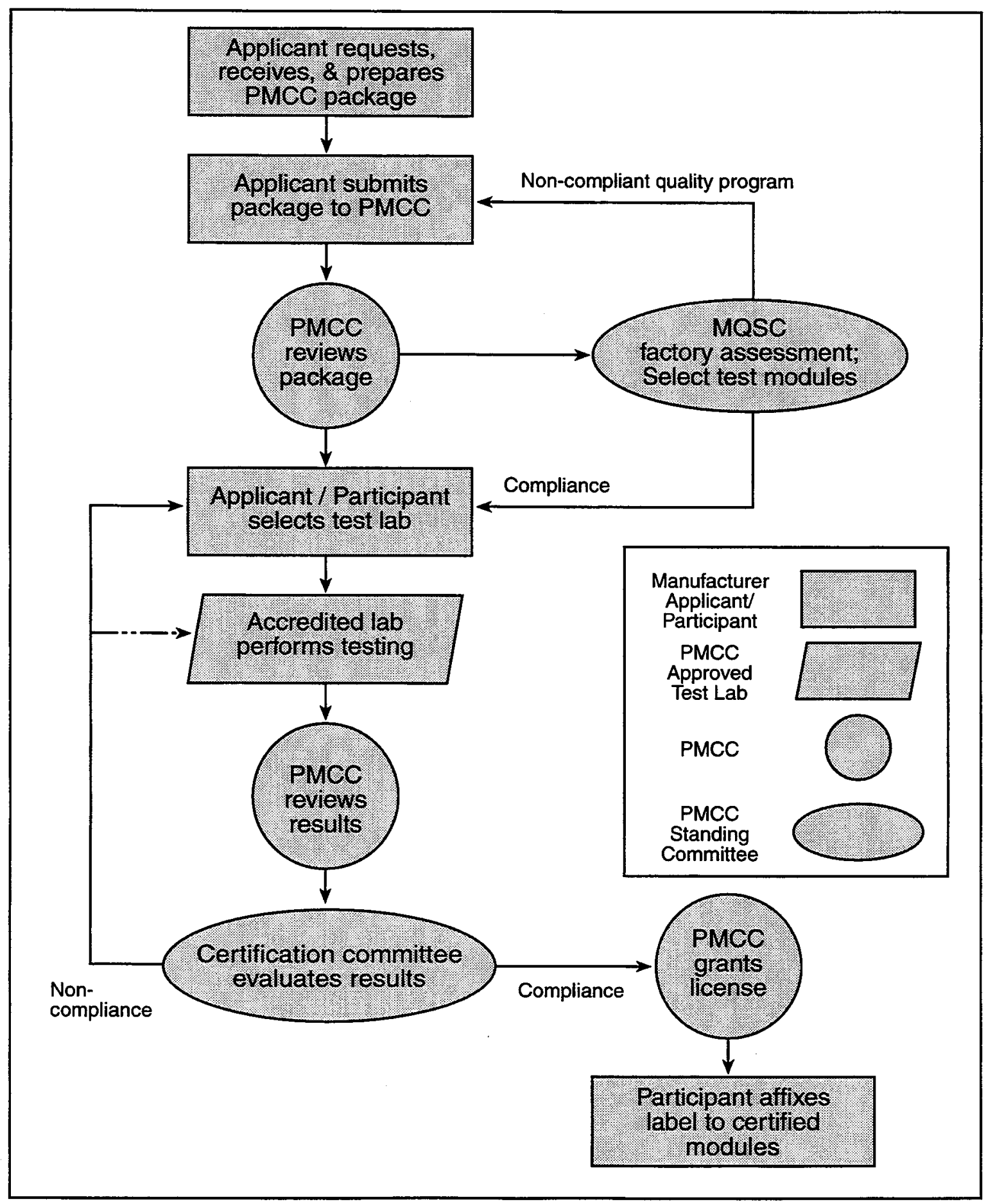

Figure D-1. Procedural Flow Diagram, Initial Certification 


\section{Application for participation}

8.1 Assembly of application package:

8.1.1 Working with the appropriate standing committees, the executive director shall prepare and/or cause to be prepared the following forms, which thereafter shall be assembled as the application package: ${ }^{2}$

(a) Form PV100, Application

(b) Form PV200, Manufacturer's factory quality system questionnaire

(c) Form PV250, Checklist for inspection and assessing the capabilities and quality system of manufacturers and producers

(d) Form PV300, Licensing agreement for the use of the certificate and mark of conformity

(e) Form PV350, Licensing fee based on product sold.

8.1.2 Having prepared the above documentation, the executive director shall distribute the forms to the appropriate standing committees for final approval. These are the product certification committee, the committee on manufacturer's quality system compliance, the committee on licensing compliance, and the audit and finance committee.

8.2 General requirements

8.2.1 Having requested the application package, the applicant must complete and submit the application (Form PV100) and the applicant's questionnaire for factory assessment (Form PV200), specimen copies of which are provided in Document PV-2. Form PV250 is also provided as a part of the application package in order to assist the applicant in ensuring that its manufacturing quality assurance system is adequate for the purpose of the PV module certification program, and to provide information on the scope of the factory assessment, a third-party audit that must be satisfactorily completed prior to random selection of the PV modules for testing.

8.2.2 Submission of Form PV200 is required at the time application is made for participation in the program. It is anticipated that some applicants will be required to resubmit PV200 at the time the applicant notifies the PMCC that they wish to be given their factory assessment.

\footnotetext{
${ }^{2}$ Examples of these forms are contained in the appendices of Document PV-2, except for Form PV350, which is contained in Appendix A of Document PV-5.
} 
8.3.1 In completing PV100, the PMCC executive office should be aware that the addresses of the official contact person (Block 3) and that of the manufacturing plant (Block 4) may or may not be the same as that of the registered corporate address requested in Block 1.

8.3.2 Applicants must be required to be specific in their answers. Block 5 must provide the exact descriptions of the module, or modules, to be offered for testing and certification. As a minimum, the information should include the material basis of the photovoltaic module (i.e., whether it is crystalline, semicrystalline or amorphous silicon, cadmium telluride, etc.), the type of transparent cover employed, the nominal power in watts (i.e., a 30-watt, 40-watt, or 50-watt module), the model name and number, and the catalog number (if different from the model number) ${ }^{3}$

8.4 Manufacturer's factory quality system questionnaire, Form PV200

8.4.1 The applicant must be required to furnish a completed Form PV200 at the time the application is submitted to PMCC. The answers should reflect the status of the factory's quality system and quality assurance program at the time of submission. If the applicant manufacturer does not have a quality system in place, by whatever name or however recently implemented, the manufacturer should be encouraged to delay submission of the application package until a factory quality system has been developed and implemented that, in general, meets the criteria presented in Form PV250.

8.4.2 In the event that the applicant requires clarification or help in completing Form PV200, selected PMCC staff and/or members of the committee on manufacturer's quality system compliance should offer whatever help is needed that may be permitted under the operational procedures for PMCC and/or the rules and procedures for the stated committee.

8.5 Submission of application

8.5.1 Upon completion of Forms PV100 and PV200, applicant must mail them to the PMCC along with a nonrefundable fee of $\$ 800$ (plus $\$ 100$ for every module type or model in excess of one for which certification is sought).

8.5.2 The executive office will accept fees paid by check or certified bank draft, or fees that are wired to PMCC's bank account.

8.5.3 Foreign manufacturers must render payment in \$U.S. via an international bank draft drawn on any major U.S. bank, or may wire the funds to PMCC's bank account.

\footnotetext{
${ }^{3}$ More precise information is required at the time the specimen modules are randomly selected and tagged for shipment to the applicant's laboratory of choice.
} 


\section{Requirements for a manufacturer's factory quality system}

9.1 Specific duties of the executive director

9.1.1 The executive director shall participate in the quality system assessor training and review seminar discussed in Section 6.3 and, as a result of the information presented, will be responsible for handling initial inquiries, questions, and comments from applicants, potential applicants, and participants in the module certification program.

9.1.2 All inquiries, questions, and comments from applicants, potential applicants, and participants that are outside the experience of the executive director, or responses from the executive director that engender further queries and discussion, will be deferred to the committee on manufacturer's quality system compliance or the committee on licensing compliance for resolution.

9.1.3 The executive director will inform applicants or potential applicants of the appropriate steps they must take depending on whether the applicant has a factory quality system in place, has an ISO 9000 factory quality system in place that is registered by a RABcertified registrar (or certified by an internationally certified registrar), or has no factory quality system in place.

9.2 Factory quality system already in place

9.2.1 If the applicant has received or obtained certification or registration of its factory quality system to either ISO 9001 or ISO 9002, or the equivalent ANSU/ASQC Q9001 or Q9002, quality systems standards, a copy of the certification or registration certificate must be submitted with the application in lieu of submitting a completed Form PV200.

9.2.2 In the event the ISO 9000 series registration has lapsed, or will lapse prior to completion of the PMCC certification process, the applicant must submit a completed Form PV200.

9.2.3 If the applicant's ISO 9000 registration/certification is current, the applicant must submit a copy of the deficiency report and its corrective action response leading to certification that applicant meets the requirements of the relevant ISO 9000 quality standard. ${ }^{4}$

9.2.4 In the event that the applicant has received a private third-party assessment of its factory quality system, but chose not to apply to a registrar for registration/certification to an ISO 9000 standard, applicant must give PMCC written permission to contact the thirdparty auditor/assessor in order to ascertain the level of compliance to ISO 9000 , to an acceptable TQM criteria document, or to an equivalent criteria, in order to determine whether or not a PMCC-initiated audit/assessment of applicant's factory quality system will be required.

\footnotetext{
${ }^{4}$ The objective of this exercise is to avoid the necessity of PMCC having to perform, or causing to be performed, a factory audit prior to random selection of modules for submission to a PMCC-approved test laboratory.
} 
9.3 Factory/manufacturer's quality system not developed

9.3.1 The executive office must ensure that the applicant's management understands that its first step will be to commit to the development of a factory quality system that will in general meet the criteria presented in Form PV250. Commitment will require that management select a quality manager (if one has not been named), provide the resources necessary to complete and implement the development of a manufacturing quality system, and to empower the quality manager and designated staff with the authority to carry out the assigned activities.

9.3.2 It will be necessary for management to name a contact person with respect to the application and participation in the certification program. It is suggested that this person be the quality manager.

9.3.3 Form PV250 is the checklist that PMCC's designated quality system auditor will employ in performing the factory assessment prior to random selection of the specimen modules for submission to the PV test laboratory.

9.3.4 The executive office must emphasize that the applicant will be required to arrange for the implementation of an internal audit prior to calling for the PMCC factory assessment of their manufacturing quality system. This internal audit must be documented and meet the requirements of Criteria 16 (16.1 through 16.5) of PV250. Although PMCC will attempt to provide nominal assistance to manufacturers who must develop their quality system from the beginning in order to comply with the PMCC module certification program requirements, two references are given in the bibliography at the end of this document.

10. Review by PMCC of application for module certification

10.1 Jurisdiction

10.1.1 Upon receipt of the application package, PMCC's executive director will examine the application (Form PV100). When satisfied with respect to its accuracy and completeness, he or she will forward it to the chairman of the MQSC committee.

10.1.2 The committee chair will inform the applicant of the expected time frame for completion of a review of the application package, barring any questions or problems that must be resolved.

10.2 Review

10.2.1 The chairman of the MQSC committee will distribute photocopies of the application package to selected members of the committee. The committee will review the application and the questionnaire (Form PV200), or quality system registration/ certification documentation in lieu thereof, to determine if the applicant appears ready for a visit by the committee-appointed auditor to perform the factory quality system assessment. 
10.2.2 If ISO 9000 registration or similar quality system certification documentation is proffered in lieu of submitting a completed Form PV200, the committee's review will be for the purpose of determining if the factory assessment can be waived. If the committee determines that no factory assessment is required, the application will be approved for an immediate visit for the purpose of randomly selecting the specimen modules to be shipped to the applicant's chosen test laboratory.

10.2.3 Should the MQSC committee have questions pertaining to the application or should it determine that the applicant is not prepared for a factory assessment, for whatever reason, the committee chair or a designated committee member will communicate with applicant's designated contact person to resolve questions, request additional information, or request that additional quality system elements be developed and implemented. A timetable will be set for submission of satisfactory responses to the committee's concerns.

10.2.4 Upon determining that the applicant has developed and implemented what appears to be the required manufacturing/factory quality system, the applicant will be notified that its application is accepted and applicant is ready for scheduling the factory assessment.

\section{The factory assessment}

\subsection{Arranging for factory assessment}

11.1.1 Applicant must communicate to PMCC several preferable dates when the factory assessment of the manufacturer's quality system will have the least impact on the applicant's ongoing operations.

11.1.2 Either prior to agreeing upon an assessment date or immediately thereafter, the applicant must submit a completed manufacturer's quality system checklist (Form PV250). Form PV250 will be used by PMCC's factory auditor to assess the existing elements and degree of implementation during the on-site assessment.

11.1.3 It is important that this checklist be submitted to PMCC at least two weeks in advance of the scheduled audit. It is the guide that: (a) the auditor will use during the assessment, (b) will make the assessment more efficient, and (c) will tend to reduce the possibility of extending the audit beyond the scheduled two days.

11.1.4 To further facilitate an efficient audit, the applicant must be encouraged to furnish PMCC with a copy of the applicant's manufacturing quality assurance manual, which is a requirement for participation in the PMCC module certification program. If applicant does not have a quality assurance manual, it must be developed and available for review by the PMCC factory auditor prior to the factory assessment (even though it is not specifically required by the tenets of Form PV250). ${ }^{5}$

\footnotetext{
${ }^{5}$ A manufacturing quality assurance manual is required, however, by PMCC Document PV-2 and by the ISO 9001 and ISO 9002 quality systems standards (and the U.S. equivalent ANSU/ASQC Q9001 and Q9002 standards).
} 
11.1.5 Applicant must make payment to PMCC for the factory assessment deposit of $\$ 2,200$. This is required prior to the arrival of the PMCC factory auditor. The scheduled factory assessment and subsequent random selection of modules for testing will not be performed until this fee has been paid. The fee covers the following:
(a) On-site assessment, 2 days at $\$ 600$
$\$ 1,200$
(b) Processing fee
$\$ 200$
(c) Air fare for PMCC auditor, estimated
$\$ 450$
(d) Hotel, 2 nights at $\$ 75$, estimated
$\$ 150$
(e) Miscellaneous (car, ground transportation, meals)
$\$ 200$
(f) TOTAL
$\$ 2,200$

11.1.6 Excess travel expenses (above that incurred by the PMCC auditor) will be returned to the applicant. The applicant will be invoiced for all reasonable expenses that are incurred for amounts greater than those allocated in lines $c, d$, and $e$ above.

11.1.7 PMCC auditors must be required to make air, car, and hotel reservations at reasonably low rates. However, they will not be required to stay in hotels/motels lacking in comfort and normal business amenities (such as a work area for preparation of reports, telephoning, etc.).

\subsection{The factory assessment}

11.2.1 The PMCC PV quality systems auditor will normally divide the on-site assessment into four segments, listed in the order they will occur, as follows:
(a) Entrance briefing
(b) Evaluation of applicant's quality system elements
(c) Evaluation of applicant's manufacturing, inspection, and test procedures
(d) Exit briefing.

11.2.2 Entrance briefing -an approximately 30 to 60 minute orientation that will cover introductions and an overview of the assessment by the auditor, explaining the purpose and scope of the assessment. The auditor will request an overview of the applicant's company, including a general description of its photovoltaic module manufacturing operations. The auditor will confirm that relevant manufacturing processes can be 
observed, that employees pertinent to the manufacturing and quality functions will be present for interviews, and that the required quality documentation can be examined. The manner of identifying nonconformance will be discussed, as will the recording of deficiencies and the corrective actions that will be necessary before participation in the module certification program can be assured.

11.2.3 Evaluation of applicant's quality system elements-the elements of the applicant's quality system that will be examined include the eighteen major headings of Form PV250. Of these, documentation, process procedures, measurement traceability in manufacturing, inspection, and testing, equipment and instrument maintenance, accountability, internal audits, and corrective actions are the most critical. The auditor will require an escort at all times while examining the quality system (and the manufacturing, inspection and test processes).

11.2.3.1 The purpose of the assessment is to find reasons to approve applicant's quality system in order to permit participation in the module certification program. While nonconformance likely will be found, deficiencies noted and corrective actions required, PMCC's objective is to ensure the quality of modules certified and labeled by the program. To this end, PMCC, its auditors, and the applicant are in reality partners in assuring that a minimum acceptable level of quality is maintained for all modules certified and labeled under the aegis of the PMCC module certification and labeling program.

11.2.4 Evaluation of manufacturing, inspection, and test procedures-actual manufacturing processes will be examined, as will inspection and test procedures. Interviews will be conducted with manufacturing employees and inspection and test technicians.

Conformance to good manufacturing practices and to written processes and procedures will be sought.

11.2.5 Exit briefing - an exit briefing will be held to discuss the assessment findings. The applicant must ensure that the official contact person, the applicant's quality manager (if different from the contact), and the appropriate company managers are present for the exit briefing. During the briefing, special attention will be devoted to any nonconformance, or deficiencies, found, and to the corrective actions that will be required prior to approval of the applicant for participation in the module certification program. The auditor will discuss the format for the corrective action responses that must be submitted to PMCC.

11.2.5.1 The applicant will be given 30 days to respond to the deficiency/nonconformance report by providing documentation of corrective actions taken up to that time, and furnishing a timetable for completion of the remaining corrective actions. 


\section{Random selection of test modules}

12.1 The production lot

12.1.1 The PMCC factory auditor will, at his or her discretion, perform the random selection of the test modules at the conclusion of the factory assessment.

12.1.2 The conditions under which the factory auditor would be permitted to decline to perform the random selection of test modules might include one or more of the following:

(a) The auditor finds that the applicant is simply not prepared for the assessment

(b) The applicant's manufacturing processes do not meet the minimum standard of good practice

(c) The inspection and test procedures do not meet the minimum standard of good practice.

12.1.3 The applicant shall ensure that the photovoltaic modules to be selected are contained in a production lot of not less than forty (40) modules.

12.1.4 The factory auditor will establish that the modules chosen have been manufactured from production tools and assembled using methods and processes established by the applicant for production runs.

12.1.5 Having assured himself or herself that the requirements of 9.1.2 and 9.1.3 are met, the auditor will randomly select ten (10) modules and affix a non-removable or otherwise indelible tag to each module. These tags are to be numerically or alphanumerically marked in accordance with a PMCC chronological system to identify the module manufacturer and model.

12.1.6 Any attempt to counterfeit or move the above tags to other modules will result in termination of the manufacturer's application for certification, and the applicant will be subject to whatever additional sanctions and remedies that may be imposed by the PMCC's board of directors.

\subsection{Pre-production prototypes}

12.2.1 Should the applicant and the PMCC reach an agreement whereby for good and cogent reasons the modules to be initially certified will be pre-production prototypes, applicant will be required to certify in writing that:

(a) Module certification will be temporary and provisional

(b) Certification will expire at the end of 9 months

(c) Complete certification testing in accordance with Document PV-3 will thereafter be required on the production model or models. 
12.2.2 The applicant should understand that a mark of conformity will not be issued, and that the certificate of conformity will state clearly that the certification applies to a prototype module or modules, and will expire at the specified date.

\section{Review and determination of applicant's suitability}

13.1 The factory auditor will submit two reports to the executive director of PMCC: (a) a manufacturing quality assessment, and (b) a deficiency/noncompliance report. This will be done within one week following the completion of the factory assessment.

13.2 Once the applicant's corrective action response has been received by PMCC, the executive director will forward the entire package to the chairman of the MQSC committee. The MQSC committee will have 30 days to review the auditor's report and corrective actions documentation furnished by the applicant manufacturer, and to render a decision as to applicant's suitability for participation in the module certification program.

13.3 The executive director of PMCC will inform applicant in writing of the results of the initial inspection and factory assessment of applicant's quality system and manufacturing processes. If the MQSC committee determines that the requirements for participation and licensing are not met, the letter will also state those criteria that the applicant does not meet, and will outline those corrective actions that will be required prior to further action on behalf of the applicant.

13.4 The applicant must provide objective evidence that the corrective actions have been taken to remove the deficiencies and nonconformance cited within ninety (90) days. However, the applicant must provide PMCC with a written response to the deficiency/nonconformity report, citing those areas that may be in disagreement, including applicant's plan and timetable to complete the remedial actions required.

13.5 Should the MQSC committee agree with applicant's position regarding one or more cited nonconformities, applicant will be so notified and further response to such deficiencies will no longer be required. In the event that a specific disagreement regarding a nonconformity or deficiency cannot be resolved between the committee and the applicant, the applicant will be invited to appeal the question to the PMCC's appeals committee as provided in Section 16 of this document.

13.6 If the applicant cannot provide objective evidence that the required remedial action has been taken, or the evidence has not been provided within the specified time period, PMCC will repeat that portion of the inspection and assessment for which a corrective action response was required. Failing either, the application will be denied and this decision will be communicated to the applicant in writing.

13.7 A reprocessing fee of $\$ 500$ plus all out-of-pocket expenses will be assessed the applicant for any factory reassessments that may be required.

13.8 Successful completion of the factory assessment can serve as an unofficial pre-audit assessment for the purposes of ISO 9000 registration/certification. 


\section{Selection of the PV module test laboratory}

14.1 Only test data from PMCC-approved test laboratories will be accepted by PMCC for consideration in meeting the requirements of the module certification program.

14.2 The executive office shall ensure applicant's understanding that PMCC approval of test laboratories capable of performing the tests required by Document PV-3 is based on laboratory accreditation procedures proscribed by Document PV-1. Laboratory accreditation procedures are carried out under the aegis of A2LA.

14.3 Applicants must be made duly aware that, except for the processes associated with arrangements for accrediting test laboratories to perform the tests required by Document PV-3, PMCC is not and will not be a party to the contract between applicant and the module test laboratory or laboratories, including the establishment of applicable testing fees charged to applicant by the test laboratories. Payment of laboratory test fees associated with testing to the requirements of Document PV-3 is entirely the responsibility of applicant.

14.4 Upon notification of applicant's suitability for participation in the PMCC PV module certification program, the applicant will be required to ship the tagged modules to a PMCC-approved test laboratory of the applicant's choosing.

14.5 Applicant should be cautioned to ensure proper packaging to avoid breakage and the cost and time required for a subsequent return to the factory for random selection of replacement test modules.

\section{Module testing}

15.1 PMCC will encourage the applicant to become fully conversant with the testing requirements contained in Document PV-3. Technical questions concerning the test requirements and technical issues that these test requirements address should be forwarded to the executive director well in advance of contracting with the test laboratory. If such questions cannot be answered by PMCC staff, they will be referred to the PMCC technical committee for response.

15.2 PMCC will encourage the applicant to fully apprise themselves of the test laboratory's policies and procedures including terms and conditions of sale, specific rules for witness of tests, transmittal of interim test results, etc., prior to contracting with the laboratory for the PV-3 test program.

15.3 The tests required by Document PV-3 fall into two categories, those that establish pass-fail criteria with respect to the minimum requirements for reliability and durability, and those that establish a performance level (however named or described).

15.4 PMCC will ensure the applicant's understanding of the following requirement-modules that fail to meet the minimum requirements of the reliability and durability tests, i.e. PV-3, will result in suspension of further testing until one of the following is determined: 
15.4.1 The laboratory determines that the problem is due to equipment or instrumentation malfunction, or to the manner in which the test is conducted.

15.4.1.1 Should it be determined that the problem is the responsibility of the laboratory, the laboratory shall be required to retest the module at its own expense and to furnish a corrective action report (CAR) to the laboratory accreditation committee that indicates satisfactory resolution of the problem.

15.4.2 The laboratory determines that the module is not representative of the other samples shipped for testing as a result of damage during shipment that was not visible during incoming inspection by the laboratory.

15.4.2.1 The laboratory, with the advice and consent of both the technical committee and the product certification committee, should be permitted to select another module from those shipped to the laboratory, but only if the results of all tests performed on the selected module are deemed to not be affected by the additional testing. Failing this assurance, the issue will be referred to the above committees to resolve the problem in a manner that is most favorable to the applicant manufacturer without compromising the integrity of the certification program.

15.4.3 The laboratory determines that the module was properly tested and that it is not representative of the other samples shipped.

15.4.3.1 The applicant manufacturer must be required to furnish a CAR for review by the manufacturer's quality system compliance, the technical and the product certification committees. Upon acceptance of the CAR by these committees, the applicant will be permitted to furnish a randomly selected module for retesting. All costs associated with random selection and retesting will be borne solely by the applicant.

15.4.4 The laboratory determines that the module was properly tested and that it is representative of the other samples shipped.

15.4.4.1 The laboratory must be required to notify both the applicant and PMCC of the failed test results, and the applicant will be given the opportunity to withdraw from the certification program without prejudice to any subsequent decision to reapply for participation in the certification program with the same or other models. Any subsequent application for participation in the certification program will be treated as a new application in terms of costs associated with the application and testing of the same or other models.

15.5 The results of the reliability and durability tests, and the performance-level tests (whether considered as power rating or energy efficiency values), will be submitted by the laboratory to both the applicant and PMCC. Once the executive director determines that the file is complete, all test information, as well as the results of the factory quality assessment, will be submitted to the product certification committee for validation of the reliability and durability tests, and for assignment of a performance or rating value that will be used on the certificate of conformity 
and/or the label that will be issued to the participant in accordance with the licensing agreement.

15.6 The executive director will also forward the results of the factory quality assessment to the product certification committee for their use in evaluating the applicant's overall suitability for certification, labeling, and licensing.

15.7 The product certification committee will review applicant's file. The committee may request additional information or clarification from either or both the laboratory and the manufacturer, and they may: (a) require additional testing, (b) require an additional site visit to assess any particular aspect of the factory's manufacturing and inspection process, or (c) conditionally approve the application subject to the resolution of any concerns they may have, including the requirement for periodic factory quality system surveillance visits, or retesting in a time frame that is earlier than the normal certification program retest requirement of every two years.

16. Appeals

16.1 The applicant has the right to appeal the results of: (a) the factory quality assessment, (b) specific reliability and durability test results, and (c) performance-level test results, and/or the performance level chosen by the product certification committee for insertion in the certificate of conformity.

16.2 The PMCC appeals board will thoroughly investigate applicant's appeal and in rendering a determination will utilize the particular expertise of other PMCC standing committees such as the technical, laboratory accreditation, and manufacturer's quality assessment committees.

16.3 The appeals board may require additional testing either at the applicant's chosen test laboratory, or at a referee laboratory.

16.3.1 In case the original test laboratory is chosen, the board shall have the right to nominate a technical expert from the appropriate standing committee to witness the testing required. Applicant shall have the right to waive the necessity for a third-party witness.

16.3.2 In the event that further testing supports the results obtained by the test laboratory originally selected by the applicant, all costs associated with said testing, including the costs associated with the use of an expert witness, will be the responsibility of the applicant. In the event that further testing supports applicant's claims, or that the results are contrary to the results obtained by the test laboratory selected by the applicant, and providing that the results support acceptance of the applicant's modules for certification, labeling, and licensing, all costs associated with the additional test requirements will be the responsibility of the original test laboratory selected by the applicant.

\section{Approval and certification processes}

17.1 Upon notification of acceptability of the applicant's module or modules for certification, labeling, and licensing by the product certification committee, and the rendering of all application and test fees due the PMCC and the test laboratory, the executive director will notify the applicant that its 
photovoltaic module or modules have been found suitable for inclusion in the registry of certified photovoltaic modules pending completion of the licensing agreement (Form PV300) and rendering to the PMCC the first year's licensing fees established therein.

17.2 A form for indicating the total watts of product sold during the previous six months (Form PV350), as well as Form PV300, will be furnished to the manufacturer at the time of notification of the determination of suitability. The manufacturer must sign Form PV300 and complete Form PV350 by listing the product sold and computing the annualized licensing fee, as provided therein.

17.3 Upon receipt of the completed Forms PV300 and PV350, and the fees computed therefrom ${ }^{6}$, the executive director will submit Form PV350 to the audit and finance committee for examination, verification, and approval.

17.3.1 Should a finding of error in the computation of either the product sold or the licensing fee be determined by the audit and finance committee, and should attempts to resolve such issues with the manufacturer be unsuccessful, the entire matter will be referred to the board of directors of PMCC for resolution.

17.4 Upon approval by the audit and finance committee, the executive director will mail or otherwise furnish to the participant a completed license giving the manufacturer the right to use the certification mark as a label of conformity (to be affixed to all certified modules sold), as well as the certificate of conformity, in the manner proscribed by the licensing agreement and the license.

18. Annual, biennial, and periodic requirements

18.1 Annual licensing fees

18.1.1 Participants are required to submit Form 350 within 30 days of the anniversary date (the date on the license). Form 350 will be mailed to participants 30 days in advance of the anniversary date.

18.1.2 Form 350 provides for an adjustment in fees for the product actually sold during the first or previous year of participation in the certification program, plus the projected fees for the second or following year, computed on basis of the previous six months.

18.2 Biennial requirements

18.2.1 The participant will be required to submit certified product for recertification every two years in order to maintain the license and the right to advertise the product as being certified by PMCC.

18.2.2 PMCC will make every attempt to use as the random selector a representative of PMCC who resides or has regular business in the closest possible proximity to the participant.

\footnotetext{
${ }^{6}$ Whether by check, bank draft, or wire transfer.
} 
18.2.3 All of the requirements and conditions that apply to the initial certification will apply to recertification of the previously certified modules, except that the assessment of the factory's quality system may be waived (see 15.3).

18.2.4 Inclusion of a new, previously non-certified module in the program will entail additional processing costs and will require a reassessment of the factory's manufacturing quality system as it relates to the new, previously non-certified product.

18.3 Surveillance audits of the factory's quality system

18.3.1 The product certification committee, with the concurrence of the committee on manufacturer's quality system compliance, may require a surveillance audit of a participant's factory quality system on an annual or less frequent basis, either as a matter of policy or when deemed necessary due to the exigencies of a participant based on the history of previous submittals, applications, site visits, testing problems, etc.

18.3.1.1 Should the PMCC's board of directors authorize and require regular periodic surveillance factory assessments, whether in lieu of the biennial frequency of test requirements or as a required element of the certification program, and thereby affecting all participants, all participants will be so notified.

18.3.2 When carried out as a matter of policy, annual surveillance audits of the factory's quality system may be less exhaustive depending on the results of the initial site assessment for a particular certified module. Participants will be notified 60 days in advance of the level of surveillance that will be conducted.

18.3.2.1 A participant's continuing registration to either ISO 9001 or ISO 9002 can be used to waive annual surveillance audits by furnishing objective evidence of same. PMCC may still require submission of a completed checklist (Form PV200).

18.3.3 Blitz surveillance audits will not be conducted as a matter of policy.

18.3.4 Participants will be given 30 days notice of any special site visits, assessments or audits that may be required due to the exigencies of a particular participant's situation.

\section{Challenge testing and factory audits}

19.1 The rules of procedure for the certification program provide for challenge of the quality or performance level advertised for certified product by either third parties or by another participant in the PMCC certification program.

19.2 The processes associated with administration of all such challenges will be treated as special cases except that: (a) the PMCC board of directors will become directly involved in all such challenges, and (b) the board of directors and the executive director will take whatever steps are deemed necessary to provide the affected participant(s) with due process procedures. 
19.3 When in order to resolve such challenges the board of directors determines that referee testing or site assessments are required, the costs of said testing and factory assessments will be borne by:

(a) The challenger when the challenge or accusation is found to be either in error or frivolous, and the test results and factory assessment resulting in certification are found therefore to be substantiated.

(b) The participant when the challenge or accusation is found to be accurate or persuasive, and the test results and/or factory assessment resulting in certification are found not to be substantiated.

(c) PMCC when the results enumerated in clause (b) are a result of PMCC's errors and when the board of directors authorizes and requires testing in support of claims made by a third party (i.e., a party that is not a participant in the PMCC certification program).

19.4 Challenges by another participant will require that both participants place the required funds in a PMCC escrow account pending resolution of the challenge. Funds will then be refunded to the party found to be correct after evaluation and resolution of the challenge.

19.5 When the challenge is found to be persuasive and/or is upheld, and depending upon the nature of the error, infraction, etc., any one of the following actions may be taken at the direction of the board:

19.5.1 As a minimum, the participant will be required to complete any corrective actions indicated by the board of directors, to file a CAR Report, and to permit a follow-up site visit to assess the affected manufacturing processes (at the participant's expense).

19.5.2 The participant's license will be suspended pending resolution of the causative problems.

19.5.3 Failure to resolve within a reasonable period the identified problems on the part of the participant during the suspension will result in revocation, or cancellation, and withdrawal of the license.

19.5.4 Willful misrepresentation or other intentional violations of the terms of the license when said violation is found as a result of the challenge will result in the immediate revocation and withdrawal of the license, depending on the seriousness of the violation.

\section{Bibliography}

1. Robert W. Peach, Ed., The ISO 9000 Handbook, CEEM Information Services, Fairfax, VA, 1994.

2. Perry L. Johnson, ISO 9000: Meeting the New International Standards, McGraw-Hill, New York, 1995. 
D-24 
Annex E

PV-5. Application and Certification Procedures for the Photovoltaic Module Certification Program 


\section{Document PV-5 \\ Application and Certification Procedures for the Photovoltaic Module Certification Program}

\section{Table of Contents}

Page

Foreword

E-3

1. Introduction

E-3

2. Scope

E-3

3. Definitions

E-4

4. Procedural flow diagram

E-4

5. Application for participation

E-6

6. Requirements for a manufacturer's factory quality system

E-7

7. Review by PMCC of application for module certification

E-9

8. The factory assessment

E-10

9. Random selection of test modules

E-12

10. Review and determination of applicant's suitability

E-13

11. Selection of the PV module test laboratory

E-14

12. Module testing

E-15

13 Appeals

E-16

14. Approval and certification processes

E-17

15. Annual, biennial, and periodic requirements

E-18

16. Challenge testing and factory audits

E-19

Bibliography

Appendix 1

Form PV350: Licensing fee based on product sold

$\underline{\text { Glossary }}$

A2LA American Association for Laboratory Accreditation

ANSI

American National Standards Institute

ASQC

American Society of Quality Control

CAR

Corrective Action Report

FQAT

Factory Quality Assessment Team

ISO

International Standards Organization

IEC

International Electrotechnical Commission

MQSC

Manufacturer's Quality System Compliance (committee)

PMCC

Photovoltaic Module Certification Corporation

RAB

Registration Accreditation Board

TQM

Total Quality Management 


\section{FOREWORD}

This document is one of a series that together purport to address the totality of the criteria and requirements of the Photovoltaic Module Certification Corporation (PMCC) photovoltaic module testing, certification, and labeling program. The other documents in this series which have been issued are:

PV-1 Criteria for a Model Quality System for Laboratories Engaged in Testing Photovoltaic Modules

PV-1.1 Calibration, Traceability, and Statistical Requirements of Accredited Laboratories Supporting the Photovoltaic Module Certification Program (Addendum to PV-1)

PV-2 Model for a Third-Party Certification and Labeling Program for Photovoltaic Modules

PV-3 Testing Requirements for a Certification and Labeling Program for Photovoltaic Modules

PV-4 Operational Procedures Manual

It is intended that this document be employed by manufacturers for the purpose of making application for participation in the PMCC photovoltaic module testing, certification, and labeling program, hereinafter called the PMCC module certification program.

\section{Introduction}

1.1 This document describes the procedures and processes required of PV module manufacturers who choose to obtain PMCC certification of one, several, or all of their models.

1.2 The principal guide for managing and administering the PMCC module certification program is Document PV-4, which has been constructed to conform to Document PV-2 (which itself conforms to ANSI Z34.1 and ISO Guide 28).

1.3 Documents PV-2 and PV-5 represent the major portions of the application package that will be available at cost to interested manufacturers who are potential applicants. All documentation will be provided to participant manufacturers at no cost.

\section{Scope}

2.1 Conformity by participating manufacturers to the requirements of this document shall be determined through initial testing according to the requirements of Document PV-3 and to the satisfactory results of a second-party assessment of the manufacturer's factory quality management system in accordance with the requirements of Document PV-2. 
2.2 Continuing conformity to the requirements of this document, and to the general requirements of the PMCC module certification program, shall depend upon evidentiary results of any supplemental, periodic, or other testing and surveillance audits of the manufacturer's quality system as may be generally instituted or specifically required by the board of directors of the PMCC and/or its agents.

\section{Definitions}

3.1 The relevant definitions pertaining to testing, calibration, and verification contained in Document PV-1, those pertaining to certification activities contained in Document PV-2, and those pertaining to the technical basis for testing contained in Document PV-3, are incorporated by reference and are not repeated herein.

3.2 Application procedures:

3.2.1 Applicant: A manufacturer or distributor of PV modules who, by their desire to produce and/or distribute said modules as PMCC-certified products, have made application for participation in the PMCC PV module certification program

3.2.2 Participant: A manufacturer or distributor of PV modules who, by their desire to produce and/or distribute said modules as PMCC-certified products, have made application for participation in the PMCC PV module certification program, have submitted their module(s) for testing to an A2LA-accredited testing laboratory approved by the PMCC for testing to the requirements of Document PV-3, and, having met all other requirements, are accepted for participation in the Certification Program and possess the right to represent their certified modules as such.

\section{Procedural flow diagram}

4.1 The procedural flow for application, payment of application fees, submission of signed licensing agreement, manufacturer's quality audit, submission of modules for testing, testing, rendering of test fees to test laboratory, rendering of required sales information and royalty payments under the terms of the license, and acceptance of the findings of the tests laboratory and PMCC, are presented in the form of a flow diagram in Figure E-1.

4.2 It is recognized that due to the exigencies of the certification program, it may be necessary from time to time to alter the exact order in which the various tasks and steps are either permitted or caused to take place. In no case shall it be construed that the participant has the right to make changes without the express written consent of the executive director of the PMCC. 


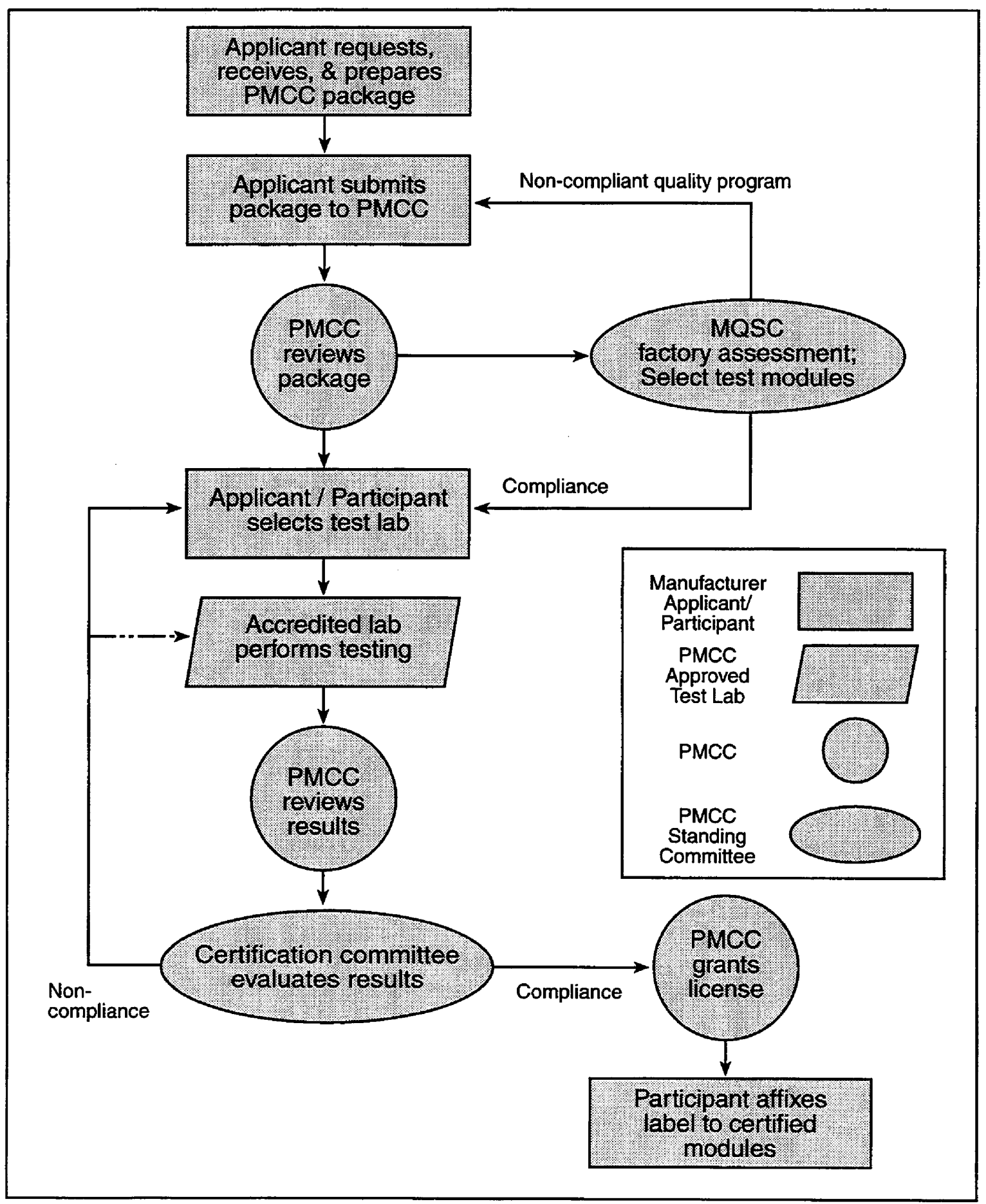

Figure E-1. Procedural Flow Diagram, Initial Certification 


\section{Application for participation}

5.1 General requirements

5.1.1 Having requested the application package, the applicant must complete and submit the application (Form PV100) and the applicant's questionnaire for factory assessment (Form PV200), which are provided as exhibits and appended to this document. Form PV250 is also provided as a part of the application package in order to assist the applicant in ensuring that their manufacturing quality assurance system is adequate for the purpose of the PV module certification program, and to provide information on the scope of the factory assessment, a third-party audit, that must be satisfactorily completed prior to random selection of the PV modules for testing. 1

5.1.2 Submission of Form PV200 is required at the time application is made for participation in the program. It is anticipated that some applicants will be required to resubmit PV200 at the time the applicant notifies the PMCC that they wish to be given their factory assessment.

5.2 Application form, Form PV100

5.2.1 In completing PV100, applicant should understand that the addresses of the official contact person (Block 3) and that of the manufacturing plant (Block 4) may or may not be the same as that of the registered corporate address requested in Block 1.

5.2.2 Applicants should be specific in their answers. Block 5 must provide the exact descriptions of the module, or modules, to be offered for testing and certification. As a minimum, the information should include the material basis of the photovoltaic module (i.e., whether it is crystalline, semicrystalline or amorphous silicon, cadmium telluride, etc.), the type of transparent cover employed, the nominal power in watts (i.e., a 30-watt, 40-watt, or 50-watt module), the model name and number, and the catalog number (if different from the model number). ${ }^{2}$

5.3 Manufacturer's factory quality system questionnaire, Form PV200

5.3.1 The applicant is required to furnish a completed Form PV200 at the time the application is submitted to PMCC. The answers should reflect the status of the factory's quality system and quality assurance program at the time of submission.

NOTE 1 -If the applicant manufacturer does not have a quality system in place, by whatever name or however recently implemented, the manufacturer should consider delaying submission of the application package until a factory quality system has been developed and implemented, and that in general meets the criteria presented in Form PV250. [Informative] ${ }^{3}$

\footnotetext{
${ }^{1}$ Examples of these forms are contained in the appendices of Document PV-2, except for Form PV350, which is contained in Appendix A of this document.

${ }^{2}$ More precise information will be required at the time the specimen modules are randomly selected and tagged for shipment to the applicant's laboratory of choice.

${ }^{3}$ Information in notes will be normative unless indicated as informative at the end of the note.
} 
5.3.2 In the event that the applicant requires clarification or help in completing Form PV200, the PMCC executive director should be contacted for whatever help is needed.

5.4 Submission of application

5.4.1 Upon completion of Forms PV100 and PV200, the applicant should mail them to the following address, along with a nonrefundable fee of $\$ 800$ (plus $\$ 100$ for every module type in excess of one for which certification is sought):

\author{
Mr. John XXXXXXXXX \\ Executive Director \\ PMCC \\ Suite XX \\ XXX West First Street \\ Anytown, State XXXXX-XXXX
}

5.4.2 The fee may be paid by check or certified bank draft, or may be wired to PMCC's bank account:

\author{
XXXXXXXX Bank \\ XXXXXX1 Office \\ Anytown, State XXXXX-XXXX \\ ABA XXXXX-XXXX \\ Account: $\quad$ PMCC \\ No. $\mathrm{XXXXX-XXXX}$
}

5.4.3 Foreign manufacturers must render payment in \$U.S. via an international bank draft drawn on any major U.S. bank, or may wire the funds to the above account.

\title{
6. Requirements for a manufacturer's factory quality system
}

6.1 Factory quality system already in place

6.1.1 If the applicant has received or obtained certification or registration of its manufacturing, or factory, quality system to either ISO 9001 or ISO 9002 , or the equivalent ANSI ASQC Q9001 or Q9002 quality systems standards, a copy of the certification or registration certificate must be submitted with the application in lieu of submitting a completed form PV200.

NOTE 2-In the event the ISO 9000 series registration has lapsed, or will lapse prior to completion of the PMCC certification process, the applicant must submit a completed Form PV200. 
6.1.2 If the applicant's ISO 9000 registration/certification is current, the applicant must submit a copy of the deficiency report and its corrective action response leading to certification that the applicant meets the requirements of the relevant ISO 9000 quality standard. ${ }^{4}$

NOTE 3-In the event that the applicant has received a private third-party assessment of its factory quality system, but chooses not to apply to a registrar for registration/ certification to an ISO 9000 standard, the applicant must give PMCC written permission to contact the third-party auditor/assessor in order to ascertain the level of compliance to ISO 9000 , to an acceptable TQM criteria document, or to equivalent criteria, in order to determine whether or not a PMCC-initiated audit/assessment of applicant's factory quality system will be required.

6.2 Factory/manufacturer's quality system not developed

6.2.1 The first step for the applicant's management is to commit to the development of a factory quality system that will in general meet the criteria presented in Form PV250. Commitment will require that management select a quality manager (if one has not been named), provide the resources necessary to complete and implement the development of a manufacturing quality system, and to empower the quality manager and designated staff with the authority to carry out the assigned activities.

NOTE 4-It will be necessary for management to name a contact person with respect to the application and participation in the certification program. It is suggested that this person be the quality assurance manager. [Informative]

NOTE 5-Form PV250 is the checklist that PMCC's designated quality system auditor will employ in performing the factory assessment prior to random selection of the specimen modules for submission to the PV test laboratory. [Informative]

6.2.2 It is emphasized that the applicant must arrange for the implementation of an internal audit prior to calling for the PMCC factory assessment of their manufacturing quality system. This internal audit must be documented and meet the requirements of Criteria 16 (16.1 through 16.5) of PV250. Although PMCC will attempt to provide nominal assistance to manufacturers who must develop their quality system from the beginning in order to comply with the PMCC module certification program requirements, several references are given in the bibliographic section at the end of this document.

${ }^{4}$ The objective of this exercise is to avoid the necessity of PMCC having to perform, or causing to be performed, a factory audit prior to random selection of modules for submission to a PMCC-approved test laboratory. 
7. Review by PMCC of application for module certification

7.1 Jurisdiction

7.1.1 Upon receipt of the application package, PMCC's executive director will examine the application (Form PV100). When satisfied with respect to its accuracy and completeness, he or she will forward it to the chairman of the PMCC committee on manufacturer's quality-system compliance (MQSC).

7.1.2 The committee chair will inform the applicant of the expected time frame for completion of a review of the application package, barring any questions or problems that must be resolved.

7.2 Review

7.2.1 The chairman of the MQSC committee will distribute photocopies of the application package to selected members of the committee. The committee will review the application and the questionnaire (Form PV200), or quality system registration/ certification documentation in lieu thereof, to determine if the applicant appears ready for a visit by the committee-appointed auditor to perform the factory quality system assessment.

7.2.2 If ISO 9000 registration or similar quality system certification documentation is volunteered in lieu of submitting a completed Form PV200, the committee's review will be for the purpose of determining if the factory assessment can be waived. If the committee determines that no factory assessment is required, the application will be approved for an immediate visit for the purpose of randomly selecting the specimen modules to be shipped to the applicant's chosen test laboratory.

7.2.3 Should the MQSC committee have questions pertaining to the application, or should it determine that the applicant is not prepared for a factory assessment, for whatever reason, the committee chair or a designated committee member will communicate with applicant's designated contact person to resolve questions, request additional information, or request that additional quality system elements be developed and implemented. A timetable will be set for submission of satisfactory responses to the committee's concerns.

7.2.4 After it has been determined that the applicant has developed and implemented what appears to be the required manufacturing/factory quality system, the applicant will be notified of the acceptance its application, and of its readiness to schedule a factory assessment. 


\section{The factory assessment}

8.1 Arranging for factory assessment

8.1.1 The applicant should communicate to PMCC several preferable dates when the factory assessment of the manufacturer's quality system will have the least impact on the applicant's ongoing operations.

8.1.2 Either prior to agreeing upon an assessment date, or immediately thereafter, the applicant must submit a completed manufacturer's quality system checklist (Form PV250). Form PV250 will be used by PMCC's factory auditor to assess the existing elements and degree of implementation during the on-site assessment.

NOTE 6-It is important that this checklist be submitted to PMCC at least two weeks in advance of the scheduled audit. It is the guide that the auditor will use during the assessment and will make the assessment more efficient, and will tend to reduce the possibility of extending the audit beyond the scheduled two days.

NOTE 7-To further facilitate an efficient audit, it is recommended that the applicant also furnish PMCC with a copy of the applicant's manufacturing quality assurance manual, which is a requirement for participation in the PMCC module certification program. If applicant does not have a quality assurance manual, it must be developed and available for review by the PMCC factory auditor prior to the factory assessment (even though it is not specifically required by the tenets of Form PV250). ${ }^{4}$ [Informative]

8.1.3 The applicant must make payment to PMCC for the factory assessment deposit of $\$ 2,200$. This is required prior to the arrival of the PMCC factory auditor. The scheduled factory assessment and subsequent random selection of modules for testing will not be performed until this fee has been paid. The fee covers the following:
(a) On-site assessment, 2 days at $\$ 600$
$\$ 1,200$
(b) Processing fee
$\$ 200$
(c) Air fare for PMCC auditor, estimated
$\$ 450$
(d) Hotel, 2 nights at $\$ 75$, estimated
$\$ 150$
(e) Miscellaneous (car, ground transportation, meals)
(f) TOTAL
$\$ 2,200$

\footnotetext{
${ }^{5}$ A manufacturing quality assurance manual is required, however, by PMCC Document PV-2 and by the ISO 9001 and ISO 9002 quality-systems standards (and the U.S. equivalent ANSI/ASQC Q9001 and Q9002 standards).
} 
8.1.4 Excess travel expenses (above that incurred by the PMCC auditor) will be returned to the applicant. The applicant will be invoiced for all reasonable expenses that are incurred for amounts greater than those allocated in lines $\mathrm{c}, \mathrm{d}$, and $\mathrm{e}$ above.

NOTE 8-PMCC auditors are required to make air, car and hotel reservations at reasonably low rates. However, they will not be required to stay in hotels/motels lacking in comfort and normal business amenities (such as a work area for preparation of reports, telephoning, etc.). [Informative]

\subsection{The factory assessment}

8.2.1 The PMCC PV quality-systems auditor will normally divide the on-site assessment into four segments, listed in the order they will occur, as follows:

(a) Entrance briefing

(b) Evaluation of applicant's quality-system elements

(c) Evaluation of applicant's manufacturing, inspection, and test procedures

(d) Exit briefing.

8.2.2 Entrance Briefing-an approximately 30- to 60-minute orientation that will cover introductions, and an overview of the assessment by the auditor, explaining the purpose and scope of the assessment. The auditor will request an overview of the applicant's company, including a general description of its photovoltaic module manufacturing operations. The auditor will confirm that relevant manufacturing processes can be observed, that employees pertinent to the manufacturing and quality functions will be present for interviews, and that the required quality documentation can be examined. The manner of identifying nonconformance will be discussed, as will the recording of deficiencies and the corrective actions that will be necessary before participation in the module certification program can be assured.

8.2.3 Evaluation of Applicant's Quality System Elements-The elements of the applicant's quality system that will be examined include the eighteen major headings of Form PV250. Of these, documentation, process procedures, measurement traceability in manufacturing, inspection and testing, equipment and instrument maintenance, accountability, internal audits, and corrective actions are the most critical. The auditor will require an escort at all times while examining the quality system (and the manufacturing, inspection, and test processes).

NOTE 9-It is important that the applicant understand that the purpose of the assessment is to find reasons to approve applicant's quality system in order to permit participation in the module certification program. While nonconformance likely will be found, deficiencies noted, and corrective actions required, PMCC's objective is to ensure the quality of modules certified and labeled by the program. To this end, PMCC, its auditors, and the applicant are in reality partners in assuring that a minimum acceptable level of quality is maintained for all modules certified and labeled under the aegis of the PMCC module certification and labeling program. [Informative] 
8.2.4 Evaluation of Manufacturing, Inspection, and Test Procedures-Actual manufacturing processes will be examined, as will inspection and test procedures. Interviews will be conducted with manufacturing employees and inspection and test technicians.

Conformance to good manufacturing practices and to written processes and procedures will be sought.

8.2.5 Exit Briefing-An exit briefing will be held to discuss the assessment findings. The applicant must ensure that the official contact person, the applicant's quality manager (if different from the contact), and the appropriate company managers are present for the exit briefing. During the briefing, special attention will be devoted to any nonconformance or deficiencies found, and to the corrective actions that will be required prior to approval of the applicant for participation in the module certification program. The auditor will discuss the format for the corrective action responses that must be submitted to PMCC.

NOTE 10 - The applicant will be given 30 days to respond to the deficiency/ nonconformance report by providing documentation of corrective actions taken up to that time, and to furnish a timetable for completion of the remaining corrective actions.

\section{Random selection of test modules}

\subsection{The production lot}

9.1.1 The PMCC factory auditor will, at his or her discretion, perform the random selection of the test modules at the conclusion of the factory assessment.

NOTE 11 -The conditions under which the factory auditor would be permitted to decline to perform the random selection of test modules might include one or more of the following: (a) the auditor finds that the applicant is simply not prepared for the assessment, (b) the applicant's manufacturing processes do not meet the minimum standard of good practice, or (c) the inspection and test procedures do not meet the minimum standard of good practice.

9.1.2 The applicant shall ensure that the photovoltaic modules to be selected are contained in a production lot of not less than forty (40) modules.

9.1.3 The factory auditor will establish that the modules chosen have been manufactured from production tools and assembled using methods and processes established by the applicant for production runs.

9.1.4 Having been assured that the requirements of 9.1.2 and 9.1.3 are met, the auditor will randomly select ten (10) modules and will affix a non-removable or otherwise indelible tag to each module. These tags are to be numerically or alphanumerically marked in accordance with a PMCC chronological system to identify the module manufacturer and model. 
NOTE 12-Any attempt to counterfeit or move the above tags to other modules will result in termination of the manufacturer's application for certification, and the applicant will be subject to whatever additional sanctions and remedies that may be imposed by the PMCC's board of directors.

$9.2 \quad$ Pre-production prototypes

9.2.1 Should the applicant and the PMCC reach an agreement whereby for good and cogent reasons the modules to be initially certified will be pre-production prototypes, applicant will be required to certify in writing that it understands that: (a) module certification will be temporary and provisional, (b) certification will expire at the end of 9 months, and, (c) complete certification testing in accordance with Document PV-3 will thereafter be required on the production model, or models.

NOTE 13-The applicant should understand that a mark of conformity will not be issued, and that the certificate of conformity will state clearly that the certification applies to a prototype module or modules, and will expire at a certain date.

\section{Review and determination of applicant's suitability}

10.1 The factory auditor will submit two reports to the executive director of PMCC: a manufacturing quality assessment and a deficiency/noncompliance report. This will be done within one week following the completion of the factory assessment.

10.2 Once the applicant's corrective action response has been received by PMCC, the executive director will forward the entire package to the chairman of the MQSC committee. The MQSC committee will have 30 days to review the auditor's report and the corrective actions documentation furnished by the applicant manufacturer, and to render a decision as to applicant's suitability for participation in the module certification program.

10.3 The executive director of PMCC will inform the applicant in writing of the results of the initial inspection and factory assessment of applicant's quality system and manufacturing processes. If the MQSC committee determines that the requirements for participation and licensing are not met, the letter will also state those criteria that the applicant does not meet, and will outline those corrective actions that will be required prior to further action on behalf of the applicant.

10.4 The applicant must provide objective evidence that the corrective actions have been taken to remove the deficiencies and nonconformance cited within ninety (90) days. However, the applicant must provide PMCC with a written response to the deficiency/ nonconformity report, citing those areas that may be in disagreement, including applicant's plan and timetable to complete the remedial actions required. 
NOTE 14-Should the MQSC committee agree with applicant's position regarding one or more cited nonconformities, applicant will be so notified and further response to such deficiencies will no longer be required. In the event that a specific disagreement regarding a nonconformity or deficiency cannot be resolved between the committee and the applicant, the applicant will be invited to appeal the question to the PMCC's appeals committee as provided in Section 13 of this document. [Informative]

10.5 If the applicant cannot provide objective evidence that the required remedial action has been taken, or evidence has not been provided in the time period required, PMCC will repeat that portion of the inspection and assessment for which a corrective action response was required. Failing either, the application will be denied and this decision will be communicated to applicant in writing.

NOTE 15-A reprocessing fee of $\$ 500$, plus all out-of-pocket expenses, will be assessed the applicant for any factory reassessments that may be required.

NOTE 16- Successful completion of the factory assessment can serve as an unofficial pre-audit assessment for the purposes of ISO 9000 registration/certification.

[Informative]

\section{Selection of the PV module test laboratory}

11.1 Only test data from PMCC-approved test laboratories will be accepted by PMCC for consideration in meeting the requirements of the module certification program.

11.2 PMCC approval of test laboratories capable of performing the tests required by Document PV-3 is based on laboratory accreditation procedures proscribed by Document PV-1. Laboratory accreditation procedures are carried out under the aegis of the American Association for Laboratory Accreditation (A2LA).

11.3 Except for the processes associated with arrangements for accrediting test laboratories to perform the tests required by Document PV-3, PMCC is not and will not be a party to the contract between applicant and the module test laboratory, or laboratories, including the establishment of applicable testing fees charged to applicant by the test laboratories. Payment of laboratory test fees associated with testing to the requirements of Document PV-3 are the sole responsibility of applicant.

11.4 Upon notification of the applicant's suitability for participation in the PMCC module certification program, the applicant is expected to ship the tagged modules to a PMCC-approved test laboratory of the applicant's choosing.

NOTE 17-The applicant is cautioned to ensure proper packaging to avoid breakage and the cost and time required for a subsequent return to the factory for random selection of test modules. [Informative] 


\section{Module testing}

12.1 The applicant should be fully conversant with the testing requirements contained in PMCC Document PV-3. Technical questions concerning the test requirements, and technical issues that these test requirements address, should be forwarded to the executive director well in advance of contracting with the test laboratory. If such questions cannot be answered by PMCC staff, they will be referred to the PMCC technical committee for response.

12.2 The applicant is encouraged to fully apprise itself of the test laboratory's policies and procedures including terms and conditions of sale, specific rules for witness of tests, transmittal of interim test results, etc., prior to contracting with the laboratory for the PV-3 test program.

12.3 The tests required by Document PV-3 fall into two categories. Those that establish pass-fail criteria with respect to the minimum requirements for reliability and durability, and those that establish a performance level in terms of the module's electrical output (however named or described).

12.4 Modules that fail to meet the minimum requirements of the reliability and durability tests (i.e., those that do not address the module's performance as defined in PV-3), will result in suspension of further testing until one of the following is determined:

12.4.1 The laboratory determines that the problem is due to equipment or instrumentation malfunction, or to the manner in which the test is conducted.

NOTE 18-Should it be determined that the problem is the responsibility of the laboratory, the laboratory shall be required to retest the module at its own expense and to furnish a corrective action report (CAR) to the laboratory accreditation committee that indicates satisfactory resolution of the problem.

12.4.2 The laboratory determines that the module is not representative of the other samples shipped for testing as a result of damage during shipment that was not visible during incoming inspection by the laboratory.

NOTE 19-The laboratory, with the advice and consent of both the technical committee and the product certification committee, will be permitted to select another module from those shipped to the laboratory but only if the results of all tests performed on the selected module are deemed to not be affected by the additional testing. Failing this assurance, the issue will be referred to the above committees to resolve the problem in a manner that is most favorable to the applicant manufacturer without compromising the integrity of the certification program.

12.4.3 The laboratory determines that the module was properly tested and that it is not representative of the other samples shipped. 
NOTE 20-The applicant manufacturer will be required to furnish a CAR for review by the manufacturer's quality system compliance, the technical and the product certification committees. Upon acceptance of the CAR by these committees, the applicant will be permitted to furnish a randomly selected module for retesting. All costs associated with random selection and retesting will be borne solely by the applicant.

12.4.4 The laboratory determines that the module was properly tested and that it is representative of the other samples shipped.

NOTE 21-The laboratory will notify both the applicant and PMCC of the failed test results, and the applicant will be given the opportunity to withdraw from the certification program without prejudice to any subsequent decision to reapply for participation in the certification program with the same or other models. Any subsequent application for participation in the certification program will be treated as a new application in terms of costs associated with the application and testing of the same or other models.

12.5 The results of both the reliability and durability tests, and the performance-level tests (whether considered as power rating or energy efficiency values), will be submitted by the laboratory to both the applicant and PMCC. Once the executive director determines that the file is complete, all test information, as well as the results of the factory quality assessment, will be submitted to the product certification committee for validation of the reliability and durability tests, and for assignment of a performance or rating value that will be used on the certificate of conformity and/or the label issued to the participant in accordance with the licensing agreement.

12.6 The executive director will also forward the results of the factory quality assessment to the product certification committee for their use in evaluating the applicant's overall suitability for certification, labeling, and licensing.

12.7 The product certification committee will review applicant's file. The committee may request additional information or clarification from either or both the laboratory and the manufacturer, and they: (a) may require additional testing, (b) may require an additional site visit to assess any particular aspect of the factory's manufacturing and inspection process, or (c) may conditionally approve the application subject to the resolution of any concerns they may have, including the requirement for periodic factory quality system surveillance visits, or retesting in a time frame that is earlier than the certification program retest requirement of every two years.

\section{Appeals}

13.1 The applicant has the right to appeal the results of: (a) the factory quality assessment, (b) specific reliability and durability test results, and, (c) performance-level test results, and/or the performance level chosen by the product certification committee for insertion in the certificate of conformity.

13.2 The PMCC appeals board will thoroughly investigate the applicant's appeal and in rendering a determination will utilize the particular expertise of other PMCC standing committees such as the technical, laboratory accreditation, and MQSC committees. 
13.3 The appeals board may require additional testing either at the applicant's chosen test laboratory, or at a referee laboratory.

NOTE 22--In case the original test laboratory is chosen, the board shall have the right to nominate a technical expert from the appropriate standing committee to witness the testing required. The applicant shall have the right to waive the necessity for a third-party witness.

NOTE 23-In the event that further testing supports the results obtained by the test laboratory originally selected by the applicant, all costs associated with said testing, including the costs associated with the use of an expert witness, will be the responsibility of the applicant. In the event that further testing supports applicant's claims, or that the results are contrary to the results obtained by the test laboratory selected by the applicant, and providing that the results support acceptance of the applicant's modules for certification, labeling, and licensing, all costs associated with the additional test requirements will be the responsibility of the original test laboratory selected by the applicant.

\section{Approval and certification processes}

14.1 Upon notification of acceptability of the applicant's module or modules for certification, labeling, and licensing by the product certification committee, and the rendering of all application and test fees due the PMCC and the test laboratory, the executive director will notify the applicant that its photovoltaic module or modules have been found suitable for inclusion in the registry of certified photovoltaic modules pending completion of the licensing agreement (Form PV300) and rendering to the PMCC the first year's licensing fees established therein.

14.2 A form for indicating the total watts of product sold during the previous six months (Form PV350), as well as Form PV300, will be furnished to the manufacturer at the time of notification of the determination of suitability. The manufacturer must sign Form PV300 and complete Form PV350 by listing the product sold and computing the annualized licensing fee, as provided therein.

14.3 Upon receipt of the completed Forms PV300 and PV350, and the fees computed therefrom, ${ }^{6}$ the executive director will submit Form PV350 to the audit and finance committee for examination, verification, and approval.

NOTE 24-Should a finding of error in the computation of either the product sold or the licensing fee be determined by the audit and finance committee, and should attempts to resolve such issues with the manufacturer be unsuccessful, the entire matter will be referred to the board of directors of PMCC for resolution.

14.4 Upon approval by the audit and finance committee, the executive director will mail or otherwise furnish to the participant a completed license giving the manufacturer the right to use the certification mark as a label of conformity (to be affixed to all certified modules sold), as well as the certificate of conformity, in the manner proscribed by the licensing agreement and the license.

\footnotetext{
${ }^{6}$ Whether by check, bank draft or wire transfer.
} 
15. Annual, biennial, and periodic requirements

15.1 Annual licensing fees

15.1.1 Participants are required to submit Form 350 within 30 days of the anniversary date (the date on the license). Form 350 will be mailed to participants 30 days in advance of the anniversary date.

15.1.2 Form 350 provides for an adjustment in fees for the product actually sold during the first or previous year of participation in the certification program, plus the projected fees for the second or following year computed on the basis of the previous six months (see Note 24).

\subsection{Biennial Requirements}

15.2.1 The participant will be required to submit certified product for recertification every two years in order to maintain the license and the right to advertise the product as being certified by PMCC.

15.2.2 PMCC will make every attempt to use as the random selector a representative of PMCC who resides or has regular business in the closest possible proximity to the participant.

15.2.3 All of the requirements and conditions that apply to the initial certification will apply to recertification of the previously certified modules, except that the assessment of the factory's quality system may be waived (see 15.3).

NOTE 25-Inclusion of a new, previously non-certified module in the program will entail additional processing costs and will require a reassessment of the factory's manufacturing quality system as it relates to the new, previously non-certified product. [Informative]

15.3 Surveillance audits of the factory's quality system

15.3.1 The product certification committee, with the concurrence of the committee on manufacturer's quality system compliance, may require a surveillance audit of a participant's factory quality system on an annual or less frequent basis, either as a matter of policy or when deemed necessary due to the exigencies of a participant based on the history of previous submittals, applications, site visits, testing problems, etc.

NOTE 26- Should the PMCC's board of directors authorize and require regular periodic surveillance factory assessments, whether in lieu of the biennial frequency of test requirements or as a required element of the certification program, affecting all participants, all participants will be so notified. [Informative] 
15.3.2 When carried out as a matter of policy, annual surveillance audits of the factory's quality system may be less exhaustive depending on the results of the initial site assessment for a particular certified module. Participants will be notified 60 days in advance of the level of surveillance that will be conducted.

NOTE 27-A participant's continuing registration to either ISO 9001 or ISO 9002 can be used to waive annual surveillance audits by furnishing objective evidence of same. PMCC may still require submission of a completed checklist (Form PV200). [Informative]

15.3.3 Unannounced surveillance audits will not be conducted as a matter of policy.

15.3.4 Participants will be given 30 days notice of any special site visits, assessments or audits that may be required due to the exigencies of a particular participant's situation.

\section{Challenge testing and factory audits}

16.1 The rules of procedure for the certification program provide for challenge of the quality or performance level advertised for certified product by either third parties or by another participant in the PMCC certification program.

16.2 The processes associated with administration of all such challenges will be treated as special cases except that: (a) the PMCC board of directors will become directly involved in all such challenges, and (b) the board of directors and the executive director will take whatever steps are deemed necessary to provide the affected participant(s) with due and speedy process procedures.

16.3 When in order to resolve such challenges the board of directors determine that referee testing or site assessments are required, the costs of said testing and factory assessments will be borne by:

(a) The challenger when the challenge or accusation is found to be either in error or frivolous, and the test results and factory assessment resulting in certification are found therefore to be substantiated.

(b) The participant when the challenge or accusation is found to be accurate or persuasive, and the test results and/or factory assessment resulting in certification are found not to be substantiated.

(c) PMCC when the results enumerated in clause (b) are a result of PMCC's errors and when the board of directors authorize and require testing in support of claims made by a third party (i.e., a party that is not a participant in the PMCC certification program).

NOTE 28-Challenges by another participant will require that both participants place the required funds in a PMCC escrow account pending resolution of the challenge. These moneys will then be refunded to the party found to be correct in evaluation and resolution of the challenge. 
16.4 When the challenge is found to be persuasive and/or is upheld, and depending upon the nature of the error, infraction, etc., any one of the following actions may be taken at the direction of the board of directors:

16.4.1 As a minimum, the participant will be required to complete any corrective actions indicated by the board of directors, to file a CAR, and to permit a follow-up site visit to assess the affected manufacturing processes (at the participant's expense).

16.4.2 The participant's license will be suspended pending resolution of the causative problems.

16.4.3 Failure to resolve within a reasonable period the identified problems on the part of the participant during the suspension will result in revocation, cancellation, and/or withdrawal of the license.

16.4.4 Willful misrepresentation or other intentional violations of the terms of the license when said violation is found as a result of the challenge will result in the immediate revocation and withdrawal of the license, depending on the seriousness of the violation.

\section{Bibliography}

1. Robert W. Peach, Ed., The ISO 9000 Handbook, CEEM Information Services, Fairfax, VA, 1994.

2. Perry L. Johnson, ISO 9000: Meeting the New International Standards, McGraw-Hill, New York, 1995. 
PV-5 Appendix 1

\section{Form PV350}

Licensing fee based on product sold 


\section{PV-5 Appendix 1}

\section{Form PV350 \\ Licensing Fee Based on Product Sold \\ Complete this form for each module certified}

Participant:

License year starting date:

Address:

Certified product model:

City:

State: Mail Code:

Country:

Section I. This section is to be completed by ALL participants. Section II is to be completed only by second-year and greater participants.

A. Product sold during the last six months:

Watts

B. Multiply line A by 2.2 (assumes a $20 \%$ per year growth rate):

Line $B$ is the basis for the amount of product sold on which the licensing fee is due for the first year, or the previous year for second-year and greater participants.

C. Multiply line $B$ by $\$ 0 . x x$ per watt:

Line $C$ is the licensing fee for the first year of your participation in the PMCC PV module certification program.

Section II. This section is for second-year and greater participants.

D. Product sold during the last six months

E. Multiply line $D$ by 2.2 :

F. Subtract line A from line B and insert here:

G. If line $F$ is less than $D$, insert difference:

$H$. If line $F$ is greater than $D$, insert difference:

I. Insert whichever line is completed ( $\mathrm{G}$ or $\mathrm{H})$, including sign:

J. Add line $\mathrm{E}$ and I and insert new basis for product sold:

K. Multiply line J by $\$ 0 . x x$ per watt:

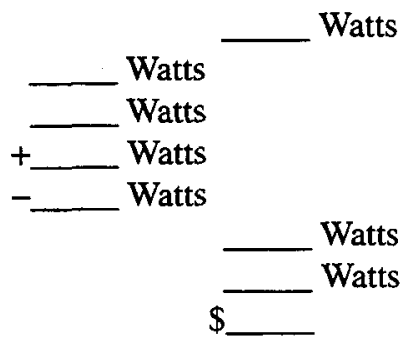

Line $\mathrm{K}$ is the licensing fee for the current certification year for the module model shown.

The undersigned, who is the of the manufacturer and participant shown, certifies that the watts of product sold in Section I and/or Section II is accurate and true to the best of my knowledge.

Attested to by:

Date: 
6 KNOW ALL MEN BY THESE PRESENTS:

8 the State of [State], and for that purpose, do hereby adopt these Articles of Incorporation:

9

10

13

14

15 17 [State].

18

\author{
ARTICLES OF INCORPORATION \\ of the \\ Photovoltaic Module Certification Corporation (PMC Corp.) \\ a Non-Profit Corporation
}

That we, the undersigned, desiring to form a Non-Profit Corporation under and pursuant to the laws of

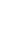

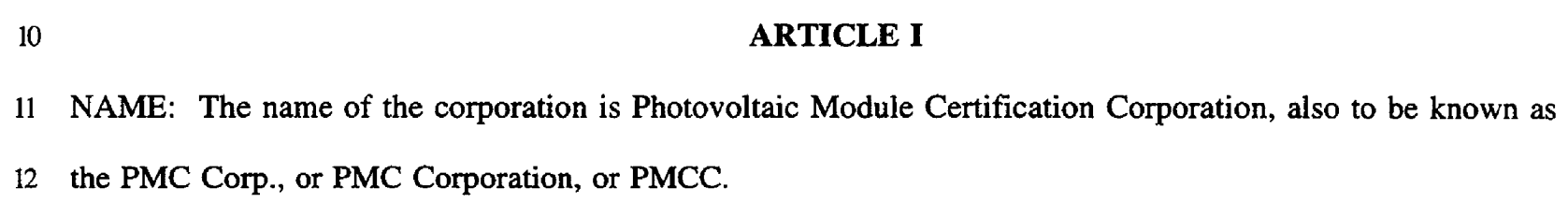
12 the PMC Corp., or PMC Corporation, or PMCC.

PRINCIPAL OFFICE: The principal office of PMCC is to be located at: [Street], [City], [State], [Zip Code].

PMCC may transact its business at the principal office and maintain other offices either within or outside

ARTICLE III

PURPOSE: This corporation is organized for the purpose of transacting any and all business for which

non-profit corporations may be incorporated under the laws of this State, as they may be amended from time to time, except that said corporation is organized exclusively for photovoltaic module certification and labeling purposes, within the meaning of Section $501(\mathrm{c})(3)$ of the Internal Revenue Code of 1986, or the corresponding provisions of any future United States Internal Revenue laws. 


\section{ARTICLE IV}

2 SPECIFIC BUSINESS: The specific business activities for which this corporation is organized and intends 3 actually to conduct in this State, which shall not limit the character of the exempt activities which this 4 corporation may ultimately conduct, are as follows: (1) to arrange for the testing of photovoltaic modules in 5 accordance with documented test procedures, said modules to be submitted by manufacturers who have agreed 6 to participate in the corporation's photovoltaic module testing, certification and labeling program, and who 7 have met the corporation's quality requirements for said participation; (2) to accredit, or cause to be 8 accredited, a laboratory or laboratories meeting the minimum testing qualifications, and minimum quality 9 requirements of the corporation's criteria document dealing with laboratory accreditation; (3) to license the use

10 of the corporation's mark of conformity by those manufacturers of modules who by the results of testing

11 conducted in direct support of the corporation's certification and labeling program, are entitled to affix said

12 mark to individual modules offered for sale by participating manufacturers; and (4) to collect whatever fees

13 are due the corporation as compensation for the right to use said mark, or marks, of conformity from

14 participating manufacturers, within the meaning of Section 501(c)(3) of the Internal Revenue Code of 1986,

15 including for such purposes, the making of distributions to organizations that qualify as exempt organizations

16 under said Section 501(c)(3), or the corresponding provisions of any future United States Internal Revenue

17 Laws. 


\section{ARTICLE V}

2 INCORPORATORS: The names and addresses of the incorporators of this corporation are:

NAME

(Name)

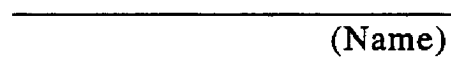

(Name)

(Name)
ADDRESS

(Address)

(City/State/Zip Code)

(Address)

(City/State/Zip Code)

(Address)

(City/State/Zip Code) 
2 BOARD OF DIRECTORS: The business and affairs of this corporation shall be conducted by a board of 3 directors who shall number not less than nor more than members. Said directors shall have the

4 authority and power to increase or decrease the number of serving directors within the limits above provided. 5 The board of directors may fill any vacancy that may occur on the board of directors pending the next annual 6 meeting of either the members, if a membership non-profit corporation, or the board of directors, if a 7 non-membership or limited membership non-profit corporation. The person(s) appointed to serve on the board 8 of directors may be appointed to serve as directors for any term of years, not to exceed 5 years, which said 9 term shall commence the date of appointment unless otherwise designated by the board of directors. The Bylaws shall specify the number of directors necessary to constitute a lawful quorum. The board of directors may, by proper resolution or resolutions passed by a lawful quorum of the whole board, designate one or more committees which, to the extent provided in said resolution or resolutions, or in the Bylaws, shall have and may exercise those powers so designated in the resolution or resolutions or in the Bylaws, on the management of activities and affairs of the corporation, and may have the power to authorize the Seal of the corporation to be fixed to all papers, documents or writings which may require it, and such committee or committees shall have such name or names as may be stated in the Bylaws, or as may be determined from time to time by resolution adopted by the board of directors. The board of directors may elect such officers of the corporation as the Bylaws may specify, who shall, subject to the provisions of the Bylaws, have such titles and exercise such duties as the Bylaws provide. The board of directors is authorized to make, adopt, alter or repeal the 20 Bylaws of this corporation, or any article therein, provided such authority and power is not vested and reserved to members of the corporation, if applicable. The names and addresses of the persons who are appointed to serve as directors of this corporation until the first annual meeting of the board of directors, or until their successors are elected and qualified, are: 
NAME

(Name)

(Name)

(Name)

(Name)

(Name)

(Name)

\section{ADDRESS}

(Address)

(City/State/Zip Code)

(Address)

(City/State/Zip Code)

(Address)

(City/State/Zip Code)

(Address)

(City/State/Zip Code)

(Address)

(City/State/Zip Code)

(Address)

(City/State/Zip Code)

(Address)

(City/State/Zip Code)

(Address)

(City/State/Zip Code) 
2 LIMITATIONS: No part of the net earnings of the corporation shall inure to the benefit of, or be distributable 3 to, its members, trustees, officers, or other private persons, except that the corporation shall be authorized and empowered to pay reasonable compensation for services rendered and to make payments and distributions in the furtherance of the purposes set forth in Article IV hereof. No substantial part of the activities of the 6 corporation shall be the carrying on of propaganda, or otherwise attempting to influence legislation, and the 7 corporation shall not participate in, or intervene in (including the publishing or distribution of statements) any political campaigns on behalf of any candidate for public office. Notwithstanding any other provision of these Articles, this corporation shall not, except to an insubstantial degree, engage in any activities or exercise any

\section{ARTICLE VIII}

DISSOLUTION: In the event of a dissolution of this corporation, any assets remaining after payment to creditors, shall be distributed for one or more exempt purposes within the meaning of Section 501(c)(3) of the Internal Revenue Code, or corresponding Section of any future Federal Tax Code, or shall be distributed to the Federal Government for public purposes. Any such assets not so disposed of, shall be disposed of by a Court of competent jurisdiction in the County where the principal office of the corporation is then located, exclusively for such purposes or to such organizations as said Court shall determine, which are organized and operated exclusively for such purposes.

\section{ARTICLE IX}

PRIVATE PROPERTY: The private property of the directors, members, if any, officers, employees and agents of the corporation shall be forever exempt from any and all debts of every kind and nature incurred by the corporation, and as authorized by the laws of this State.

INDEMNIFICATION: The corporation shall indemnify every director, officer, employee and agent, or his or her heirs, executors and administrators, against expenses reasonably incurred by him or her in connection with any action, suit or proceedings to which he or she may be a party by reason of his or her being, or having been, a director, officer, employee, or agent of the corporation, except in relation to those matters which he or she shall be adjudicated to be liable for negligence or misconduct. In the event of a settlement, indemnification shall be provided only in connection with such matter covered by the settlement as to which the corporation is advised by counsel that the person to be indemnified did not commit such breach of duty. This right of indemnification shall not be exclusive of other rights to which he or she may be entitled. As used in this Article, expenses shall include amounts of judgments, penalties or fines rendered or levied against such director, officer, employee or agent, and the amounts paid in settlement by him or her shall have been first approved by the directors of this corporation.

\section{ARTICLE XI}

DIRECTOR'S LIABILITY: No director of this corporation shall be personally liable to the corporation for monetary damages for breach of fiduciary duty as a director; provided, however, that this Article shall not be construed as eliminating or limiting the liability of a director by one or more of the following acts, namely: (1) A breach of duty or loyalty to the corporation; (2) Any acts or omissions that are not in good faith or that involve intentional misconduct or a knowing violation of the law; (3) The authorizing of an unlawful payment or distribution out of the corporate assets; (4) Any transaction made in the furtherance of the exempt purposes of the corporation which the director derived an improper personal benefit; or (5) Any act or acts that can be 
defined under the laws of this State as "Director Conflicts of Interest".

2

\section{ARTICLE XII}

ANNUAL MEETING: The annual meeting of the Board of Directors is to be held at a place either within or without this State as fixed by the Bylaws.

\section{ARTICLE XIII}

DURATION: The existence of this corporation shall be perpetual unless sooner terminated as provided for by law.

\section{ARTICLE XIV}

NON-MEMBERSHIP PROVISIONS: The corporation shall not be a membership corporation with members, unless by a two-thirds vote of the Board of Directors, these Articles of Incorporation are so amended to change this corporation from a non-membership to a membership corporation with members.

\section{ARTICLE XV}

FISCAL YEAR: The fiscal year of the corporation shall end on of each year.

\section{ARTICLE XVI}

STATUTORY (RESIDENT) (REGISTERED) AGENT: The name and address of the initial Statutory (Resident) (Registered) Agent of this corporation is: day of 19 
2 STATE OF )

3

) SS.

4 County of ( )

$5 \quad$ On this the County of day of 19 , before me, the undersigned, a Notary Public in and for 7

8

known to me to be the person(s) whose name(s) is (are) subscribed to the foregoing ARTICLES OF , personally appeared: contained.

IN WITNESS WHEREOF, I hereunto set my hand and official seal.

\section{MY COMMISSION}

15 EXPIRES: 


\section{BYLAWS \\ of the \\ PHOTOVOLTAIC MODULE CERTIFICATION CORPORATION}

ARTICLE I

NAME AND SCOPE

1. The name of the corporation shall be the "Photovoltaic Module Certification Corporation," a not-forprofit corporation hereinafter referred to as "the Corporation ," or "PMCC."

2. The Corporation may, at its pleasure and by a majority vote of the membership body, change its name.

3. The main office of the Corporation shall be located in Anytown, State, as designated by the Board of Directors. A Registered Office and a Registered Agent shall be maintained consistent with the requirements for not-for-profit corporations in the State of Incorporation (STATE).

4. The scope of the Corporation's activities shall be international, although emphasis shall be placed on its national activities, and shall include liaison and cooperative developments with other organizations, institutions and corporations for the furtherance of its objective of promoting the certification of photovoltaic modules, and the sale of certified modules, produced by manufacturers from throughout the world.

\section{ARTICLE II PURPOSES AND OBJECTIVES}

The purposes and objectives for which the Corporation is organized are:

1. To develop and implement product certification programs for photovoltaic solar energy conversion modules used in the generation of electric power over a wide range of applications. The PMCC certification programs shall be open to any potential licensee from the photovoltaic module manufacturing community whose finished product is a market-ready module of a type and power level for which a certification program has been established, regardless of whether that module has been certified and labeled and/or marked by any other domestic or international photovoltaic module certification body.

2. Develop and/or adopt photovoltaic module test methods and consensus standards required for testing and evaluation of module reliability, durability and performance in accordance with the requirements adopted for the certification program. The development of any consensus standards that are needed, and which are not available within the domestic or international standards community, shall be done 
in cooperation with, and within the framework of, U.S. domestic standards bodies such as IEEE, ASTM, and ANSI (the U.S. National committee representative for the U.S. Technical Advisory Groups to ISO/TC 180 and IEC/TC 82).

3. Adopt photovoltaic module performance rating standards for photovoltaic modules.

4. To educate the public, public institutions, and private commercial organizations on the benefits of using Certified Photovoltaic Modules carrying the label, or mark, of PMCC.

5. To educate the public, public institutions, and private commercial organizations, on the advancements, improvements, uses, and benefits of photovoltaic solar energy conversion modules, systems and arrays.

6. To encourage and promote cooperation and understanding between PMCC and its counterparts in other nations and regions of the world, an example of the latter being Certification Bodies operating in the EEC. The objective of such cooperation shall be the establishment of Memorandums of Understanding (MOUs) providing for reciprocity between PMCC and regional photovoltaic module certification programs throughout the world.

7. To make available to any interested member of the photovoltaic industrial community descriptive material setting forth the Corporation's certification programs and its module rating standards, including Document PV-3.

8. To administer and manage testing, certification and labeling programs based upon Document PV-3 and whatever module rating standards are in place.

9. To award PMCC's certification mark, and concomitantly, the certification label, pursuant to Document PV-3 and the module rating standards, to qualified participants whose modules have been determined to be qualified for award of said mark and/or label.

\section{ARTICLE III}

\section{POWERS}

In furtherance, and not in limitation thereof, of the general powers conferred by the laws of STATE and the objectives and purposes herein set forth, it is expressly provided that the Corporation shall also have the following powers, viz:

1. To borrow or raise monies for any of the purposes of the Corporation and, from time to time, without limit as to amount, to draw, make, accept, endorse, execute and issue promissory notes, drafts, bills 
3 2. To purchase, lease, accept and receive by gift, device or bequest, hold, sell, mortgage, or otherwise

of exchange and other negotiable and nonnegotiable instruments and evidences of indebtedness. acquire, dispose of or deal in real and personal property of all kinds, except that the acceptance and receipt of gifts, devices or bequests shall not pose either the appearance or fact of a conflict of interest, or contravene either these Bylaws or the laws of STATE.

3. To enter into, make, perform, carry out and enforce any contract, agreement or transaction which it may desire to enter into, pursuant to any of its general purposes, with any persons, firm, association, trust or corporation, and to do and perform any and all of the objectives and purposes of the Corporation not forbidden by its Certificate of Incorporation or these Bylaws, or by the laws of the United States of America or STATE.

4. To have offices and promote and accomplish its objectives and purposes within or without STATE, in other states and the territories, colonies, possessions and dependencies of the United States of America as well as in foreign nations.

5. Subject to the provisions of its Articles of Incorporation and these Bylaws, to do, perform and engage in such other acts, things, business, transactions and operations as may be incidental to, or that may facilitate, the business and general purposes of the Corporation.

To have all of the powers conferred upon a corporation by the laws of STATE, except as herein prohibited or forbidden and to do any and all of the things hereinbefore set forth, to the same extent as natural persons might or lawfully could do.

\section{ARTICLE IV \\ MEMBERSHIP}

1. The Corporation shall have no members.

\section{ARTICLE V \\ BOARD OF DIRECTORS}

1. Authority and Responsibility

1.1 The governing body of the Corporation shall be its Board of Directors.

1.2 The Board of Directors shall have supervision, control and direction of the affairs of the Corporation, its product certification and laboratory accreditation programs, its committees, and its publications. 
1 1.3 The Board of Directors shall determine the general policies of the Corporation, shall actively prosecute the objectives and purposes of the Corporation, and shall supervise the disbursement of its funds.

.4 The Board may adopt Rules and Regulations for the conduct of its business.

\section{Board Composition}

The Board of Directors shall be composed of eleven members.

2.2 Six members shall be from the commercial and industrial community, defined as "manufacturers, suppliers, dealers, distributors and individuals who are engaged in the manufacture, production, distribution and/or sale of components or finished product relating to photovoltaic modules and systems," and hereinafter referred to as Industry Sector Members. Industry Sector Members shall be nominated and elected by the Certification Program Participants (i.e., applicants and licensees).

Three members shall be from the public utility sector, defined as "employees or representatives of electrical utility companies," hereinafter referred to as Utility Sector Members. Utility Sector Members shall be nominated by the electrical utility industry, by individual public utilities, or by an association of electrical utilities, and shall be elected by the Certification Program Participants.

2.4 Two members shall be from the public sector, defined as "employees or representatives of public foundations, public interest groups, state organizations, states, or associations of states," and hereinafter referred to as Public Sector Members. Public Sector Members shall be nominated by their constituencies, and shall be elected by the Certification Program Participants.

\section{Alternates to the Board of Directors}

3.1 Alternates to the Board of Directors shall be nominated and appointed or elected to the Board of Directors in the same manner as other board members. Each sector (the Industry, Utility and Public Sectors) shall be represented by one alternate. Alternate Directors may vote only in the absence of a regular director from the constituency they represent.

\section{ARTICLE VI}

\section{INTERIM BOARD OF DIRECTORS}

The Interim Industry Sector board members shall be comprised of the Corporation's Incorporators as provided in the Articles of Corporation. These directors shall be the President, Secretary and Treasurer of the Corporation as therein provided. 
1 2. It shall be the first duty of the Interim Board of Directors to adopt these Bylaws and to announce and advertise, or cause to be announced and advertised, a solicitation of applications from the U.S.-based Industry Sector for participation in the PMCC photovoltaic module certification and labeling program.

It shall be the second duty of the Interim Board of Directors to announce and advertise, or cause to be announced and advertised, a solicitation for nominations to the PMCC Board of Directors as set forth in Article $\mathrm{V}$ of these Bylaws. The Interim Board shall thereafter accept nominations from the Industry, Utility and Public Sectors, including a sufficient number of nominations from the Industry Sector, to fill vacancies created by the resignations of said Incorporator Directors at the completion of their Interim duties, said resignations being either for personal reasons or by reason of failure of the Incorporator Director to meet the membership requirements of the full sitting Board as contemplated by these Bylaws. Two nominations shall be accepted for each seat on the Board of Directors, which shall include nominations of any Interim Board Member who desires to have his or her name placed on the ballot and who meets one of the Sector Requirements as defined in Article V, sections 2.3 through 2.5 .

3. Nominations for Alternate Directors shall not be accepted by the Interim Board of Directors.

4. If less than the required number of nominations are received from each of the three Sectors for the purpose of completing the Board of Directors, the Interim Board of Directors shall nominate two willing candidates who are known to represent each Sector for which an insufficient number of said nominations were received.

5. Not less than 75 days prior to the first annual meeting of the Corporation, the Chair of the Interim Board of Directors, who shall be elected by two of the three votes, or failing same shall be selected by lot, shall prepare and disseminate a ballot to all Applicants for participation in the PMCC Photovoltaic Module Certification and Labeling Program, and to all Industry Sector manufacturers who furnish a bona fide affidavit that they intend to apply within the next six months for participation in the program, said ballot to be for the election of the full PMCC Board of Directors in accordance with the terms specified in Article VII.

6. Ballots shall be due not less than 21 days prior to the annual meeting of the Corporation. The nominees within each of the three Sectors receiving the largest number of votes cast, as certified by the Chair of the Interim Board of Directors, shall be elected to the longest regular terms of the initial full sitting Board of Directors. The nominees receiving the next largest number of votes cast shall be elected to the next longest regular terms. The nominees receiving the next largest number of votes cast shall be elected to fill Alternate Board Member seats. Tie votes shall be decided by the newly elected Board of Directors in a mail ballot prior to the first annual meeting of the Corporation. 


\section{ARTICLE VII}

\section{TERMS OF OFFICE}

1. For the initial Board of Directors, four (4) Industry Sector, two (2) Utility Sector, and one (1) Public Sector members shall be selected for a two-year term; two (2) Industry Sector, one (1) Utility Sector, and one (1) Public Sector members shall be selected for a one-year term; and all alternates shall be selected for a one-year term.

2. Thereafter, Directors and Alternates shall be elected for a term of two (2) years.

3. The Interim Board of Directors shall assume office immediately upon adoption of these Bylaws. Terms of office for all elected Board Members shall commence at the beginning of the Annual Meeting of the Corporation following the notice of the election results.

4. Directors and Alternates shall hold office until the successor is duly elected and qualified, or until resignation, ineligibility, or removal.

5. Directors and Alternates shall be elected to fill the vacancies of the Directors whose terms are expiring.

\section{ARTICLE VIII VACANCIES \& REMOVAL}

1. Upon the occurrence of any vacancy in any office of the Corporation elected by the Program Participants, the Board may appoint one of its members to fill such office for the remainder of the original term.

2. The Board of Directors may remove a Director by affirmative vote of $67 \%$ of all of the Directors eligible to vote on grounds of disability, incapacity, failure to comply with these Bylaws, substantial failure to perform his or her duties as a Director, or any other act which is found to be prejudicial to the purposes, objectives, stature, or well-being of the Corporation.

3. Prior to the removal of a Director, there shall be submitted to such Director a written notice of the alleged ground for removal and the Director shall be offered the opportunity to answer such allegations in writing and to appear in person, or by counsel, at a hearing conducted by the Board of Directors.

4. The Board of Directors may undertake such investigation in connection with the consideration of the removal of a Director as it deems necessary or appropriate under the circumstances and may appoint a special committee for such purpose, or may delegate such investigation to a Standing Committee. 
4 1. The Board of Directors shall hold no less than one regular meeting each year. One meeting each year shall be designated as the Annual Meeting of the Corporation.

72 . The time and place of meetings shall be designated by the Chair of the Board of Directors. Notice of each regular meeting of the Board shall be sent by mail to each Director at least sixty (60) days in advance of said meetings.

3. Special meetings of the Board of Directors may be called by the Chair at a time and place he or she designates, and shall be called upon demand of the majority of the Directors at such time and place as such Directors designate. Notice of special meetings shall be sent by regular mail at least thirty (30) days in advance except that such meetings may be called with less notice given in case of emergency, providing the Chair can be assured that a quorum of the Board will be present.

4. Notices of special meetings shall state the purposes thereof and the questions and matters to be considered thereat.

1. A quorum at any meeting of the Board of Directors shall be constituted by the presence of at least seven (7) Directors, which shall include not less than four Industry Sector Members, at least two (2) Utility Sector Members, and at least one (1) Public Sector Member.

\section{ARTICLE XI}

\section{RULES}

Unless otherwise prescribed by these Bylaws, and if a quorum is present, any actions or decisions taken by the Board of Directors shall be valid providing it is affirmatively passed by a simple majority of those present. 


\section{ARTICLE XII}

\section{VOTING}

1. An affirmative vote in number greater than a two-thirds majority of all Directors eligible to vote shall be required to adopt or amend product certification and rating requirements and standards; operating guidelines for the certification program; and test laboratory accreditation standards, criteria and guidelines.

2. Such votes may be taken at regular or special meetings of the Board of Directors, or by telephone, or by facsimile, or by mail ballot. Votes may be by voice, hand or written, and mail, ballot. Voting by telephone shall be accompanied by tape recording of the vote, providing a voiced agreement of all of the parties thereto is recorded.

3. Directors shall be given no less than ten (10) days to vote. Votes received by mail or telephone shall be preserved by the Secretary of the Corporation until the next meeting of the Board of Directors and shall be recorded in the minutes of that meeting. Results of all such mail or telephone votes shall be mailed to all Directors within fifteen days after the deadline for receipt of mail votes or the recording of telephone votes.

4. Voting may not be by proxy. Alternates' votes may be counted as provided by these Bylaws.

\section{ARTICLE XIII}

\section{ABSENCES}

1. If any member of the Board of Directors is absent from two consecutive meetings, and the Board shall have determined that the reasons for such absence are insufficient, the Director's resignation shall be deemed to be tendered and accepted.

\section{ARTICLE XIV COMPENSATION \& REIMBURSEMENT OF EXPENSES}

1. No Director shall be paid any compensation for services to the Corporation, but the Board of Directors may authorize the reimbursement of any reasonable and customary expenses incurred by a Director in the performance of his or her duties.

2. Nothing herein contained shall be construed to preclude any Director from serving the corporation in any other capacity and receiving compensation therefor. 


\section{OFFICERS OF THE CORPORATION}

4 1. $\quad$ Officers

6 1.1 The elected officers of the Corporation shall consist of a Chair, a Vice Chair, a Secretary and a Treasurer. Only Directors of the Corporation shall be eligible to serve as elected officers of the Corporation, except that Alternate Directors shall not be eligible to service as elected officers.

1.2 The Board of Directors shall elect or appoint an Executive Director, who shall be a paid officer of the Corporation. The Executive Director shall be a nonvoting, ex-officio member of the Board of Directors.

1.3 The Board of Directors may also elect one of its own as President of the Corporation to provide a close working relationship with the Executive Director of the Corporation and the Corporation's office functions and staff.

\section{Nomination and Election of Officers}

2.1 The officers of the Corporation shall be elected annually at the Annual Meeting of the Board of Directors from a slate of nominees submitted by the Nominating Committee, a committee of the Board. New offices may be created and filled at any meeting of the Board.

2.2 Terms of office for elected Officers shall commence at the beginning of the Annual Meeting of the Corporation. Each Officer shall hold office until their successor shall have been duly elected and qualified. Members of the Board shall have served as a Director of the Corporation for a period of at least one year in order to be eligible for nomination to the office of Chair.

\section{Removal of Officers}

3.1 The Board of Directors may remove an Officer in the same manner as it may remove a Director (see Article VII).

\section{4. $\quad$ Vacancies}

4.1 If the office of Chair becomes vacant, the Vice Chair, if he or she is willing and able to serve, otherwise the Treasurer, if he or she is willing and able to serve, otherwise the Secretary, if he or she is willing and able to serve, otherwise a Director elected by the Board and willing and able to serve, shall become the Chair. Any vacancy in any other office shall be filled by the Board at its next regular Meeting, or at a special Meeting held in part or in its entirety for that purpose. 
14.2 An office shall be vacant if the holder of such office dies, resigns, becomes ineligible to hold such

$45 . \quad$ Compensation and Reimbursement of Expenses

5

$65.1 \quad$ No Officer shall be paid any compensation for service to the Corporation.

7

8 5.2 The Board may authorize reimbursement of any reasonable and customary expenses incurred by an 9 10

$115.3 \quad$ Nothing herein contained shall be construed to preclude any Officer from servicing the Corporation in 12 13 any other capacity and receiving compensation therefrom.

\section{ARTICLE XVI COMMITTEES OF THE BOARD}

\section{Establishment of Committees}

1.1 The Board of Directors shall have the power to create standing and special committees and/or task groups of the Corporation and to define, limit or enlarge the function of any such committee or task group consistent with these Bylaws.

1.2 The Chair shall appoint and remove any committee chair(s) and member(s) and fix the terms of such appointment(s) unless otherwise prescribed by these Bylaws.

1.3 The Board may assign any matter to any committee, make rules with respect to their governance not inconsistent with these Bylaws, and discharge or terminate any such committees.

1.4 The Board shall formulate and adopt General Rules of Procedure for Standing Committees with respect to their governance and shall ratify the specific Rules of Procedures for all Standing Committees.

1.5 Each Standing Committee may formulate its own specific Rules of Procedure, regulations and policies, subject to being consistent with the General Rules of Procedure for Standing Committees.

1.6 Any regulations or policies which affect the rights of the Program Participants, or privileges or obligations of the Program Participants, shall be subject to confirmation by the Board of Directors before becoming effective. 
32.1 Nominating Committee-The Nominating Committee for Officers of the Board of Directors shall be constituted on an annual basis not less than sixty days prior to the Annual Meeting of the Board. The Nominating Committee shall consist of three members of the Board who will be Directors at the Annual Meeting appointed by the Chair with the concurrence of the Board of Directors. The Nominating Committee shall nominate at least one candidate for each elective corporate office. All nominees shall then be consulted to determine their willingness to undertake the duties of the position to which the committee shall nominate them. Not less than fifteen days before the Annual Meeting, the Nominating Committee shall submit its recommended slate of candidates to the Board of

Directors. The candidates for each respective corporate office receiving the largest number of votes in the election of Officers held at the Annual Meeting, or as soon thereafter as conveniently possible, shall be elected.

2.2 Executive Committee-The Board of Directors may delegate such powers and authority to the Executive Committee, not inconsistent with the laws of STATE, or these Bylaws, as in its discretion is deemed warranted. Actions of the Executive Committee shall be reported to the Board of Directors for ratification at the next Board Meeting following said action, or actions. The Executive Committee shall consist of not less than three nor more than five members and shall be chaired by the Corporation's President, who may also be the Chair of the Board of Directors, and its members shall consist of all duly elected officers, and the Executive Director, who shall have voting rights. In addition to the Officers of the Board, and the Executive Director of the Corporation, the Board may elect up to two members to the Executive Committee who are not duly elected Officers of the Corporation to serve on the Executive Committee. Failing to elect said additional members, the Chair may appoint additional members to complete the roster of up to five members of the Executive Committee. The President, or if none, the Chair of the Board, shall preside. A majority of the members of the Committee shall constitute a quorum for the transaction of business and any action taken shall be valid providing it is affirmatively passed by a majority of the members of the entire Executive Committee. Vacancies shall be filled in the manner prescribed by Article XIV section 4.

\section{3. $\quad$ Standing Committees}

3.1 Technical Committee-The Technical Committee shall be responsible for the continued maintenance of the test methods, rating methodologies, and minimum criteria for certification. The Chair of the Technical Committee may be the Corporation's Technical Director, if such person is employed by the Corporation, or may be employed by one of the Program Participants. The committee shall serve as the Corporation's liaison to the relevant committees of domestic and international standards-writing bodies, which shall include ASTM, IEEE, and IEC, and shall keep the Board of Directors apprised of domestic and international standards, methodologies, and developments of procedures which may affect the Corporation's product certification programs. The Technical 
Committee shall be charged with maintenance of Document PV-3 and, additionally, shall perform such other duties and tasks as may be assigned by the Chair or the Board of Directors.

Laboratory Accreditation Committee--The Laboratory Accreditation Committee shall be charged with defining and implementing, and thereafter continually monitoring and overseeing, the Corporation's Laboratory Accreditation Program, including the maintenance of Document PV-1. The Committee's Chair may be employed by one of the Participants in the Certification Program.

Product Certification Committee-The Product Certification Committee shall be charged with defining and implementing, and thereafter continually monitoring and overseeing, the Corporation's Certification Procedures, which are the operational procedures developed on the basis of Document PV-2. This Committee shall also have the responsibility for maintaining Document PV-2, and any changes required thereto as a result of changes to ANSI Z34.1 and ISO Guide 28. This committee shall be composed of the Chairpersons of all other Standing Committees of the Corporation.

3.4 Committee on Manufacturer's Quality-System Compliance-The Committee on Manufacturer's Quality-System Compliance shall be charged with defining and implementing, and thereafter continually monitoring and overseeing, the requirements of Section 6 of Document PV-2. The principal requirement for selection of the Chair shall be that the person chosen shall have background in quality system management, compliance, or auditing (either internal or external). This Committee shall use Quality-System Assessors who are not employed by a Certification Program Participant either as an employee or consultant in any capacity.

3.5 Committee on Licensing Compliance-The Committee on Licensing Compliance shall be responsible for defining and implementing the Corporation's provisions for licensing its Certification Mark and Certificate and for development of procedures for monitoring compliance by Participant manufacturers, and for review of licensing violations brought to its attention.

Audit and Finance Committee-The Audit and Finance Committee shall be Chaired by the Treasurer of the Corporation, and shall include the Executive Director of the Corporation as a voting member. The duties of the Committee shall include (1) preparation of industry audits of product sold, which shall include compliance estimates related to revenues received from participants based on product sold, and (2) preparation, annually and as otherwise requested by the Chair or the Board of Directors, of recommendations for approval by the Board of the orderly receipt, expenditure and disbursement of the Corporation's funds. The Committee shall be responsible for the preparation and submittal of the Corporation's annual budget. The Committee shall also from time to time review income and expenditures to ensure that the Corporation's objectives can be adequately met. 
13.7 Committee on Appeals and Disputes-The Committee on Appeals and Disputes shall be chaired by the President of the Corporation, who may be the Chair of the Board of Directors, and shall be comprised of Board Members or employees of Program Participants who do not serve on other Standing Committees.

Article XVII

\section{CORPORATE SEAL}

1. The Board of Directors shall provide a suitable seal containing the name of the Corporation and the place and year of incorporation.

2. The Corporate Seal shall be maintained in the custody of the Secretary of the Corporation, or the Secretary's designee.

Article XVIII

\section{FISCAL YEAR \& AUDIT}

1. The fiscal year of the Corporation shall be from January 1 through December 31.

2. An audit of the books and records of the Corporation shall be made at least every five years by a Certified Public Accountant and a copy of the audit shall be available in the administrative offices for inspection by any Director of the Corporation.

\section{Article XIX}

\section{DISSOLUTION OF THE CORPORATION}

1. In the event of the dissolution or final liquidation of the Corporation, the Board shall, after making provisions for the payment of all liabilities of the Corporation, dispose of all the assets of the Corporation in such manner, or to such organization or organizations organized and operated exclusively for charitable, educational or scientific purposes as shall at the time qualify as an exempt organization or organizations under Section 501(c) of the Internal Revenue Code, or the corresponding provision of any United States Internal Revenue Law in force at the time, as the Board shall determine. 


\section{$41 . \quad$ Contracts}

6 The Board may authorize its Administrative Staff, any Officer or Officers, agent or agents of the Corporation, in addition to the Officer so authorized by these Bylaws, to enter into any contract or execute and deliver any instrument in the name of and on behalf of the Corporation.

$10 \quad 1.2$ Such contract authority may be general or confined to specific issues at hand.

2. Checks, Drafts, and Deposits

13

2.1 All checks, drafts or other orders for payment of money, or notice of other evidence of indebtedness incurred in the name of the Corporation, shall be signed by such Officer, or Officers, Agent or Agents of the Corporation in such manner as shall from time to time be determined by resolution of the Board of Directors.

2.2 All funds of the Corporation shall be deposited from time to time to the credit of the Corporation bank or trust company, or other depositories, as the Board of Directors my select.

3. Non-profit Character

3.1 The Corporation shall not afford any pecuniary gain, incidentally or otherwise, to its Directors, elected Officers, or committee volunteers.

3.2 The Corporation's directors, officers and committee volunteers shall have no personal liability for carrying out their corporate duties and obligations.

Article XXI

\section{BOOKS \& RECORDS}

1. The Corporation shall keep correct and complete books and records of accounts, and shall also keep minutes of the proceedings of its Board, and shall keep at its registered or principal office a record giving the names and addresses of those entitled to vote. All books and records of the Corporation may be inspected by any Director or the Director's agent or attorney for any proper purpose at any time within normal business hours. 
The Corporation shall indemnify, either via the corporation or through a suitable liability insurance carrier, to the extent permitted by the laws of STATE, every individual who has been or now is (1) a duly appointed or elected Director or duly appointed or elected Alternate of the Corporation; or (2) a duly elected or appointed Officer of the Corporation; or (3) an employee of the Corporation in the performance of the Employee's specified duties; or (4) any person who may have been or is now serving the Corporation at the Corporation's request as a representative, Director, or Officer of another corporation, whether for profit or not for profit.

2. The individuals identified in the previous paragraph shall be indemnified against expenses actually and necessarily incurred by him, or her, in connection with the defense of any action, suit or proceeding in which he, or she, is named a party by reason of being or having serviced in such capacity as described above, except in relation to matters to which he, or she, shall be adjudged in such action, suit or proceeding, to be liable for negligence or misconduct in the performance of a duty.

3. Such indemnification shall not be deemed exclusive of any other rights to which such individual, or individuals, may be entitled under any Bylaw, agreement, vote of the Board of Directors, or otherwise.

\section{Article XXIII}

\section{AMENDMENTS TO BYLAWS}

1. These Bylaws by be altered, amended, or repealed by affirmative majority vote of two-thirds of all Directors eligible to vote if at least fifteen day's written notice is given of the intention to alter, amend, repeal or adopt new Bylaws prior to convening a Meeting of the Board of Dixectors for the stated purpose, or where one of the stated purposes, is to so alter, amend, repeal or adopt new Bylaws.

\section{Article XXIV}

\section{AMENDMENTS TO THE ARTICLES OF INCORPORATION}

1. Amendments to the Articles of Incorporation shall be made in the following manner: The Board of Directors shall adopt a resolution setting forth the proposed amendment and directing that it be submitted to a vote at the next meeting of the Board of Directors. Written notice setting forth the proposed amendment or a summary of the changes to be affected thereby shall be given to each Director entitled to vote at least 30 days prior to the Meeting of the Board of Directors at which the proposed amendment is to be considered. The proposed amendment shall be adopted upon receiving the affirmative vote of at least two-thirds of all Directors eligible to vote. 
for

\section{Standing Committees}

6

\section{SECTION 1: AUTHORITY}

1.1 By the authority of the Photovoltaic Module Certification Corporation (PMCC) Board of Directors, the Executive Committee has duly constituted the establishment of standing committees.

1.2 These Rules of Procedure shall govern the operations of each standing committee.

1.3 These rules may be modified by each standing committee to meet its particular needs but may not be modified in any manner which would contravene the purpose and objectives of PMCC as defined by the Board of Directors, or which would substantively alter the due process rights afforded herein. Any modifications proposed by a standing committee must be approved by a two-thirds majority of the voting members of the standing committee, and by a two-thirds majority of the voting members of the PMCC Board of Directors, and by a two-thirds majority of the Participating Manufacturers in the Certification Program.

\section{SECTION 2: SCOPE AND OBJECTIVES}

2.1 Each standing committee is to perform the functions and fulfill the responsibilities assigned to it by the PMCC Executive Committee, acting for the Board of Directors.

2.2 The standing committees shall develop standards and protocols, and shall render decisions which insure the greatest benefit for the largest number, yet protect all interests and not seriously injure anyone.

2.3 The standing committees shall not engage in influencing enactment of building or other codes, or in propaganda, or in other activities designed to influence legislation.

\section{SECTION 3: ORGANIZATION}

3.1 Each standing committee shall, at its first meeting, set forth in detail its proposed scope and objectives in a manner consistent with the scope and objectives more generally set forth by PMCC in establishing any such standing committee. Upon adoption of its specific rules of procedure and its proposed scope and objectives by a two-thirds majority of the voting membership of the standing committee, said proposal shall be submitted to PMCC for review, modification if necessary, and 
approval. Once approved by PMCC, the proposed scope and objectives shall be set forth as Attachment " $\mathrm{A}$ " thereto and shall be incorporated into the rules of procedures with the same force and effect as if originally included therein.

3.2 Every good-faith effort shall be made to have the membership of the standing committee reasonably balanced so as to include representation of various affected interests, except to the extent that certain classes of members who represent affected parties may be excluded from membership on certain committees because of conflicts of interest.

3.3 The standing committee officers shall consist of a Chair, Vice Chair and Secretary. The Chairs of standing committees shall be appointed by the President of PMCC. The Vice Chairs and Secretaries of standing committees shall be appointed by the Chairs of the affected standing committees and shall be approved by a simple majority of both the PMCC Board of Directors and members of the standing committee.

3.4 If the Chair is absent, the Vice Chair shall preside. If both the Chair and the Vice Chair are absent, the committee shall select one of its members to act as temporary Chair. Any standing committee member may hold more than one of the offices described herein.

3.5 Subcommittees may be established by each standing committee as required.

3.6 The standing committee Chairs shall be from Participating Manufacturers in the PMCC Certification Program.

3.7 Standing committees may be added, or eliminated, at the discretion of the President of PMCC upon approval by a simple majority of the Board of Directors. Currently active standing committees shall be listed, along with brief scope statements, in Appendix 1 attached hereto.

\section{SECTION 4: $\quad$ SPECIFIC DUTIES OF THE COMMITTEE}

4.1 The specific duties of each standing committee shall be specified by the President and approved by the Board of Directors of PMCC.

4.2 These specific duties shall be framed in suitable language and contained in Section 4, Specific Duties of the Committee, Specific Rules of Procedure, for each standing committee. 
SECTION 5: DUTIES OF COMMITTEE OFFICERS AND MEMBERS

2

$3 \quad 5.1 \quad$ CHAIR

5 5.1.1 The standing committee Chairs shall be appointed by the President of PMCC.

6

7 5.1.2 Committee Chairs shall:

8

5.1.2.1 Preside at all meetings.

5.1.2.2 Prepare agendas for all meetings.

5.1.2.3 Be charged with the responsibility of ensuring that detailed written records of discussions, including minutes of committee meetings, decisions, drafts of proposed documents, amendments thereto, and dissenting opinions are accurately kept by the Secretary, forwarded to the President and Executive Director of PMCC and made accessible to all Participating Manufacturers and the public. 1

5.1.2.4 Ensure that reports on the activities and progress of the standing committees are prepared and submitted to the President and Executive Director on a regular basis.

5.1.2.5 Appoint such subcommittees as necessary to assist in the operation of the committee. All actions of such subcommittees are subject to confirmation by the full committee and by the President of PMCC.

5.1.2.6 Notify the Executive Director and President in the event that any committee member has failed to attend two consecutive committee meetings or failed to cast a vote on any written ballot.

5.1.2.7 Review and, if satisfied, submit, with approval, invoices reflecting expenses incurred by technical committee and subcommittee members to the Executive Director of PMCC for payment if payment of expenses has been authorized by the Executive Director.

5.1.2.8 Be an ex-officio, nonvoting, advisory member of all subcommittees and working groups.

${ }^{1}$ N.B. While the deliberations and actions of the PMCC must be "open" to public scrutiny, the actual procedures for ensuring "openness" should be reviewed by competent counsel. 
$15.2 \quad$ VICE CHAIR

2

3 5.2.1 Committee Vice Chairs shall be appointed by the respective Committee Chairs and approved by the PMCC Board of Directors and members of the applicable committee.

5

6 5.2.2 The Vice Chairs shall:

7

\subsection{SECRETARY}

5.3.1 Committee Secretaries shall be appointed by the respective Committee Chairs and approved by the PMCC Board of Directors and members of the applicable committee.

5.3.2 The Secretaries shall attend all meetings of the applicable committee, and keep the minutes thereof, and shall circulate copies of minutes of committee meetings to members of the applicable committee, and to the Executive Director, President, and designated counsel of PMCC on a timely basis.

5.3.3 The Secretaries shall issue notices of meetings; conduct correspondence for the applicable committee; inform subcommittee members of their appointments and duties; and keep a complete list of the members of the applicable committee and subcommittees. All committee records shall be available for public review.

\subsection{COMMITTEE MEMBERS}

5.4.1 With the advice and consent of a simple majority (more than 50\%) of the Board of Directors and of the voting Participating Manufacturers, Committee Chairs shall appoint the officers and members of the respective standing committees.

\subsubsection{Committee members:}

5.4.2.1 Are expected to attend all meetings of their respective committees and to respond diligently to all correspondence.

5.4.2.2 Shall act as Chair, Vice Chair and/or Secretary of a subcommittee, if appointed. 
5.4.2.3 Shall act as Liaison to other standing committees, if appointed.

5.4.2.4 Shall responsibly and diligently exercise voting privileges and cast a vote on each ballot issued for the applicable committee.

5.4.2.5 Shall promptly notify either the President and Executive Director of PMCC of any procedural irregularities he or she may have reason to believe exist. If not satisfied with resolution of the matter, he or she may petition to the PMCC Board of Directors for review of the determination rendered by the President and Executive Director.

5.4.2.6 Shall notify the Executive Director of PMCC in the event that the Chair of the applicable committee has failed to attend two consecutive committee meetings, or has failed to cast a vote on any written ballot.

\section{SECTION 6:}

\section{REMOVAL OF MEMBERS OF STANDING COMMITTEES}

Should a standing committee member fail to attend two consecutive committee meetings or fail to cast a vote on two consecutive written ballots, either personally or through a properly appointed alternate, or proxy, the President of PMCC, upon being so notified by the Standing Committee Chair, shall consider, and may direct with the approval of a two-thirds majority of the members of the Board of Directors, that said member shall be removed from the standing committee.

Should the absent or nonvoting member of a standing committee be the Chair of the said committee that fails to meet the criteria stated in paragraph 6.1 , it shall be the responsibility of the standing committee as a whole, or any member thereof, to notify the President and the Executive Director of PMCC.

\section{SECTION 7: $\quad$ MEETINGS}

7.1 The standing committees shall meet at least twice annually or as otherwise directed by the President of PMCC, or the Executive Director acting on behalf of the President. Notice must be given committee members at least 60 days in advance of the meeting. A proposed agenda shall accompany the notice of meeting.

Additional meetings may be called by the Chairs of the respective standing committees, and must be called by the Chair of any standing committee at the request of more than $50 \%$ of the committee membership. Notice must be given to committee members 30 days in advance of the meeting when practical. For emergency meetings, a minimum notice of 48 hours will be provided. During periods in which PMCC may be under any contractual obligation to develop standards, procedures, protocols or other documentation, each standing committee involved in the development of said standards, 
procedures, protocols, etc., shall meet in accord with a schedule to be prepared by the standing committee and approved by the President of PMCC, said schedule to meet the minimum requirements of such contracts.

A minimum of a two-thirds majority of the committee membership must be present at each meeting in order to conduct business. Proxies shall not be permitted. A committee member may designate in writing to the Chair an alternate to represent the member at specific committee meetings. Any such alternate, if approved by the committee, shall have voting power and shall be counted as a member in attendance for the purpose of determining a quorum and conducting business. The President of PMCC shall be promptly notified of all such alternates.

The rules contained in Robert's Rules of Order ${ }^{2}$ shall govern the committee in all cases to which they are applicable and in which they are not inconsistent with the Rules of Procedure of the applicable committee as stated in its Specific Rules of Procedure.

All interested parties, including members of the general public, shall be permitted to attend meetings of the following standing committees: Executive Committee, Technical Committee, Laboratory Accreditation Committee, and Product Certification Committee (see Footnote 1, Section 5.1.2.3). The Chair may recognize any observer for the purpose of permitting succinct oral comments on relevant points, provided the orderly conduct of the meeting will not be disrupted. However, written comments by observers attending meetings shall be encouraged and shall be duly accepted and considered.

7.5 All dissenting views and the reasons in support thereof shall be stated with particularity. After consideration, written comments shall be prepared in response to all dissenting viewpoints, indicating action taken by the committee and the reasons therefor. All such dissenting views and actions taken by the committee in response thereto shall be duly recorded and maintained in the minutes of the meetings.

The committees shall at all times maintain complete records including minutes of all meetings. These records shall include copies of all voting ballots, dissenting opinions and replies thereto, and all alternative viewpoints considered by the committee.

7.7 Each standing committee shall submit regular reports to the President and the Executive Director detailing the activities and progress of the committee. Such reports may be presented in the format required by the President of PMCC.

2Based on Robert's "Rules of Order," the monograph by O. Garfield Jones "Parliamentary Procedure at a Glance, New Edition," LCCCN 77-161641, Hawthorn Books, 260 Madison Ave., New York, NY 10016, 1971. 
17.8 During periods in which PMCC is under any contractual obligation to develop standards, procedures, protocols, documentation, etc., each standing committee involved in the development of said documentation shall submit a progress report to the President of PMCC on a monthly basis, and shall submit their required contributions to any technical or other reports required by the contract to be furnished by PMCC to the contracting sponsor.

\section{SECTION 8: VOTING PROCEDURE}

8.1 All votes relating to standards, procedures, and protocol approval shall be by written ballot. The Secretary of the said committee shall prepare a written ballot for each vote to be taken by members of the affected committee at the request of the Chair, or upon the request of more than $50 \%$ of committee members, presented to the Secretary through the Chair of any standing committee.

8.2 The ballots must provide sufficient information to permit an informed vote on a proposed standard, procedure, protocol, etc. The ballot must include the following four options with the accompanying description of each option.

(1) Vote Affirmative

(2) Vote Affirmative with Comment

a) Member agrees with the standard but desires to make editorial changes such as word and sentence clarification, styling, metric equivalents, etc.

Vote Negative

a) A negative vote requires a reason to be validated.

b) Member must give a specific and detailed discussion of the objection to the standard, procedure, protocol, or document, or to specific language in said standard, procedure, protocol, or document, substantiating his or her position with appropriate data and references.

(4) Vote Abstain

a) Member lacks expertise.

b) Abstention by ballot helps validate due process because it is included in computing the number of ballots required to validate all voting.

8.3 Each committee member shall be provided one ballot. The ballots shall be returned by hand, through the mail, or by facsimile, to the Secretary of the committee, who shall compile the results and notify the Chair of the committee. A voting member must be permitted a minimum of 30 days to return any ballot. The Chair shall inform the membership of the committee, and the President and Executive Director of PMCC, of the results as promptly as possible.

8.4 A minimum return of $90 \%$ of the ballots, or ballots from all committee members except one, whichever is the lesser number, is required to validate the vote on a ballot. A minimum of a two-thirds majority of the sum of the affirmative and negative votes cast must be affirmative for the standard, 
procedure, protocol or document to be accepted by the committee. The number of abstentions returned shall not exceed one third of all ballots mailed in order for the results to be considered valid.

8.5 The committee must consider all the negative votes and comments appearing thereon. Each negative vote will be discussed and classified as either:

(1) Non-Related, or Non-Relevant

a) Negative votes that lack any meaningful comment.

b) By a vote of a two-thirds majority of the members present and voting, the committee can vote to overrule the objection and to disregard it.

(2) Non-Persuasive

a) Opinion is poorly supported, or in obvious error.

b) By a vote of a two-thirds majority of the members present and voting, the committee can vote to overrule the objection and to disregard it.

(3) Uphold

a) The standard, procedure, protocol or document shall be revised in accordance with the objection if:

b) A two-thirds majority of the members present and voting uphold the objection. If so, the standard, procedure, protocol or document will be sent to the appropriate standing committee, subcommittee or task group, with appropriate comment, for revision. If returned to a subcommittee, the standard should be re-submitted for approval to the applicable standing committee with a new subcommittee or task-group ballot.

8.6 All requirements set forth herein relating to written ballots shall apply to written ballots issued for voting by subcommittees and task-groups of standing committees.

\section{SECTION 9: PROCEDURE FOLLOWING APPROVAL OF PROPOSED STANDARDS, PROCEDURES,} PROTOCOLS, DOCUMENTS, ETC.

9.1 Upon the approval of any proposed standards, procedures, protocols, or documents, the affected standing committee shall submit a final report to the President of PMCC for review and approval by the Board of Directors. The final report shall include:

(1) The data considered by the committee.

(2) The data supportive of and contrary to the proposed standard, procedure, protocol or document.

(3) Results of the balloting.

(4) The recorded objections to the proposed standard, procedure, protocol or document.

(5) Copies of all the committee minutes.

(6) Names and affiliations of the members who worked on the affected standing committee.

(7) Identification of all organizations or individuals who are not members of PMCC or a standing committee who participated in development of the proposed standard, procedure, protocol or 
document, as well as a description of the extent of the participation of any such organizations.

Any such additional information or reports as may be requested by the President or the Executive Director, or a Board Member of PMCC.

\section{SECTION 10: PROCEDURAL REVIEW AND APPEAL}

Special procedures as required by the scope and duties of specific standing committees as defined in the Specific Rules of Procedure for specific standing committees.

10.1 The PMCC Board of Directors, serving as the sponsoring group for photovoltaic module certification standards, procedures, protocols and documents developed by the standing committees of PMCC, is vested with and retains the ultimate responsibility for insuring that said standards, procedures, protocols and documents are developed, reviewed, revised or withdrawn in a fair and equitable manner and that all interests are adequately represented in any such action.

10.2 The scope of review by the PMCC Board of Directors, with the exception of the determination of whether new standards, procedures, protocols and documents shall be developed, shall be limited to the determination that all rules of procedure are being, or have been, diligently adhered to by the staff of PMCC and the standing committees and all duly established subcommittees. PMCC shall not initiate the development of new standards, procedures, protocols and documents without the approval of the PMCC Board of Directors.

10.3 Any interested person claiming to be adversely affected by these Rules of Procedure, or failure to comply with these Rules of Procedure, may petition the PMCC Board of Directors for review.

10.4 If a member of a standing committee has reason to believe that procedural irregularities exist, the member shall first notify the President, or Executive Director, of PMCC. If not satisfied with the resolution offered by the President and/or the Executive Director, the member may petition the PMCC Board of Directors for review of the matter.

10.5 The PMCC Board of Directors shall entertain all appeals relating to procedural matters, including appeals related to committee balance and representation of affected interests. The Board shall promptly decide on each petition and issue a written response.

10.6 Upon completion of the procedural review and final determination by the PMCC Board of Directors that these Rules of Procedure have been fully met, the Board shall direct the Executive Director to arrange for final publication of the approved standards, procedures, protocols or documents. 
1

3

4

5

61 Executive Committee

7 2. Technical Committee

$83 . \quad$ Laboratory Accreditation Committee

94 Product Certification Committee

$105 . \quad$ Committee on Manufacturer's Quality-System Compliance

$116 . \quad$ Committee on Licensing Compliance

$127 . \quad$ Audit and Finance Committee

13 8. Appeals Board

Appendix 1

Standing Committees

of the

Photovoltaic Module Certification Corporation (PMCC)

14 


\section{SECTION 1: AUTHORITY}

7

8 By the authority of the Photovoltaic Module Certification Corporation (PMCC) Board of Directors,

\section{Photovoltaic Module Certification Corporation (PMCC)}

Specific Rules of Procedure

for the

\section{APPEALS COMMITTEE}

1.2 These Rules of Procedure shall govern the operations of the Appeals Committee.

1.3 Except as provided herein, the General Rules of Procedure for Standing Committees are incorporated by reference in these rules, and shall be deemed to apply to the conduct of the affairs of the Appeals Committee. In the event of a conflict between specific provisions of the General Rules and these Rules of Procedure, the applicable provisions of these Rules of Procedure for the Appeals Committee shall take precedence.

\section{SECTION 2: $\quad$ SCOPE AND OBJECTIVES}

2.1 The Appeals Committee shall have overall responsibility for resolution of disputes, complaints and appeals.

2.2 The Board of Directors shall approve of resolutions of all disputes, complaints and appeals.

2.3 The Appeals Committee shall receive, hear, consider and attempt to resolve the following:

2.3.1 Appeals of decisions affecting participating manufacturers.

2.3.2 Disputes between a program-accredited testing laboratory and an applicant, or participating, manufacturer.

2.3.3 Disputes between participants and the Executive Director, or staff, of the PMCC.

2.3.4 Complaints from third parties such as purchasers of PMCC-certified product, other end users, or other manufacturers.

2.3.5 Complaints referred to the Appeals Committee by other Standing Committees of the Corporation. 
3 3.1 Members of the Appeals Committee may also be members of the PMCC Board of Directors, but may 4 not be members of any other Standing Committee of the Corporation.

5

63.2 The Chair shall be appointed by the President of PMCC.

7

8 3.3 The Appeals Committee shall consist of not less than five nor more than seven members deemed by

9 the Committee Chair and the Board of Directors to have the requisite background, education, and experience 10 pertinent to the Corporation's Photovoltaic Module Certification Program. At least three members of the Appeals Board shall have a technical background with a knowledge of photovoltaic technologies.

\section{SECTION 4: $\quad$ SPECIFIC DUTIES OF THE APPEALS BOARD}

4.1 As its first items of business, the Appeals Committee shall ratify and adopt, or revise subject to approval by the Board of Directors, the Procedures for Handling Complaints, Appeals and Disputes contained in Document PV-4 Operational Procedures Manual - Photovoltaic Module Testing. Certification and Labeling Program.

4.2 The types of appeals that will be accepted for resolution shall include:

\subsubsection{Denials of participation.}

4.2.2 Denials of certification.

4.2.3 Disputes relating to test results.

4.2.4 Disputes relating to rated performance levels.

4.2.5 Disputes of audited findings of product sold.

4.2.6 Complaints from third parties, other committees, etc.

4.3 The Appeals Committee shall have the prerogative of calling for opinions from qualified outside consultants, and shall as a matter of course request the consultation of the Chairman of the affected Standing Committee.

37

\section{SECTION 5: GENERAL PROVISIONS}

395.1 Sections 5 through 10 of the General Rules of Procedure for Standing Committees are incorporated by reference and shall be deemed as the rules of procedure for the Appeals Committee. 
Rules of Procedure

for the

\section{AUDIT AND FINANCE COMMITTEE}

7 SECTION 1: AUTHORITY

9 1.1 By the authority of the Photovoltaic Module Certification Corporation (PMCC) Board of Directors, the Executive Committee has duly constituted the establishment of an Audit and Finance Committee.

2.2 The Audit and Finance Committee shall establish liaison with the Audit and Finance Committee with respect to (1) the format and structure of the License Agreement, and (2) keeping the Audit and Finance Committee informed of audit results of certified product sold.

2.3 The Audit and Finance Committee shall ensure that (1) the application fees, manufacturer's plant inspection fees, and licensing fees charged by PMCC are sufficient to maintain a positive cash flow and to provide adequate reserves for the Corporation, and (2) to the extent possible the manufacturers report accurately the annual volume of certified product sold.

\section{SECTION 3: ORGANIZATION}

3.1 The Chair shall be the Treasurer of the Corporation. 
$1 \quad 3.2$ The Audit and Finance Committee shall consist of not less than five ${ }^{1}$ nor more than seven members deemed by the Committee Chair and the Board of Directors to have the requisite financial, budgeting and administrative backgrounds and education, or experience in lieu thereof, pertinent to the Corporation's Photovoltaic Module Certification Program.

$84.1 \quad$ As its first items of business, the Audit and Finance Committee shall:

4.1.1 Establish the structure and level of the fees that shall accompany Applications for Certification by PMCC.

The Audit and Finance Committee shall apply its auditing procedures to all participating manufacturers on a regular, periodic basis as an ongoing responsibility of the Committee.

4.1.2 Establish the site inspection and quality system assessment fees associated with the evaluation of Applicant's ability to consistently manufacture quality product, and establish the upper limit to laboratory test fees that will be charged to Applicants (providing contracts between PMCC and the testing laboratory(ies) are used).

4.1.3 Establish the basis for, and level of, the compensation to be rendered to PMCC by participating manufacturers for the license (license fee) giving the manufacturer the right to use PMCC's Mark, or label, and/or Certificate of Conformity.

4.1.4 Establish the method and frequency by which manufacturers will report the quantity of certified product sold on an annual basis.

4.1.5 Establish and maintain the method of audit, and the depth (completeness) of audit, designed to ascertain the veracity of the manufacturer's reports of certified product sold.

4.3 The Audit and Finance Committee shall have as a minimum the following additional duties:

4.3.1 Notification of the Committee on Licensing Compliance of any and all discrepancies found in auditing manufacturer's reports of product sold.

${ }^{1}$ It is anticipated that, during the first several months after the formation of this committee, five members may not be readily available to serve on this committee. If so, it will then be necessary for the Committee to modify these rules to coincide with the number of persons available to serve, but in no event shall the number of members be less than three. 
4.3.2 Notification of the Committee on Licensing Compliance of any and all discrepancies found either in other auditing techniques that may be developed, or in any third-party notifications that are brought to the attention of the Audit and Finance Committee.

5 4.3.3 Provide budget projections at regular intervals to the Executive Director, the President and the Board 6 of Directors of the Corporation.

7

8 SECTION 5: GENERAL PROVISIONS

105.1 Sections 5 through 10 of the General Rules of Procedure for Standing Committees are incorporated by 11 reference and shall be deemed as the rules of procedure for the Audit and Finance Committee. 


\section{Photovoltaic Module. Certification Corporation (PMCC)}

\section{Specific Rules of Procedure \\ for the \\ LABORATORY ACCREDITATION COMMITTEE}

\section{SECTION 1: $\quad$ AUTHORITY}

1.1 By the authority of the Photovoltaic Module Certification Corporation (PMCC) Board of Directors, the Executive Committee has duly constituted the establishment of a Laboratory Accreditation Committee.

1.2 These Rules of Procedure shall govern the operations of the Laboratory Accreditation Committee.

1.3 Except as provided herein, the General Rules of Procedure for Standing Committees are incorporated by reference in these rules, and shall be deemed to apply to the conduct of the affairs of the Laboratory Accreditation Committee. In the event of a conflict between specific provisions of the General Rules and these Rules of Procedure, the applicable provisions of these Rules of Procedure for the Laboratory Accreditation Committee shall take precedence.

\section{SECTION 2: SCOPE AND OBJECTIVES}

2.1 The Laboratory Accreditation Committee shall define and implement, and thereafter continually monitor and oversee, the Corporation's Laboratory Accreditation Program.

2.2 The Committee shall maintain Document PV-1 by ensuring that its provisions continually reflect changes in the published requirements of ISO Guides 25 and 38.

2.3 The Laboratory Accreditation Committee shall, as one of its first action items, initiate contact with American Association for Laboratory Accreditation (A2LA), which shall be requested to provide laboratory assessments and accreditation services in support of the Corporation's Photovoltaic Module Certification Program, said laboratory assessments to conform to PMCC Document PV-1.

\section{SECTION 3: ORGANIZATION}

3.1 The Laboratory Accreditation Committee shall consist of not less than five ${ }^{1}$ nor more than seven

1It is anticipated that, during the first several months after the formation of this committee, five members may not be readily available to serve on this committee. If so, it will then be necessary for the Committee to modify these rules to coincide with the number of persons available to serve, but in no event shall the number of members be less than three. 
members deemed by the Committee Chair and the Board of Directors to have the requisite technical background and education, or experience in lieu thereof, in laboratory practices dealing with photovoltaic technologies pertinent to the Corporation's Photovoltaic Module Certification Program.

\section{SECTION 4: SPECIFIC DUTIES OF THE LABORATORY ACCREDITATION COMMITTEE}

4.1 As its first items of business, the Laboratory Accreditation Committee shall:

4.1.1 Accept and ratify, or modify, and adopt PMCC Document PV-1, entitled Criteria for a Model Quality System for Laboratories Engaged in Testing Photovoltaic Modules.

4.1.2 Provide for the notification, or advertisement, of the intention of the Corporation to provide the photovoltaic manufacturing community with a product certification program, and the solicitation of laboratories that are interested in providing test services in support of the PMCC module certification program.

4.1.3 Provide for the advertisement and solicitation of persons who are technically proficient in photovoltaic laboratory test technologies and who (1) have experience in quality-systems auditing, or are willing to receive training in laboratory quality-systems assessment, and (2) are interested in working with A2LA as paid laboratory quality-system auditors in the assessment of photovoltaic testing laboratories on a contract basis.

4.2 The Laboratory Accreditation Committee shall provide recommendations, liaison, and technical support to the Corporation's Technical Committee in the event that initially, or at any future time, the Technical Committee undertakes the development of a photovoltaic proficiency test procedure that may be used by A2LA and PMCC in determining the capability of test laboratories to perform photovoltaic testing as one criteria in determining the test laboratory's capability to render quality test services to the Program's participating module manufacturers.

As one of its initial items of business, the Laboratory Accreditation Committee shall, in conjunction with A2LA, arrange for any training required of potential assessors in (1) quality-system auditing if said potential assessors are experienced in photovoltaic testing technology but are not familiar with quality-systems standards, or (2) photovoltaic testing technologies in test methods relevant to the Corporation's certification program, if said potential assessors are experienced in quality-systems auditing but not in the relevant photovoltaic technologies.

The Committee shall consider the establishment of a nominal laboratory accreditation fee that is in addition to that imposed on the laboratory by A2LA, and that is paid directly to the Corporation for the privilege of testing photovoltaic modules in support of the PMCC certification program. The Committee shall consider this issue, and the amount of fees to be levied, on an annual basis, and 
shall provide such recommendations to the Board of Directors as may be required.

3 4.5 The Laboratory Accreditation Committee shall develop the criteria for selecting either (a) several 4 accredited test laboratories to support the Corporation's module certification program, or (b) a single 5 accredited test laboratory. These criteria shall be reconsidered on at least an annual basis and any changes deemed necessary, or desirable, shall be communicated to the Board of Directors as a recommendation for adoption as a policy of the Corporation.

9 4.6 As necessary, the Committee shall develop and maintain, and from time to time modify criteria, procedures, and relevant checklists for between-assessment surveillance visits and review of the quality-system and testing capabilities of laboratories chosen to provide testing in support of the Corporation's certification programs. Criteria and procedures developed in connection with said laboratory surveillance shall be communicated to the Board of Directors as a recommendation for adoption as a policy of the Corporation.

\section{SECTION 5: GENERAL PROVISIONS}

185.1 Sections 5 through 10 of the General Rules of Procedure for Standing Committees are incorporated by reference and shall be deemed as the rules of procedure for the Laboratory Accreditation Committee. 
Rules of Procedure

for the

\section{LICENSING COMPLIANCE COMMITTEE}

\section{SECTION 1: AUTHORITY}

91.1 By the authority of the Photovoltaic Module Certification Corporation (PMCC) Board of Directors, the Executive Committee has duly constituted the establishment of a Committee on Licensing Compliance.

1.2 These Rules of Procedure shall govern the operations of the Committee on Licensing Compliance.

1.3 Except as provided herein, the General Rules of Procedure for Standing Committees are incorporated by reference in these rules, and shall be deemed to apply to the conduct of the affairs of the Committee on Licensing Compliance. In the event of a conflict between specific provisions of the General Rules and these Rules of Procedure, the applicable provisions of these Rules of Procedure for the Committee on Licensing Compliance shall take precedence.

\section{SECTION 2: SCOPE AND OBJECTIVES}

2.1 The Committee on Licensing Compliance shall have overall responsibility for tracking compliance of manufacturers with respect to the License Agreement, and shall establish formal liaison with the Audit and Finance Committee.

2.2 The Committee on Licensing Compliance shall ensure that (1) the licensing protocols remain consistent with industry needs, (2) the requirements of Document PV-2 are maintained consistent with the criteria dealing with licensing compliance, and (3) participating manufacturers are provided with due process with respect to the issuance of notices of non-compliance, corrective actions and notices of potential cancellation of the License.

\section{SECTION 3: ORGANIZATION}

3.1 Membership on the Committee on Licensing Compliance and the Audit and Finance Committee may include the same person or persons.

3.2 The Chair shall be appointed by the President of PMCC. 
13.3 The Committee on Licensing Compliance shall consist of not less than five ${ }^{1}$ nor more than seven members deemed by the Committee Chair and the Board of Directors to have the requisite background, education, and experience pertinent to the Corporation's Photovoltaic Module Certification Program.

\section{SECTION 4: SPECIFIC DUTIES OF THE COMMITTEE ON LICENSING COMPLIANCE}

4.1 As its first items of business, the Committee on Licensing Compliance shall:

4.1.1 Accept, ratify and adopt the Licensing Agreement that is contained in PMCC Document PV-4 entitled Operations Manual for the PMCC Photovoltaic Module Certification Program. Any modifications or changes to the Licensing Agreement shall be submitted to the PMCC Board of Directors for Approval.

4.1.2 Develop appropriate procedures for monitoring licensing compliance by participating manufacturers.

4.2 The Committee on Licensing Compliance shall review complaints of licensing violations received by PMCC from third parties, including users and purchasers of the certified product, and other manufacturers.

4.3 The Committee on Licensing Compliance shall first notify the affected manufacturer of the complaint, taking care to protect the identity of the complainant, and shall request a response from the manufacturer.

4.4 Upon determination that the complaint of violation of the Licensing Agreement is valid, the Committee on Licensing Compliance shall immediately demand that a verifiable Corrective Action be taken by the manufacturer, and that the appropriate evidence be furnished to the Committee.

4.5 Upon receiving incontrovertible proof that a licensing violation may be of sufficient gravity to immediately justify the cancellation of the manufacturer's license, the Committee shall prepare a report of the violation for the Board of Directors, citing the violation.

4.6 If, after review of a manufacturer's Corrective Action response to the notice of a violation, the Committee on Licensing Compliance considers the Corrective Action to be sufficient, it shall so notify the Board of Directors.

${ }^{1}$ It is anticipated that, during the first several months after the formation of this committee, five members may not be readily available to serve on this committee. If so, it will then be necessary for the Committee to modify these rules to coincide with the number of persons available to serve, but in no event shall the number of members be less than three. 
4.6.1 On the contrary, if the Corrective Action is considered to be insufficient, or if the manufacturer either refuses to respond, or procrastinates in responding, the matter shall be referred to the Board of Directors for the appropriate action.

4

\section{SECTION 5: GENERAL PROVISIONS}

6

75.1 Sections 5 through 10 of the General Rules of Procedure for Standing Committees are incorporated by 8 reference and shall be deemed as the rules of procedure for the Committee on Licensing Compliance. 


\section{F-50}


Rules of Procedure

for the

\section{MANUFACTURER'S QUALITY-SYSTEM COMPLIANCE COMMITTEE}

SECTION 1: $\quad$ AUTHORITY

8

1.1 By the authority of the Photovoltaic Module Certification Corporation (PMCC) Board of Directors, the Executive Committee has duly constituted the establishment of a Committee on Manufacturer's Quality-System Compliance.

1.2 These Rules of Procedure shall govern the operations of the Committee on Manufacturer's QualitySystem Compliance.

1.3 Except as provided herein, the General Rules of Procedure for Standing Committees are incorporated by reference in these rules, and shall be deemed to apply to the conduct of the affairs of the Committee on Manufacturer's Quality-System Compliance. In the event of a conflict between specific provisions of the General Rules and these Rules of Procedure, the applicable provisions of these Rules of Procedure for the Committee on Manufacturer's Quality-System Compliance shall take precedence.

\section{SECTION 2: SCOPE AND OBJECTIVES}

2.1 The Committee on Manufacturer's Quality-System Compliance shall have overall responsibility for establishing and maintaining the criteria presented in Appendix 2 of Document PV-2, Model for a Third-Party Certification and Labeling Program for Photovoltaic Modules.

2.2 The Committee shall administer the application of the criteria to candidate manufacturers that have submitted applications for certification under the rules and protocols established for the program.

2.3 The objectives of the Committee on Manufacturer's Quality System Compliance shall be to (1) determine the existence of a quality program resident at the participant's manufacturing plant, (2) determine the degree of compliance practiced by the candidate manufacturer with respect to Appendix 2 of Document PV-2, (3) encourage compliance, and (4) provide clear and concise instructions on the corrective actions necessary for admittance to the Photovoltaic Module Certification Program. 
3 3.1 Representatives of manufacturers and program participants shall be excluded from membership on the Committee on Manufacturer's Quality-System Compliance.

NOTE 1-Membership on the Committee on Manufacturer's Quality-System Compliance and the Product Certification Committee may include the same person or persons.

The Chair shall be appointed by the President of PMCC.

3.3 The Committee on Manufacturer's Quality-System Compliance shall consist of not less than five ${ }^{1}$ nor more than seven members deemed by the Committee Chair and the Board of Directors to have the requisite product certification background and education, or experience in lieu thereof, in photovoltaic technologies pertinent to the Corporation's Photovoltaic Module Certification Program.

\section{SECTION 4: SPECIFIC DUTIES OF THE COMMITTEE ON MANUFACTURER'S QUALITY-SYSTEM} COMPLIANCE

4.1 As its first items of business, the Committee on Manufacturer's Quality-System Compliance shall:

4.1.1 Accept, ratify and adopt Appendix 2 of Document PV-2 entitled Model for a Third-Party Certification and Labeling Program for Photovoltaic Modules. Any modifications or changes to Appendix 2 shall be submitted to the PMCC Board of Directors for Approval.

4.1.2 Provide for formal liaison to the Product Certification Committee on Licensing Compliance.

4.2 The Committee on Manufacturer's Quality-System Compliance shall be responsible for all product certification matters to be considered in the PMCC Photovoltaic Module Certification Program.

4.3 The Committee on Manufacturer's Quality-System Compliance shall have as a minimum the following additional duties:

4.3.1 Select, train, or cause to be trained, assessors who will audit applicant manufacturer's quality systems.

1It is anticipated that, during the first several months after the formation of this committee, five members may not be readily available to serve on this committee. If so, it will then be necessary for the Committee to modify these rules to coincide with the number of persons available to serve, but in no event shall the number of members be less than three. 
NOTE 2-The terms "assessors" and "auditors" will be used interchangeably for the purposes of this program.

NOTE 3-Manufacturers of photovoltaic modules who are registered or otherwise certified to comply with ANSI/ASQC Q9001 or Q9002, ISO 9001 or 9002 , or EN 24001 or 24002, shall be required only to provide evidence of such to be placed in consideration for certification by PMCC.

4.3.2 Schedule and perform, or cause to be performed, initial site visits and assessments of the applicant's manufacturing plant and the quality system resident thereat.

4.3.3 Evaluate assessment reports and issue corrective action requests as required by the assessor, or auditor, as amended by the Committee.

4.3.4 Evaluate corrective action responses and render decisions as to the suitability of the manufacturer for inclusion in the PMCC program.

\section{SECTION 5: GENERAL PROVISIONS}

5.1 Sections 5 through 10 of the General Rules of Procedure for Standing Committees are incorporated by reference and shall be deemed as the rules of procedure for the Committee on Manufacturer's QualitySystem Compliance. 


\section{Rules of Procedure \\ for the \\ PRODUCT CERTIFICATION COMMITTEE}

7 SECTION 1: AUTHORITY

9 1.1 By the authority of the Photovoltaic Module Certification Corporation (PMCC) Board of Directors, the Executive Committee has duly constituted the establishment of a Product Certification Committee.

1.2 These Rules of Procedure shall govern the operations of the Product Certification Committee.

1.3 Except as provided herein, the General Rules of Procedure for Standing Committees are incorporated by reference in these rules, and shall be deemed to apply to the conduct of the affairs of the Product Certification Committee. In the event of a conflict between specific provisions of the General Rules and these Rules of Procedure, the applicable provisions of these Rules of Procedure for the Product Certification Committee shall take precedence.

\section{SECTION 2: SCOPE AND OBJECTIVES}

2.1 The Product Certification Committee shall have oversight responsibility for the Operational Procedures of the product certification program adopted by the PMCC Board of Directors.

2.2 The Product Certification Committee shall ensure that (1) the program protocols remain consistent with industry needs, and (2) the requirements of Document PV-2 are maintained consistent with the criteria and provisions of ANSI Z34.1 and ISO/IEC Guide 28 dealing with third-party certification programs.

\section{SECTION 3: ORGANIZATION}

3.1 Representatives of manufacturers and program participants shall be excluded from membership on the Product Certification Committee.

NOTE 1-Membership on the Product Certification Committee and the Committee on Manufacturer's Quality-System Compliance may include the same person or persons.

3.2 The Chair shall be appointed by the President of PMCC.

40 
$1 \quad 3.3$ The Product Certification Committee shall consist of not less than five ${ }^{1}$ nor more than seven members deemed by the Committee Chair and the Board of Directors to have the requisite product certification background and education, or experience in lieu thereof, in photovoltaic technologies pertinent to the Corporation's Photovoltaic Module Certification Program.

\section{SECTION 4: $\quad$ SPECIFIC DUTIES OF THE PRODUCT CERTIFICATION COMMITTEE}

4.1 As its first items of business, the Product Certification Committee shall:

4.1.1 Accept, ratify and adopt PMCC Document PV-2, entitled Model for a Third-Party

Certification and Labeling Program for Photovoltaic Modules. Any modifications or changes to Document PV-2 shall be submitted to the PMCC Board of Directors for Approval.

4.1.2 Provide for formal liaison to the Committee on Manufacturer's Quality-System Compliance and the Committee on Licensing Compliance.

4.2 The Product Certification Committee shall be responsible for all product certification matters to be considered in the PMCC Photovoltaic Module Certification Program.

4.3 The Product Certification Committee shall have as a minimum the following additional duties:

4.3.1 Review, evaluate and approve, or disapprove, of the results of all qualification and electrical performance tests submitted by the laboratory(ies) accredited and selected for testing to the requirements of the Photovoltaic Module Certification Program.

4.3.2 Review problem applications forwarded by the Executive Director of the PMCC Program.

4.3.3 Request additional information such as retest, explanations, etc., as appropriate, including testing by a referee laboratory(ies) when required.

4.3.4 Render final decision on the suitability of applicant's product for certification.

4.3.5 Establish and issue a performance value, and authorize the Executive Director to issue a license to use the mark and/or certificate of conformity.

${ }_{1}$ It is anticipated that, during the first several months after the formation of this committee, five members may not be readily available to serve on this committee. If so, it will then be necessary for the Committee to modify these rules to coincide with the number of persons available to serve, but in no event shall the number of members be less than three. 
1 SECTION 5: GENERAL PROVISIONS

2

35.1 Sections 5 through 10 of the General Rules of Procedure for Standing Committees are incorporated by 4 reference and shall be deemed as the rules of procedure for the Product Certification Committee.

5 


\author{
Specific Rules of Procedure \\ for the \\ TECHNICAL COMMITTEE
}

SECTION 1: AUTHORTYY

1.1 By the authority of the Photovoltaic Module Certification Corporation (PMCC) Board of Directors, the Executive Committee has duly constituted the establishment of a Technical Committee.

1.2 These Rules of Procedure shall govern the operations of the Technical Committee.

1.3 Except as provided herein, the General Rules of Procedure for Standing Committees are incorporated by reference in these rules, and shall be deemed to apply to the conduct of the affairs of the Technical Committee. In the event of a conflict between specific provisions of the General Rules and these Rules of Procedure, the applicable provisions of these Rules of Procedure for the Technical Committee shall take precedence.

\title{
SECTION 2: $\quad$ SCOPE AND OBJECTIVES
}

2.1 The Technical Committee shall be responsible for the selection and adoption of the test methods, rating methodologies, and minimum criteria for photovoltaic module certification. The Committee shall maintain liaison with the appropriate committees and subcommittees of ASTM, IEEE, IEC, and ISO.

2.2 The Technical Committee shall maintain Document PV-3, and shall ensure that the test methods and rating methodologies contained therein are consistent with industry needs and are up to date in terms of the state of the art relating to test methods, standards, and protocols. It shall be the policy of the Technical Committee to use, wherever possible, test methods, standards, protocols and specifications that have been developed, either domestically or internationally, by consensus procedures and processes. Further, it shall be the policy of the Committee to use, to the extent possible, international standards that have been promulgated in IEC/TC82 and ISO/TC180.

\section{SECTION 3: ORGANIZATION}

3.1 The Chair may be the Technical Director of the Corporation providing such a person is employed for that purpose. 
13.2 The Technical Committee shall consist of not less than five nor more than seven members deemed by the Committee Chair and the Board of Directors to have the requisite technical background and education, or experience in lieu thereof, in photovoltaic technologies pertinent to the Corporation's Photovoltaic Module Certification Program.

\section{SECTION 4: SPECIFIC DUTIES OF THE TECHNICAL COMMITTEE}

8 4.1 As its first items of business, the Technical Committee shall:

4.2 The Technical Committee shall be responsible for all technical matters to be considered in the PMCC Photovoltaic Module Certification Program.

\subsection{Proficiency Test Procedure:}

4.3.1 A Proficiency Test Procedure shall be developed by the Technical Committee to aid the laboratory quality assessor, or assessors, and the Laboratory Accreditation Committee, in evaluating the module testing proficiency and capabilities of candidate testing laboratories.

4.3.2 The Proficiency Test Procedure will be for use by laboratories that have applied for accreditation in support of the Corporation's module certification program.

4.3.3 In evaluating the concept of a photovoltaic Proficiency Test Procedure, the Committee shall ensure that PV module performance measurements are accurate and repeatable, and that laboratories involved shall participate in round-robin testing in collaboration with appropriate national and international laboratories to establish accurate and reliable test values against which candidate independent testing laboratories may be judged.

4.3.4 The Committee shall be responsible for providing its technical expertise to the Laboratory Accreditation Committee with respect to interpretation of the results of testing the photovoltaic Proficiency Test Procedure by candidate testing laboratories. 


\section{SECTION 5: GENERAL PROVISIONS}

2

35.1 Sections 5 through 10 of the General Rules of Procedure for Standing Committees are incorporated by $4 \quad$ reference and shall be deemed as the rules of procedure for the Technical Committee.

5 
Annex G

Partial Business Plan for the PMCC 


\section{Partial Business Plan for the PMCC}

Table of Contents

Page

Benefits of a certification program

G-3

Marketing brochure

G-10

Table G-1: Marketing contact list

G-12

Table G-2: Draft initial operating budget

G-14 


\section{Benefits of a Certification Program}

1. Increased sales due to customer confidence in the product. A certification program will differentiate mature technology products from products that do not meet reliability or performance standards; poor quality modules and the module manufacturer may be exposed due the inability to pass the certification requirements and potential module failure in the field.

2. Reduced cost of qualification testing ${ }^{1}$. A nationally and internationally accepted certification program will eliminate the need for multiple qualification tests (e.g., JPL Block IV and V; NREL/ SERI IQT; CEC 503; IEEE 1262; IEC 1215, PVUSA) and eliminate the need for a manufacturer to conform to a variety of specifications by various customers. It could also eliminate the need for customers to develop their own procurement qualification/performance specifications (e.g. the PVUSA qualification specification). Also, UL would accept the certification [rogram certified tests which are common to UL 1703 , if certain conditions are met ${ }^{2}$.

3. Nearly all large purchases of energy systems are highly competitive and such purchases usually have some stringent requirements for performance and durability. A single certification program will eliminate or minimize potential conflicting requirements.

4. When there are incentive-based purchases (such as those by groups of utility companies), the purchasing agency is likely to insist on some level of performance, durability, and safety. A consensus-driven certification program simplifies these types of purchase.

5. A certification program provides for faster module qualification than testing to a broad selection of qualification standards (since there is only one specification to deal with), communications are easier with a single entity (the certification body) and rules of procedures eliminate common testing or procedural problems (or provides a ready solution to such problems).

6. The program facilitates communications between supplier and customer by establishing common terminology.

7. Leverage for reciprocity with potential European, Japanese, and other international certification programs (for example, via a memorandum of understanding).

8. Simplified purchase contracts. The vendor specifications could simply require the product to have the PV certification label.

9. Increased competitiveness in the international market.

10. The program increases the certainty of passing a "rated power" test (such as PVUSA testing) for system acceptance (e.g., Yuma Proving Grounds).

11. A certification program reduces a manufacturer's product liability by sharing that liability with the certification body, the testing laboratory, and the accreditation body.

\footnotetext{
${ }^{1}$ These costs will be quantified in a companion document to be developed.

${ }^{2}$ The following is per correspondence with Tom Lundtveit (UL) dated January 12, 1995:

UL would accept the certified tests (from a certification program) for UL 1703, provided either of the following are met:

- UL witnesses and supervises all tests, or

- UL certifies the test lab, in which case, UL would accept the data as if UL conducted the tests.

Certification of the test lab would require an initial assessment of about $\$ 6,000$. Annual assessments would also be necessary, which would cost about $\$ 2,000$ annually. Living and travel expenses are extra. In addition, if long distance travel is involved, for example a foreign country, travel time at $\$ 1,200$ per day needs to be factored in.
} 


\section{Benefits of developing a U.S. PV certification program versus using a European (e.g. ESTI), Japanese, or other foreign certification programs}

1. The total cost of a U.S. program will be less than a non-U.S. program ${ }^{3}$. Annual audits and inspections will be less expensive if done by a domestic organization.

2. An effective certification program must be actively marketed to major users by the certifying organization. A domestic program will be less expensive to market to local users, and the local users will be more inclined to accept the domestic program. Management personnel of a domestic certification program are much more likely to actively market the PV certification program to the U.S. manufacturers' benefit.

3. U.S. manufacturers can provide significant input for a domestic program, since some manufacturers will participate in the establishment and management of such an organization (e.g., board members and technical committee members).

4. Faster certification; no shipping delays with a domestic lab; communications are easier and more timely.

5. Simpler certification; no international documents.

6. A U.S. program stimulates U.S. business.

7. Testing can be monitored and problems discussed in-person, rather than being performed at a distant place where test methods and interpretation of results are subject to language barriers and political considerations.

8. Greater acceptance of U.S. PV modules by major U.S. purchasers (government and private).

\section{General Comments by Committee Members}

- This education is absolutely in the right direction.

- This educational program must emphasize the lower costs and simplified purchasing aspects of such a program.

- Don't make too snazzy a marketing blitz; it wont give the impression of lower costs.

- Include testimonials or examples from other industries showing how such a program inevitably saves costs. A survey of associated transaction costs sent to executives may be the first step.

\footnotetext{
${ }^{3}$ These costs will be quantified in a companion document to be developed.
} 


\section{Specific Comments and Questions by Committee Members}

Comment 1. The only customer request for certification is for UL certification.

Response 1. The only existing certification program for PV today is the UL certification program. However, nearly all industrial, commercial and institutional customers (e.g., SMUD, PG\&E, PVUSA, $\mathrm{DOD}$ ), require a module qualification test. The $\mathrm{UL}$ certification is often an additional requirement. For years both domestic and international buyers required JPL Block V qualification tests. There is no longer a single internationally accepted qualification test. Buyers (domestic and international) are requiring any one of the following tests: JPL Block IV or V, SERI/NREL IQT, CEC 503, IEC 1215, or PVUSA - and more are on the way (e.g. IEEE 1262)!. Are you going to perform all of these tests in order to sell to a variety of customers?

The UL 1703 specification addresses safety issues and the UL Label on a module provides confidence that the module is safe. It says little or nothing about the reliability or performance of a product.

JPL Block IV and V, SERI/NREL IQT, CEC 503, IEC 1215 and PVUSA address issues related to module performance, safety, and susceptibility to known failure mechanisms, with emphasis on testing for potential degradation of module performance resulting from environmental weathering, mechanical loading, corrosion, and shadowing.. These tests provide confidence that the module will perform reliably in the field.

It is important to make the distinction between module qualification tests and module certification. Module qualification testing is a one-time test for a given module type. A module certification program may perform the same qualification test, but it also includes other requirements to ensure continuing compliance, such as an initial and periodic audits of the factory, plus spot checks of module performance and reliability (in the same manner that UL maintains a license with their clients).

Comment 2. The time frame does not appear to be any shorter than other certification programs (i.e., FSEC suggests two months to one year).

Response 2. There are no other certification programs (except UL 1703)! The proposed PV Certification program, when properly marketed, would provide a nationally and internationally recognized performance/qualification test Label which could eliminate the time and expense for a manufacturer to qualifying to JPL Block IV and V, SERI/NREL IQT, CEC 503, IEC 1215 and PVUSA and others which are being developed.

The minimum time required to perform any of the above qualification tests is about 60 days, since the thermal cycle test ( 200 cycles) requires 50 days. The full battery of test would typically take $90-120$ days, depending on the available equipment for parallel testing. If there is a backlog of testing to be done, it could take longer than 120 days.

Doing one internationally accepted certified qualification/performance test is certainly faster that five of the existing qualification tests. And it is not only the actual qualification test that requires time.

Negotiating, for example, with a potential buyer who requires the JPL Block V qualification test that the PVUSA test is equally valid, may take a considerable amount of time. These negotiations do occur on a regular basis with many of the PV manufacturers. And yes, some customers still call out JPL Block V. 
Comment 3. UL is nationally and internationally accepted - why should we be duplicating or incurring additional costs?

Response 3. Yes, UL is accepted both nationally and internationally, but the UL program is focused on product safety. The UL Label gives the user of the product confidence that the product is safe from electrical shock and fire hazards. Major PV purchasers also want to know that the PV module is reliable and that the advertised performance values are valid. The proposed PV Module Certification Program is intended to provide this assurance.

Comment 4. UL Certification has acceptance and I see no evidence that State, local or municipality inspectors would be willing to accept anything else.

Response 4. State local and municipalities generally inspect to ensure compliance with safety standards (NEC and UL) and local ordinances. The PV Certification Corporation would petition the state and local government agencies to endorse the PV certification program for product reliability and durability requirements. And if the state and local government agency is the PURCHASER of the product, they will have much to gain (and nothing to lose) by requiring PV module certification. And, yes, they will continue to require the UL Label.

Comment 5. Quality and cost of the product are what we believe will increase our competitive advantage in the international market, not a new certification program.

Response 5. A certification program will verify the quality of a product, by an independent third-party testing organization. Third-party testing generally has much more credibility than the claims of a manufacturer. A certification program will also prevent a supplier (i.e., your competitor) from making false claims about quality, reliability, durability and performance, and taking business on low price. The solar thermal certification program (Solar Rating and Certification Corporation) is a good example of a certification program that has weeded out inferior products, instilled confidence in buyers and stimulated the market.

Comment 6. JPL, NREL, or PVUSA or other demonstration projects could waive their qualification test requirements for UL certified modules - they do not - they should.

Response 6. They do not and they should not provide such waivers. The UL Label provides assurance of a safe product, but says little about product reliability, durability and performance. The proposed PV Module Certification program would provide assurance of product reliability, durability and performance. 
Comment 7. Marketing costs for a new certifying organization could be deployed elsewhere in the industry to give US manufacturers a competitive advantage. UL already has this acceptance.

Response 7. Nearly every major industry has found it cost effective to implement certification programs - from solar thermal collectors to the automotive industry. The photovoltaic industry has matured to the point where a module certification program for reliability and performance will be cost-effective. Such a program will reduce the total cost of convincing the buyer that the product is reliable and meets advertised performance values. The Label will also separate the quality products from the inferior products!

You may be interested in the very pertinent points made by one of our new committee members:

Nearly all large purchases of energy systems are highly competitive and such purchases usually have some stringent requirements for performance and durability. A single certification program will eliminate or minimize conflicting requirements.

When there are incentive-based purchases (such as those by groups of utility companies, e.g., UPVG), the purchasing agency is likely to insist on some level of performance, durability, and safety. A consensusdriven certification program simplifies these types of purchases.

...a consensus certification program is faster, simpler, and cheaper...

Question 1. Who is working the issue of "A nationally and internationally accepted certification program will eliminate the need for multiple qualification tests" mentioned in the second bullet? ...

Answer 1. No one is currently working the issue. This is the task of the Certification Body (probably the Executive Director). One of the major activities of the Director is to market the Certification Program. This marketing activity is also one of the values of a Certification program.

Question 2. What prohibits a US test laboratory from getting approval through a non-US certification body? Has this approach been investigated? Can we learn anything from the ISO 9000 oversight methodology?

Answer 2. There is no other PV certification body in place today, although the EC and ISPRA are apparently developing such a program. Travel costs associated with periodic audits of the accredited laboratory and manufacturers would be prohibitive unless local US auditors were used. If US auditors are used, then the remaining negatives is the difficulty is communicating with an international organization, and US organizations has less influence over such a program.

Question 3. What are the likely difference among the US, EC and Japanese programs?

Answer 3. The non-US certification programs will likely cost more and the US manufacturers will probably not be members of the certification body board (and thus will have little control over the program). 
Question 4. When was the last time you looked into a manufacturer's certification pedigree before buying a product for the first time or repeat purchases? Does it matter what label is on a product before you buy it? Ultimately it's the product's performance against the customer's expectations that matters.

Answer 4. The Label must be properly marketed before it has value. Properly marketed, the Label will be synonymous with customer confidence (performance, reliability and durability) in the product. And properly marketed, the Label will be required as a condition of purchase for major customers. (In the area of safety, UL has done a superb job of marketing their Label. How many appliances have you purchased that did not have the UL label?) It is not enough for the manufacturer to claim good performance, reliability and durability, since most customers have neither the equipment to perform the required tests nor the patience to wait one to five years for a product to prove satisfactory. The Label will provide confidence that the product meet minimum standards today and, due to continued factory audits of a certification program, that the Labeled product purchased next month or next year will also be satisfactory.

Question 5. Footnote ii: What is the certification criteria in the statement "UL would accept the certified tests for UL 1703 if UL certifies the test lab"? Is this redundant to the requirements listed in "Criteria for a Module Quality System for Laboratories Engaged in Testing Photovoltaic Modules (PV-1, Rev. c1?

Answer 5. After the proposed PV module certification program is established for performance, reliability and durability, many major buyers will require this label as well as the UL label for safety. Many of the test will be the same, such as 200 thermal cycles from $-40 \mathrm{C}$ to $+90 \mathrm{C}$. If the thermal cycling test is performed for IEEE 1262 qualification, UL would accept the results of this for the UL 1703 Label if the conditions of footnote ii are met. Otherwise, this test will have to be repeated (another $\$ 10 \mathrm{~K}$ !) for the UL label. 


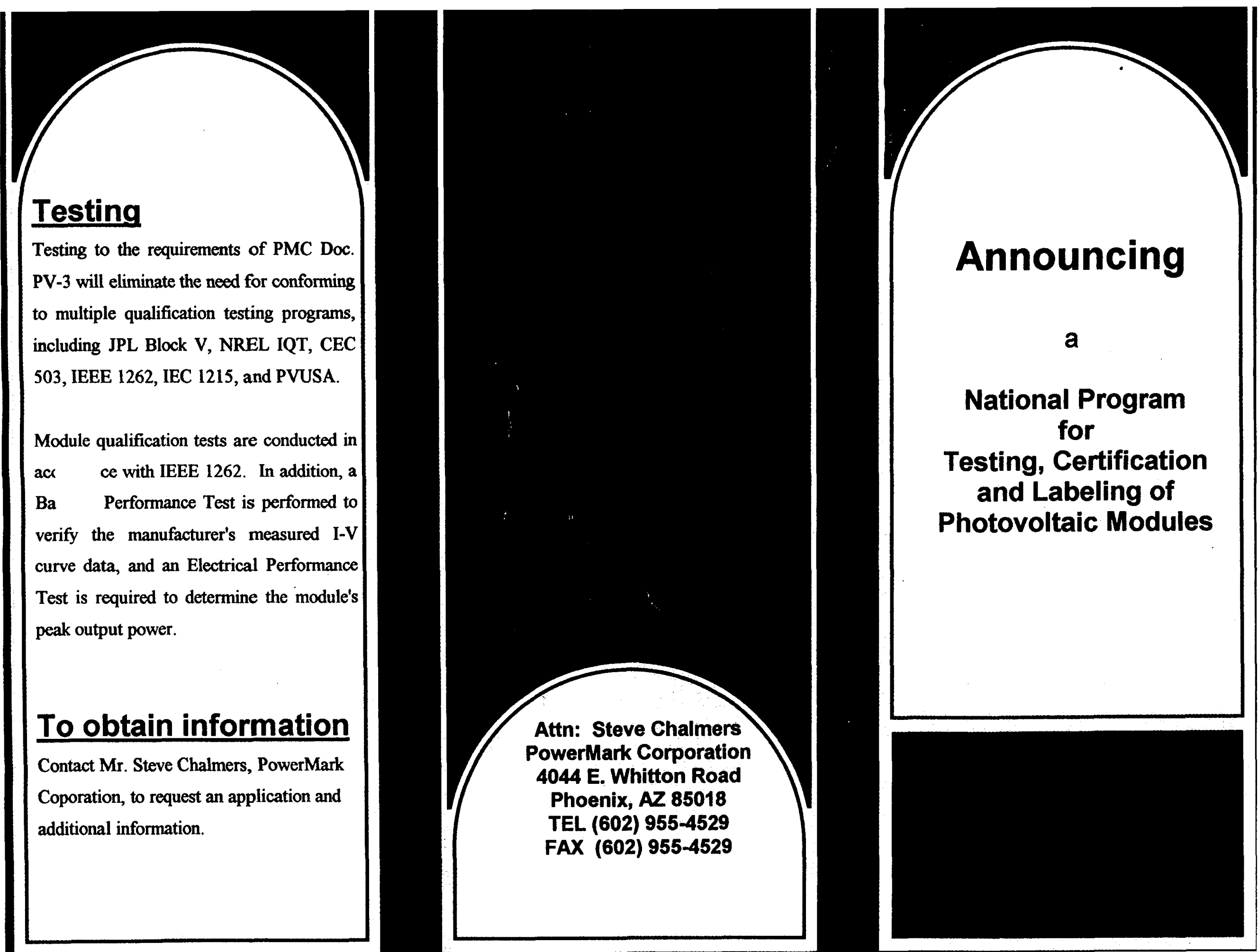




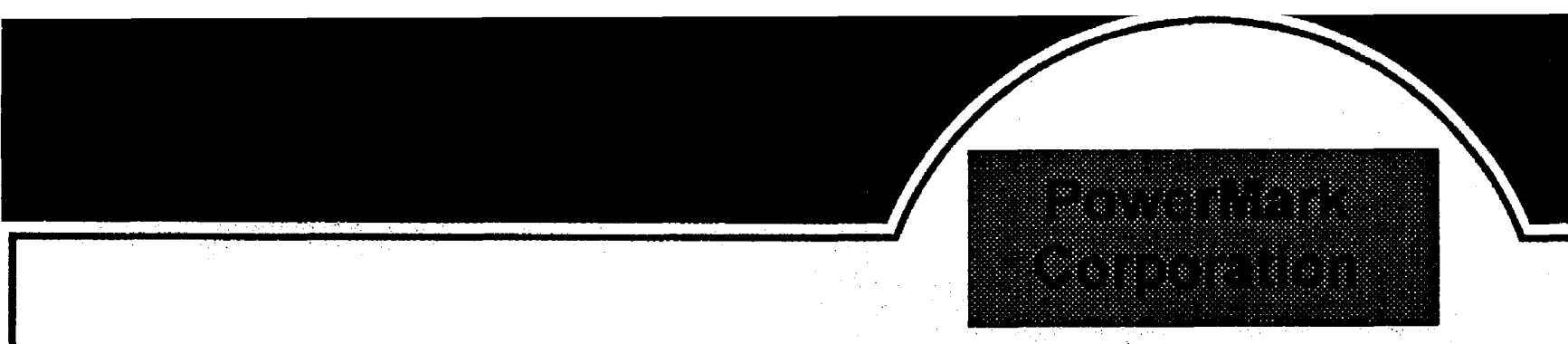

\section{PMC}

PowerMark Corporation (PMC) was formed to provide PV manufacturers with a module certification program that, through the process of product labeling, attests to the module's quality.

Product certification involves the formal process of licensing the manufacturer to use a Certificate of Conformity. This program involves the use of formal quality system criteria for the manufacturer, PMC itself, the test laboratories authorized to perform testing in support of the program, and the laboratory accreditation body selected by PMC.

PMC's module certification program is based on both U.S. and Internaional consensus-developed standards.

\section{Quality}

Manufacturers are required to conform to selected elements of ISO 9001 . Laboratories are required to be accredited to ISO Guide 25, and PMC has been configured to conform to the quality system requirements of ANSI Z34.1 \& ISO Guide 28.

\section{Requirements}

To join the program, a manufacturer must sign a licensing agreement, render the specified fees to PMC, and submit the required number of modules to a designated laboratory for testing to PMC Doc. PV-3 Testing Requirements for a Certification and Labeling Program for Photovoltaic Modules.

\section{Benefits}

The benefits of a PV module certification program are:

- Provide evidence, e.g., a label, that a module meets certain minimum requirements.

- Increased sales as a result of customers' perceived confidence in the product.

- Potential for reduced costs associated with qualification testing.

- Potential reciprocity with European and future Japanese certification programs.

- Purchase specifications could simply require PMC certification, simplifying PV contracting.

- Increased competitiveness in the international marketplace.

- Real improvement, and an increased perception of improvement, in the quality of US-manufactured photovoltaic modules. 
Table G-1. Marketing Contact List

\begin{tabular}{|c|c|c|c|c|c|c|c|}
\hline & ORGANIZATION & TECHNICAL & MARKETING & CEO & SEIA & FAX & MAILING ADDRESS \\
\hline 1 & Amonix & $\begin{array}{l}\text { Sewang Yoon } \\
310-325-8091\end{array}$ & & \begin{tabular}{|l|} 
Vahan \\
Garboushian \\
310-325-8091 \\
\end{tabular} & & $310-325-0771$ & $\begin{array}{l}3545 \text { Lomita Blvd., \#A, } \\
\text { Torrance, CA } 90505\end{array}$ \\
\hline 2 & $\begin{array}{l}\text { Advanced Photovoltaic } \\
\text { Systems, Inc. }\end{array}$ & & \begin{tabular}{|l} 
Dan Shugar, VP \\
$415-871-2275$
\end{tabular} & & Dan Shugar & $415-871-2279$ & $\begin{array}{l}150 \text { Tehama Court, } \\
\text { San Bruno, CA } 94066\end{array}$ \\
\hline 3 & ASE Americas & $\begin{array}{l}\text { Moneer Azzam } \\
508-667-5900 \times 210\end{array}$ & $\begin{array}{l}\text { Paul Wormser } \\
508-667-5900 \times 281\end{array}$ & $\begin{array}{l}\text { Klaus Albrecht } \\
\text { President } \\
508-667-5900 \\
\end{array}$ & Klaus Albrecht & $508-663-2868$ & $\begin{array}{l}\text { 4 Suburban Park Drive, } \\
\text { Billerica, MA } 01821\end{array}$ \\
\hline 4 & AstroPower & $\begin{array}{l}\text { Cheryl Keith } \\
\text { 302-366-0400 }\end{array}$ & & $\begin{array}{l}\text { Allen Barnett } \\
\text { President } \\
302-366-0400 \\
\end{array}$ & Allen Barnett & $302-368-6474$ & $\begin{array}{l}\text { Solar Park, } \\
\text { Newark, DE 19716-2000 }\end{array}$ \\
\hline 5 & Atlantis Energy & & & & $\begin{array}{l}\text { Steve Coonen VP } \\
916-274-2743\end{array}$ & $916-274-2564$ & $\begin{array}{l}14790 \text { Mosswood, } \\
\text { Grass Valley, CA } 95945\end{array}$ \\
\hline 6 & Besicorp Group, Inc. & & & & $\begin{array}{l}\text { Michael Zinn } \\
\text { President } \\
914-336-7700 \\
\end{array}$ & & $\begin{array}{l}1151 \text { Flatbush Road, } \\
\text { Kingston, NY } 12401\end{array}$ \\
\hline 7 & BP Solar & & & & $\begin{array}{l}\text { Richard V. Sowter } \\
\text { VP, Sales-Mktg } \\
\text { 713-560-3011 } \\
\end{array}$ & & $\begin{array}{l}\text { PO Box 4587, } \\
\text { Houston, TX } 77210-4587\end{array}$ \\
\hline 8 & Corning & & & & $\begin{array}{l}\text { Thomas J. Dwyer } \\
\text { Mgr., Mkt. Dev. } \\
\text { 607-974-4801 }\end{array}$ & & $\begin{array}{l}\text { Corporate Marketing One, } \\
\text { Riverfront Plaza, HQ-E1-06-C26 } \\
\text { Corning, NY 14831-0001 }\end{array}$ \\
\hline$\overline{9}$ & $\begin{array}{l}\text { Energy Conversion } \\
\text { Devices }\end{array}$ & & & & $\begin{array}{l}\text { Barbara Levin } \\
\text { Special Projects } \\
810-280-1900\end{array}$ & $810-280-1456$ & $\begin{array}{l}1675 \text { West Maple Road, } \\
\text { Troy, MI } 48084\end{array}$ \\
\hline 10 & ENTECH & & & \begin{tabular}{|l} 
W.H. Hesse \\
President \\
214-456-0900 \\
\end{tabular} & W.H. Hesse & $214-456-0904$ & $\begin{array}{l}\text { PO Box 612246, } \\
\text { DFW Airport, TX } 75261\end{array}$ \\
\hline 11 & $\begin{array}{l}\text { EPV (Energy } \\
\text { Photovoltaics) }\end{array}$ & & & & \begin{tabular}{|l|} 
Zoltan J. Kiss \\
President \\
$609-587-3000$ \\
\end{tabular} & $609-587-5355$ & $\begin{array}{l}\text { PO Box 7456, } \\
\text { Princeton, NJ } 098543\end{array}$ \\
\hline 12 & Evergreen Solar & $\begin{array}{l}\text { Jack Kanoka } \\
617-736-1744\end{array}$ & & $\begin{array}{l}\text { Mark Farber } \\
\text { President } \\
617-736-1744\end{array}$ & Mark Farber & 617-736-1979 & $\begin{array}{l}\text { 49 Jones Rd., } \\
\text { Waltham, MA } 02154\end{array}$ \\
\hline 13 & Golden Photon & $\begin{array}{l}\text { Scot P. Albright } \\
\text { Manager } \\
\text { 303-271-7173 }\end{array}$ & & & Scot P. Albright & $303-271-7410$ & $\begin{array}{l}4545 \text { McIntyre Street, } \\
\text { Golden, CO } 80403\end{array}$ \\
\hline
\end{tabular}


Table G-1. Marketing Contact List (continued)

\begin{tabular}{|c|c|c|c|c|c|c|c|}
\hline & ORGANIZATION & TECHNICAL & MARKETING & CEO & SEIA & FAX & MAILING ADDRESS \\
\hline 14 & Hoxan America & & & & $\begin{array}{l}\text { Thomas R. } \\
\text { Siebert } \\
908-980-0777\end{array}$ & 908-980-0488 & $\begin{array}{l}\text { One Centennial Plaza, \#3F, } \\
\text { Piscatawary, NJ } 08854\end{array}$ \\
\hline 15 & Kyocera America, Inc. & & & & $\begin{array}{l}\text { Alan Panton } \\
\text { President } \\
619-576-2647\end{array}$ & $619-569-9412$ & $\begin{array}{l}8611 \text { Balboa Avenue, } \\
\text { San Diego, CA } 92123\end{array}$ \\
\hline 16 & Photocomm Inc. & $\begin{array}{l}\text { Robert W. Spotts } \\
602-948-8003\end{array}$ & & $\begin{array}{l}\text { Robert Kauffman } \\
\text { President, } \\
\text { 602-948-8003 }\end{array}$ & Robert Kauffman & $602-483-6431$ & $\begin{array}{l}7681 \text { East Gray Rd., } \\
\text { Scottsdale, AZ } 85260\end{array}$ \\
\hline 17 & $\begin{array}{l}\text { Siemens Solar } \\
\text { Industries }\end{array}$ & \begin{tabular}{|l} 
Don Aldrich \\
$805-388-6531$
\end{tabular} & Eric Daniels & & $\begin{array}{l}\text { Dr. George } \\
\text { Roland } \\
\text { President } \\
805-388-6341\end{array}$ & $805-388-6557$ & $\begin{array}{l}4650 \text { Adohr Lane, } \\
\text { Camarillo, CA } 93010\end{array}$ \\
\hline 18 & Solar Cells, Inc. & $\begin{array}{l}\text { Dan Sandwisch } \\
419-534-3377 \\
\end{array}$ & & & $\begin{array}{l}\text { James Brown } \\
419-537-0131 \\
\end{array}$ & \begin{tabular}{|l|}
$419-534-2794$ \\
$419-537-8831$ \\
\end{tabular} & $\begin{array}{l}1202 \text { N. Westwood Ave, } \\
\text { Toledo, OH } 43607\end{array}$ \\
\hline 19 & Solar Kinetics & & & & $\begin{array}{l}\text { Gus Hutchison } \\
214-556-2376 \\
\end{array}$ & $214-869-4158$ & $\begin{array}{l}\text { 10635 King Williams Drive, } \\
\text { Dallas, TX } 75220\end{array}$ \\
\hline 20 & Solarex & $\begin{array}{l}\text { John Wohlgemuth } \\
\text { 301-698-4375 }\end{array}$ & $\begin{array}{l}\text { Leonard May } \\
\text { 301-698-4200 }\end{array}$ & & $\begin{array}{l}\text { Dr. Harvey Forrest } \\
\text { President } \\
301-970-4300\end{array}$ & $301-698-4201$ & $\begin{array}{l}630 \text { Solarex Court, } \\
\text { Frederick, MD } 21701\end{array}$ \\
\hline 21 & $\begin{array}{l}\text { Solec International, } \\
\text { Inc. }\end{array}$ & & $\begin{array}{l}\text { Joel Davidson } \\
\text { 310-970-0065 }\end{array}$ & $\begin{array}{l}\text { Ishaq Shahryar } \\
\text { President } \\
310-970-0065\end{array}$ & Ishaq Shahryar & $310-970-1065$ & $\begin{array}{l}12533 \text { Chadron Ave, } \\
\text { Hawthorne, CA } 90250\end{array}$ \\
\hline 22 & Spire & $\begin{array}{l}\text { Steve Hogan } \\
617-275-6000 \times 312\end{array}$ & & $\begin{array}{l}\text { Roger Little } \\
\text { President } \\
617-275-6000 \\
\end{array}$ & Roger Little & $617-275-7470$ & $\begin{array}{l}\text { One Patriots Park, } \\
\text { Bedford, MA 01730-2396 }\end{array}$ \\
\hline 23 & SunPower Corporation & $\begin{array}{l}\text { Richard Swanson } \\
\text { 415-968-3403 }\end{array}$ & $\begin{array}{l}\text { Richard Swanson } \\
\text { 415-968-3403 }\end{array}$ & $\begin{array}{l}\text { Richard Swanson } \\
415-968-3403\end{array}$ & Richard Swanson & $415-968-3418$ & $\begin{array}{l}435 \text { Indio Way, } \\
\text { Sunnyvale, CA } 94086\end{array}$ \\
\hline 24 & $\begin{array}{l}\text { United Solar Systems } \\
\text { Corp. }\end{array}$ & $\begin{array}{l}\text { Troy Glatfelter } \\
810-362-4170\end{array}$ & $\begin{array}{l}\text { Larry Slominski } \\
810-362-4170\end{array}$ & $\begin{array}{l}\text { Shinoichiro } \\
\text { Nagashima } \\
\text { President } \\
\text { 313-362-4170 }\end{array}$ & $\begin{array}{l}\text { Shinoichiro } \\
\text { Nagashima }\end{array}$ & $810-362-4442$ & $\begin{array}{l}1100 \text { W. Maple Rd., } \\
\text { Troy, MI } 48067\end{array}$ \\
\hline 25 & Utility Power Group & \begin{tabular}{|l|} 
Gilbert Duran \\
$818-700-1995$
\end{tabular} & & & $\begin{array}{l}\text { Michael Sterns } \\
\text { President } \\
818-700-1995\end{array}$ & $818-700-2518$ & $\begin{array}{l}\text { 9410-G DeSoto Ave., } \\
\text { Chatsworth, CA } 91311\end{array}$ \\
\hline
\end{tabular}


Table G-2. Draft Initial Operating Budget

\begin{tabular}{|c|c|c|c|c|c|c|c|c|c|c|}
\hline & \multicolumn{10}{|c|}{ Expenses by year, in thousands of $\$$ and $\%$ of total } \\
\hline & \multicolumn{2}{|c|}{$\mathbf{1}$} & \multicolumn{2}{|c|}{2} & \multicolumn{2}{|c|}{3} & \multicolumn{2}{|c|}{4} & \multicolumn{2}{|c|}{5} \\
\hline & $\mathbf{k \$}$ & $\%$ & $\mathbf{k} \$$ & $\%$ & $\mathbf{k} \$$ & $\%$ & $\mathbf{k \$}$ & $\%$ & $\mathbf{k} \$$ & $\%$ \\
\hline $\begin{array}{l}\text { Executive director: } x x \% \text { FTE, } \\
\text { salary \& benefits [1] }\end{array}$ & 46 & 28 & 48 & 29 & 72 & 35 & 100 & 41 & 105 & 41 \\
\hline $\begin{array}{l}\text { Office manager: } 100 \% \text { FTE, } \\
\text { salary \& benefits [2] }\end{array}$ & 26 & 16 & 27 & 16 & 29 & 14 & 30 & 12 & 32 & 12 \\
\hline Office supplies & 3 & 2 & 3 & 2 & 3 & 1 & 3 & 1 & 3 & 1 \\
\hline Telephone, fax & $\overline{4}$ & 2 & 4 & 2 & 4 & 2 & 4 & 2 & 4 & 2 \\
\hline Travel-domestic & 15 & 9 & 16 & 9 & 17 & 8 & 17 & 7 & 18 & 7 \\
\hline Travel-international & 0 & $\overline{0}$ & $\overline{0}$ & 0 & 0 & 0 & 0 & 0 & 0 & 0 \\
\hline Entertainment & 2 & 1 & $\overline{2}$ & 1 & 2 & 1 & 2 & 1 & $\overline{2}$ & 1 \\
\hline Office space-rent [3] & 5 & 3 & 5 & 3 & 5 & 3 & 6 & 2 & 6 & 2 \\
\hline Marketing communications & 3 & 2 & 3 & 2 & 3 & 1 & 3 & 1 & 3 & 1 \\
\hline $\begin{array}{l}\text { Capital equipment (office } \\
\text { furniture, computers) }\end{array}$ & 4 & 2 & 4 & 2 & 4 & 2 & 4 & 2 & 4 & 2 \\
\hline $\begin{array}{l}\text { Professional fees(legal and } \\
\text { accounting) }\end{array}$ & 10 & 6 & 11 & 6 & 11 & 5 & 12 & 5 & 12 & \\
\hline Other & 3 & 2 & 3 & 2 & 3 & 1 & 3 & 1 & 3 & \\
\hline Subtotal & 118 & 74 & 123 & 74 & 151 & 74 & 183 & 74 & 193 & 74 \\
\hline Overhead @ 35\% & 41 & 26 & 43 & 26 & 53 & 26 & 64 & 26 & 67 & 26 \\
\hline TOTAL & 160 & 100 & 166 & 100 & 204 & 100 & 248 & 100 & 260 & 100 \\
\hline
\end{tabular}

Note 1: Executive director-50\% FTE 1st and 2nd years, 75\% 3rd year, 100\% 4th and thereafter; starting salary, $\$ 70 \mathrm{k} / \mathrm{year}$, benefits at $30 \%$ of salary.

Note 2: Office manager-starting salary, $\$ 20 \mathrm{k} / \mathrm{year}$, benefits at $30 \%$ of salary.

Note 3: 1 st year, $\$ 400 /$ month for two office combination, including utilities and janitorial. 


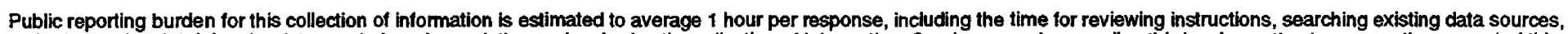

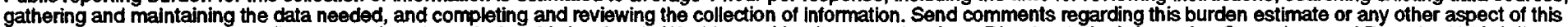

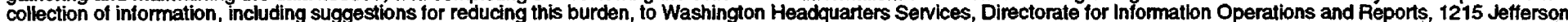
Davis Highway, Suite 1204, Artington, VA 22202-4302, and to the Office of Management and Budget, Paperwork Reduction Project (0704-0188), Washington, DC 20503.

\section{AGENCY USE ONLY (Leave blank) \\ 2. REPORT DATE \\ August 1996 \\ 3. REPORT TYPE AND DATES COVERED \\ Technical Report}

\section{TITLE AND SUBTITLE}

Photovoltaic Module Certification/Laboratory Accreditation Criteria Development: Implementation Handbook

6. AUTHOR(S)

C.R. Osterwald, R.L. Hammond, B.D. Wood, C.E. Backus, R.L. Sears, G.A. Zerlaut, and R.V. D'Aiello

7. PERFORMING ORGANIZATION NAME(S) AND ADDRESS(ES)

NREL, Golden, CO $80401-3393$

Arizona State University, Tempe, AZ 85287-5806

SC-International, Inc., Phoenix, AZ 85023

RD Associates, Tempe, AZ 85284

\section{SPONSORING/MONITORING AGENCY NAME(S) AND ADDRESS(ES)}

National Renewable Energy Laboratory

1617 Cole Blvd.

Golden, CO 80401-3393

5. FUNDING NUMBERS

TA: PV660109

8. PERFORMING ORGANIZATION REPORT NUMBER

\section{SUPPLEMENTARY NOTES}

12a. DISTRIBUTION/AVAILABILITY STATEMENT 12b. DISTRIBUTION CODE

UC-1270

\section{ABSTRACT (Maximum 200 words)}

This document covers the second phase of a two-part program. Phase I provided an overview of the structure and function of typical product certification/laboratory accreditation programs. This report (Phase II) provides most of the draft documents that will be necessary for implementing a photovoltaic (PV) module certification/laboratory accreditation program. These draft documents include organizational documents, such as articles of incorporation, bylaws, rules of procedure, and a marketing and educational program. In Phase I, a 30 member criteria development committee was established to guide, review, and reach a majority consensus regarding criteria for a PV certification/laboratory accreditation program. Committee members represented PV manufacturers, end users, standards and codes organizations, and testing laboratories. A similar committee was established for Phase II; the criteria implementation committee consisted of 29 members. Twenty-one of the Phase I committee members also served on the Phase II committee, which helped to provide program continuity during Phase II.

\section{SUBJECT TERMS}

photovoltaics ; photovoltaic modules ; module certification ; laboratory accreditation ; implementation handbook
15. NUMBER OF PAGES 249

16. PRICE CODE
17. SECURTYY CLASSIFICATION OF REPORT Unclassified
18. SECURITY CLASSIFICATION OF THIS PAGE Unclassified
19. SECURITY CLASSIFICATION OF ABSTRACT Unclassified
20. LIMITATION OF ABSTRACT

UL 